\title{
AERONET-based models of smoke-dominated aerosol near source regions and transported over oceans, and implications for satellite retrievals of aerosol optical depth
}

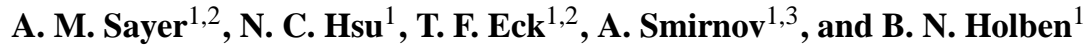 \\ ${ }^{1}$ NASA Goddard Space Flight Center, Greenbelt, Maryland, USA \\ ${ }^{2}$ Goddard Earth Sciences Technology And Research (GESTAR), Universities Space Research Association (USRA), \\ Columbia, Maryland, USA \\ ${ }^{3}$ Sigma Space Corporation, Lanham, Maryland, USA
}

Correspondence to: A. M. Sayer (andrew.sayer@nasa.gov)

Received: 5 August 2013 - Published in Atmos. Chem. Phys. Discuss.: 25 September 2013

Revised: 15 September 2014 - Accepted: 16 September 2014 - Published: 31 October 2014

\begin{abstract}
Smoke aerosols from biomass burning are an important component of the global aerosol system. Analysis of Aerosol Robotic Network (AERONET) retrievals of aerosol microphysical/optical parameters at 10 sites reveals variety between biomass burning aerosols in different global source regions, in terms of aerosol particle size and single scatter albedo (SSA). Case studies of smoke observed at coastal/island AERONET sites also mostly lie within the range of variability at the near-source sites. Differences between sites tend to be larger than variability at an individual site, although optical properties for some sites in different regions can be quite similar. Across the sites, typical midvisible SSA ranges from $\sim 0.95-0.97$ (sites dominated by boreal forest or peat burning, typically with larger fine-mode particle radius and spread) to $\sim 0.88-0.9$ (sites most influenced by grass, shrub, or crop burning, typically smaller finemode particle radius and spread). The tropical forest site Alta Floresta (Brazil) is closer to this second category, although with intermediate SSA $\sim 0.92$. The strongest absorption is seen in southern African savannah at Mongu (Zambia), with average midvisible SSA $\sim 0.85$. Sites with stronger absorption also tend to have stronger spectral gradients in SSA, becoming more absorbing at longer wavelengths. Microphysical/optical models are presented in detail so as to facilitate their use in radiative transfer calculations, including extension to UV (ultraviolet) wavelengths, and lidar ratios. One intended application is to serve as candidate optical models for use in satellite aerosol optical depth (AOD) retrieval al-
\end{abstract}

gorithms. The models presently adopted by these algorithms over ocean often have insufficient absorption (i.e. too high SSA) to represent these biomass burning aerosols. The underestimates in satellite-retrieved AOD in smoke outflow regions, which have important consequences for applications of these satellite data sets, are consistent with the level of underestimated absorption.

\section{Introduction}

For several decades, satellite observations have provided a powerful tool for monitoring many aspects of the earth system, including the atmospheric aerosol loading. Quantities such as aerosol optical depth (AOD) have generally been retrieved with lower uncertainties over oceans than land surfaces, due to the comparative homogeneity of open ocean surface properties and general lack of strong oceanic aerosol point sources. Despite this, significant differences can still exist between AOD retrieved using different instruments or algorithms, in both clean and polluted conditions, and for real measurements as well as simulated data, and uncertainty in other relevant aerosol properties can be larger (Remer et al., 2008; Kokhanovsky et al., 2010; Sayer et al., 2012a).

To some extent, these differences can be the result of differences between sensor radiometric calibration, cloud screening, or sampling/averaging-related issues (Mishchenko et al., 1999; Kaufman et al., 2005; Kahn et al., 
2007; Levy et al., 2009; Sayer et al., 2010b). However, even over oceans, measurements made by past and current spaceborne sensors do not provide sufficient information to retrieve unambiguously all relevant (surface and atmospheric) parameters of interest (Hasekamp and Landgraf, 2005). Thus, algorithms must make assumptions about these quantities, tied to the particular strengths and weaknesses of the instrument in question. Ocean surface reflectance can generally be modelled with lower uncertainties than that over land, and most algorithms parametrise oceanic surface reflectance as a combination of wind-roughened sun glint and foam, with an additional contribution linked to oceanic chlorophyll concentration (e.g. Sayer et al., 2010a). However, aerosol properties present greater difficulty.

The aerosol microphysical composition (particle size, shape, mixing state, chemical composition) and vertical location are the chief inherent aerosol properties of interest. In satellite AOD retrieval algorithms these are often parametrised as a combination of aerosol components, each with specified size distribution and spectral refractive index, whose total abundance and relative weight are varied in order to best match the top-of-atmosphere (TOA) radiance observed by the sensor (e.g. Martonchik et al., 1998; Mishchenko et al., 1999; Remer et al., 2009; Thomas et al., 2009; Sayer et al., 2012a).

Several apparent optical (i.e. radiative) properties arise from this information. The first is the spectral dependence of the AOD itself, often parametrised in terms of the Ångström exponent, $\alpha=-d \ln \tau_{\lambda} / d \ln \lambda$, over some wavelength range. Throughout this study, the AOD is denoted $\tau_{\lambda}$ (where $\lambda$ is the wavelength in nanometres, and is used to indicate a spectrally varying quantity). The second is the scattering phase matrix, particularly the phase function. The cosine-weighted average of the phase function (asymmetry parameter, $g_{\lambda}$ ) is related to the extent of scattering in the forward vs. backward hemispheres by aerosol particles at a given wavelength, and is often presented as a diagnostic of directionality of aerosol scattering or used in radiative transfer calculations. The third optical property is the single scattering albedo (SSA, or $\omega_{0 \lambda}$ ), defined as the ratio of scattering AOD to total AOD, and is thus a measure of the extent of light absorption by the aerosol at a given wavelength. A further derived quantity is the absorption Angström exponent, $\alpha_{\mathrm{abs}}$, which is an analogue of $\alpha$ based instead on the absorption optical depth (i.e. $\left.\tau_{\lambda}\left[1-\omega_{0 \lambda}\right]\right)$ which has been used as an indicator of aerosol composition (Andreae and Gelencsér, 2006; Russell et al., 2010). Values of $\alpha_{\mathrm{abs}} \sim 1$ suggest pure black carbon aerosol (Bergstrom, 1973; Bond, 2001), while larger values suggest the increasing presence of organic carbon or dust.

Multiple permutations of inherent aerosol properties can lead to similar apparent aerosol optical properties, which often limits the ability of satellite measurements to distinguish between aerosols of different compositions but which nevertheless appear optically similar. A corollary is that for some applications (e.g. radiative calculations) knowledge of chem- ical composition may not be necessary if the apparent optical properties are known. Thus, although aerosol properties in satellite AOD retrieval algorithms and radiative calculations are often specified as microphysical models, it may be more appropriate to think in terms of optical models for these applications.

As AOD increases, so does its contribution to the observed radiance in the shortwave (and in some cases longwave) spectrum, and so does the sensitivity of the retrieval algorithm to these assumptions about aerosol composition (e.g. Hyer et al., 2011; Lee et al., 2012). It is therefore important that these assumptions are realistic, in order to minimise errors in retrieved AOD. Existing satellite data sets typically use microphysical properties derived from in situ measurements, semi-empirical considerations, or else leverage retrievals of microphysical properties from sources with a higher information content, such as those in the Aerosol Robotic Network (AERONET; Holben et al., 1998). An exception to this is the Polarization and Directionality of the Earth's Reflectance (POLDER) sensor, whose multidirectional and polarisation measurements offer increased information content, allowing algorithms to use weaker constraints about microphysical assumptions as compared to other sensors (Dubovik et al., 2011; Hasekamp et al., 2011).

The aerosol burden over the ocean is typically composed of a combination of hydrated sea salt particles and biogenic organic aerosols (O'Dowd and de Leeuw, 2007), with (regionally and seasonally dependent) contributions from transported continental aerosols (such as sulfates, nitrates, carbonaceous aerosols from industry or biomass burning, and mineral dust). Biomass burning is an important contributor to the global aerosol burden. Smoke aerosols near their source regions are strongly optically dominated by finemode absorbing particles, with properties dependent on the substance which is burning as well as type of combustion (flaming vs. smouldering) and temperature/moisture content (e.g. regional/global reviews by Streets et al., 2003; Reid et al., 2005a, b; Janhäll et al., 2010). Some chemical changes within the aerosol occur rapidly (minutes-hours) after emission, changing aerosol microphysical and radiative properties from those at the burning location (Radke et al., 1991; Hobbs et al., 1997; Martins et al., 1997; Reid et al., 1998; Abel et al., 2003; Magi and Hobbs, 2003; Vakkari et al., 2014). Comparatively less well-studied are properties after longer-term (i.e. days) transport, particularly to the oceans, where further ageing, partial wet/dry deposition, and mixing with air masses of different origins may further alter the properties of the aerosol (e.g. Reid et al., 1999).

The foci of this study are first to use AERONET inversions of aerosol microphysical properties from key biomass burning sites to develop optical models for use in applications such as satellite AOD retrieval or radiative calculations. This aspect is an extension of an earlier effort by Dubovik et al. (2002), albeit in greater detail (in terms of model description and range of biomass burning sites considered), with 
around a decade more of observations to draw from, and with an enhanced AERONET inversion algorithm with significantly improved data quality screening. The second focus is then to identify whether isolated cases of smoke-dominated air masses observed at coastal/island AERONET sites fall within the range of apparent optical properties of smoke from these near-source biomass burning sites, to assess whether these optical models derived from over-land data are also applicable for over-ocean cases. Although this similarity has been assumed to be the case, it has not to the authors' knowledge been examined on a large scale; ageing on timescales of several days has been observed to alter optical properties of smoke aerosols (e.g. Reid et al., 1998, 1999), but it is not clear whether, on the whole, their optical properties remain within the range of nearer-source properties. Individually these coastal/island sites lack sufficient sampling to create climatological models directly. The ability of the models to represent the variability of optical properties within a given site, and the level of similarity in apparent optical properties between sites with diverse underlying microphysical properties, are also discussed.

The analysis proceeds as follows. Section 2 introduces the AERONET inversion algorithm data and assorted notation used. Then, the properties of smoke aerosols from AERONET sites near major global biomass burning source regions are examined in Sect. 3. As there are limited in situ measurements or AERONET sites located in the common biomass burning oceanic outflow regions, these climatological properties are then compared to cases of occasional smoke observed at coastal/island AERONET sites in Sect. 4. Section 5 illustrates potential biases in existing over-ocean satellite AOD data sets as a result of insufficient absorption in presently assumed aerosol microphysical properties, and Sect. 6 provides a perspective on the results.

\section{AERONET direct-sun and inversion data}

\subsection{Overview and terminology}

The sun photometers used by AERONET measure spectral direct-beam solar radiation, as well as directional diffuse radiation in the solar almucantar. The former are used to determine columnar spectral AOD and water vapour, provided at a temporal resolution of approximately 10-15 min. AERONET direct-sun AOD has a typical uncertainty of 0.01-0.02 (Holben et al., 1998; Eck et al., 1999) and is provided at multiple wavelengths (dependent on site) from 340 to $1640 \mathrm{~nm}$, together with $\alpha$ over certain wavelength ranges. Unless otherwise specified, references to $\alpha$ and $\alpha_{\text {abs }}$ herein indicate that calculated over the wavelength range $440-870 \mathrm{~nm}$ (by regression of all available $\tau_{\lambda}$ over that wavelength range); $\alpha$ was calculated over the $440-870 \mathrm{~nm}$ range in order to be more sensitive to fine/coarse relative AOD magni- tudes rather than to fine-mode particle size (Eck et al., 1999; 2010; Reid et al., 1999).

The spectral AOD is also used, along with almucantar measurements of sky radiance taken over a large range of scattering angles, in the inversion algorithm of Dubovik and King (2000), and Dubovik et al. (2006). This retrieves aerosol volume size distribution (in 22 logarithmically spaced bins with radii $r$ from 0.05 to $15 \mu \mathrm{m}$ ) and spectral complex refractive index at 440,675, 870, and $1020 \mathrm{~nm}$. These retrieved quantities are further used to derive various aerosol size distribution parameters, as well as SSA and $g$. Cloud screening and other quality checks (Smirnov et al., 2000; Holben et al., 2006) are performed in order to remove potentially unreliable retrievals. Retrievals passing these checks are denoted "level 2"; these level 2 data from the current version 2 algorithm are used in this study.

The notation adopted herein for aerosol microphysical properties follows that of Sayer et al. (2012b) and numerous other AERONET-based studies. The number size distribution $d N(r) / d \ln (r)$ describes the number of aerosol particles with radius in the infinitesimal size range $r \pm d \ln (r)$; the related volume size distribution is obtained (for spherical particles) by multiplying this by a factor of $(4 / 3) \pi r^{3}$. Total columnar aerosol particle number $\left(C_{\mathrm{n}}\right)$ and volume $\left(C_{\mathrm{v}}\right)$ are obtained by integrating these distributions over $\ln (r)$. The logarithmic volume mean radius $\left(r_{\mathrm{v}}\right)$ is a frequently used metric of average aerosol particle size, defined as

$$
\ln \left(r_{\mathrm{v}}\right)=\frac{\int_{-\infty}^{\infty} \ln (r) \frac{d V(r)}{d \ln (r)} d \ln (r)}{\int_{-\infty}^{\infty} \frac{d V(r)}{d \ln (r)} d \ln (r)} ;
$$

also often-used is the effective radius $\left(r_{\text {eff }}\right)$, which is the ratio of the third to the second moment of the size distribution. The broadness of the distribution is often characterised by its spread (also called width), $\sigma$, where

$$
\sigma=\sqrt{\frac{\int_{-\infty}^{\infty}\left(\ln (r)-\ln \left(r_{\mathrm{v}}\right)\right)^{2} \frac{d V(r)}{d \ln (r)} d \ln (r)}{\int_{-\infty}^{\infty} \frac{d V(r)}{d \ln (r)} d \ln (r)}} .
$$

The geometric standard deviation, $e^{\sigma}$ in this notation, is sometimes used instead of $\sigma$. The above definitions are independent of the shape of the size distribution. In practice, aerosols are often represented as a combination of lognormally distributed components, for which the number size distribution is defined as a summation over $n_{\mathrm{c}}$ components as 
$\frac{d N(r)}{d \ln (r)}=\sum_{i=1}^{n_{\mathrm{c}}} \frac{C_{\mathrm{n}, i}}{\sqrt{2 \pi} \sigma_{i}} e^{-\frac{1}{2}\left(\frac{\ln (r)-\ln \left(r_{\mathrm{n}, i}\right)}{\sigma_{i}}\right)^{2}}$

and the modal radius for each component is also its median and geometric mean. The equivalent formulation for aerosol volume is arrived at by substituting $r_{\mathrm{n}}$ with $r_{\mathrm{v}}$, and $C_{\mathrm{n}}$ with $C_{\mathrm{v}}$. Transformations between number and volume quantities for lognormal components are also provided using this notation by Sayer et al. (2012b).

Observed aerosol size distributions are typically (although not exclusively) bimodal ( $\left.n_{\mathrm{c}}=2\right)$; e.g. Dubovik et al. (2002). In these cases, and adopted here, the smaller (fine) mode properties are denoted with a subscripted $\mathrm{f}$ (i.e. $r_{\mathrm{v}, f}, \sigma_{\mathrm{f}}$ ) and the larger (coarse) mode properties with a subscripted c. Analogously, fine- and coarse-mode AOD are denoted $\tau_{\mathrm{f}, \lambda}$ and $\tau_{\mathrm{c}, \lambda}$, respectively. This AERONET data set defines fine- and coarse-mode properties by locating the inflection point in the retrieved size distribution (in the range $0.44<r<0.99 \mu \mathrm{m})$; results are mostly numerically only weakly sensitive to the precise fine/coarse demarcation point. Throughout this work, "fine" refers to accumulation-mode aerosols; smaller "nucleation-mode" aerosols may also be present, with some of these existing on the smaller- $r$ tail of the fine mode, and others below this limit (although in that case so small as to be optically inactive in this spectral range).

\subsection{Uncertainties on retrieved quantities}

Dubovik et al. (2000) performed an error analysis for the version 1 AERONET inversion algorithm, and presented uncertainties in retrieved size distribution and refractive index/SSA under different conditions. For level 2 data at moderate aerosol loadings ( $\tau_{440} \sim 0.4$ ) and microphysical properties corresponding to biomass burning aerosols, associated one-standard-deviation uncertainties for such retrievals are $25 \%$ on the binned size distribution (for $0.1<r<7 \mu \mathrm{m}$; larger on the tails), 0.04 on the real part of the refractive index, and $30 \%$ on the imaginary part of the refractive index, giving an uncertainty in SSA of approximately 0.03. Higher AOD can decrease some of these uncertainties further. Size distributions remain reliable at lower aerosol loadings, although refractive index uncertainties increase significantly, leading to correspondingly higher uncertainties in SSA.

An important refinement to the current version 2 AERONET inversion is the use of site-specific rather than global average surface reflectance models, which can result in significant differences in retrieved SSA (and, to a lesser extent, size distribution) between versions 1 and 2 (Eck et al., 2008). AERONET's version 2 algorithm also models particles as mixtures of spheres and spheroids (Dubovik et al., 2006), while in version 1 only spheres were used; this is important for modelling larger nonspherical particles such as mineral dust (Kahn et al., 1997; Mishchenko et al., 1997;
Dubovik et al., 2000), although small smoke aerosol particles (whether spherical or nonspherical) have been found to be modelled adequately as spheres by Mie theory (e.g. Reid and Hobbs, 1998; Reid et al., 2005b). AERONET version 1 and 2 data can therefore differ significantly in some cases. A version 3 inversion algorithm is in development but at the time of writing is expected to be a year from data release, and differences in retrieved quantities between versions 2 and 3 are expected to be smaller than between versions 1 and 2 .

Dubovik et al. (2000) present uncertainty estimates for only volume size distribution, refractive index, and SSA. Propagating these uncertainties onto the the higher-level size distribution parameters (for a typical biomass burning model from Dubovik et al., 2002, and assuming uncertainties in each bin of $d V(r) / d \ln (r)$ are uncorrelated) suggest uncertainties on AERONET-derived $r_{\mathrm{v}, f}$ of $0.01 \mu \mathrm{m}, \sigma_{\mathrm{f}}$ of 0.06 , $r_{\mathrm{v}, c}$ of $0.2 \mu \mathrm{m}$, and $\sigma_{\mathrm{c}}$ of 0.06 for individual retrievals. These in turn lead to uncertainties of the order $0.015-0.04$ on finemode $g$ (larger uncertainties at longer wavelengths) and order 0.01 or less (smaller uncertainties at longer wavelengths) on coarse-mode $g$.

Although AERONET retrieves a spectrally varying refractive index, it is assumed to apply to all aerosol size bins (i.e. it is size-independent). This will introduce additional errors if the aerosols comprising the fine and coarse modes have different refractive indices. However, as smoke aerosols are strongly optically dominated by their fine modes (for the sites considered in this study, the median fine-mode relative contribution to total AOD for the data used was found to range from 91 to $98 \%$ at $440 \mathrm{~nm}$, and $58-95 \%$ at $1020 \mathrm{~nm}$ ), the neglect of separate fine-/coarse-mode refractive indices is likely to introduce negligible additional error into the analysis.

The AERONET inversion products cannot be considered a ground truth in the same way that the direct-sun data products often are. Several studies have previously performed direct or indirect comparisons between AERONET SSA and that determined by other techniques (e.g. various in situ methods). Reid et al. (2005a) reviewed aerosol optical properties, including SSA, and noted that in situ SSA for smoke aerosols was often lower than that retrieved by radiometric methods (e.g. AERONET version 1), although this is thought in part (but not necessarily in totality) to reflect a low bias in some in situ techniques, for which corrections can be made (see Reid et al., 2005a, and some discussion in Eck et al., 2010). More recently, several studies (Leahy et al., 2007; Lee et al., 2007, Schafer et al., 2008; Johnson et al., 2009; Schafer et al., 2014) have compared AERONET version 2 SSA against that inferred from other techniques, and generally found good agreement (within the stated data set uncertainties) across a wide range of absorption strengths for fine-mode-dominant aerosol cases. 


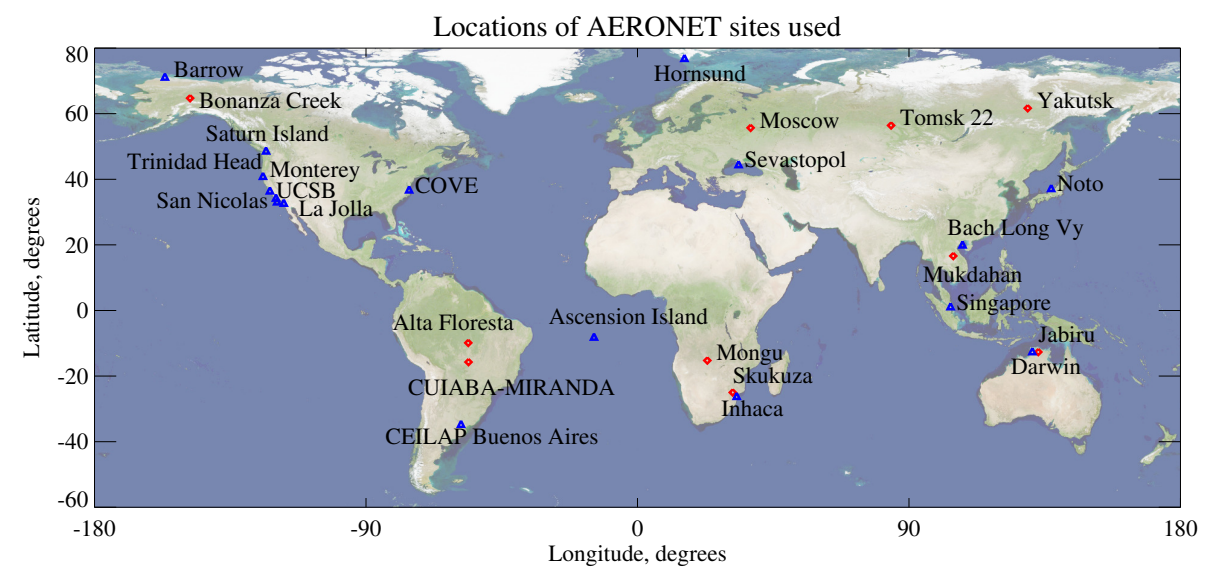

Figure 1. Locations of AERONET sites used in this work. Red diamonds indicate the near-source sites, and blue triangles the coastal/island sites with occasional cases of smoke-dominated aerosols.

\section{Properties of smoke aerosol from near-source sites}

\subsection{Site selection}

Level 2 version 2 AERONET inversion data (Holben et al., 2006) from 10 AERONET sites, shown in Fig. 1 (and with key information and references in Table 1), are used to investigate the microphysical properties of smoke aerosols over a range of different burning regions. Some of these sites were used in a similar analysis by Dubovik et al. (2002); the analysis here benefits from a decade more of observations, as well as improvements made to the version 2 AERONET database since that time (e.g. surface reflectance inputs; Eck et al., 2008). Giles et al. (2012) also examined a few of these sites, although that study was focussed on characterising global aerosol absorption properties from a variety of types, rather than creation of microphysical/optical models to represent these aerosols. State/country information for each site is provided the first time a site is discussed in the text.

The geographic distribution of sites sampled is limited by the available AERONET data record. Van der Werf et al. (2010) provide a breakdown of estimates of the contribution of different source regions and burning types to carbon and certain trace gas emissions from 1997 to 2009. The largest contributions were from tropical sources (Africa, followed by Asia and the Americas); if stratified by type of burning, the largest single contributor to carbon emissions has been grassland and savannah fires, accounting for around 50\% of carbon. The remainder was mostly from various types of forest fires, with agricultural fires and peat burning comparatively minor on a global scale (although strong interannual variability of peat burning, with enhancements during El Niño periods). Thus, the boreal sites are perhaps overrepresented in number compared to their influence on the global biomass burning emissions budget, but this increased number of boreal sites (and examination of intersite similarity) is in- tended to counterbalance their lower data volume compared to many of the tropical sites.

Some regions contain several sites in relatively close proximity; in this case, typically the site with the largest data record and smallest influence from other aerosol sources was chosen. Manual inspection reveals that data from these nearby sites are generally similar. For example, Mukdahan (Thailand) was chosen as a key site for south-eastern Asia, although quantitatively similar results are obtained if data from Pimai (also in Thailand) are used instead. Both sites primarily sample nearby agricultural burning, and forest burning from elsewhere in the region. In contrast, the site in the city of Chiang Mai (north-western Thailand) was not used as, while close to biomass burning source regions, it also has a significant urban contribution to the aerosol, coupled with the local topography leading to a "trapping" of pollutants (Janjai et al., 2012; Gautam et al., 2013). An exception is central and eastern Russia, where two sites (Tomsk 22 and Yakutsk) were included because the sites individually have a comparatively low data volume. Note that the Tomsk 22 site lies in an area fairly remote from other aerosol sources, about $60 \mathrm{~km}$ away from the similarly named Tomsk AERONET site; the latter is in the outskirts of the city of Tomsk and thus more susceptible to the influence of urban aerosols.

Although AERONET contains several long-term sites in the Sahel, the peak season for biomass burning there (November-February) coincides with strong dust activity, such that the aerosol is normally a mixture of biomass burning smoke and dust (Pandithurai et al., 2001; Roberts et al., 2009). Johnson et al. (2008) and Eck et al. (2010) found cases where these smoke aerosols were highly absorbing, with midvisible SSA as low as 0.76, although the more common cases of mixed smoke and dust in this region are less absorbing. Limiting to smoke-dominant cases leaves a small data volume (and an unrepresentative sample of the true nature of the aerosol in that region). Additionally, the smoke and dust in this area often occur in distinct vertical layers and so a 


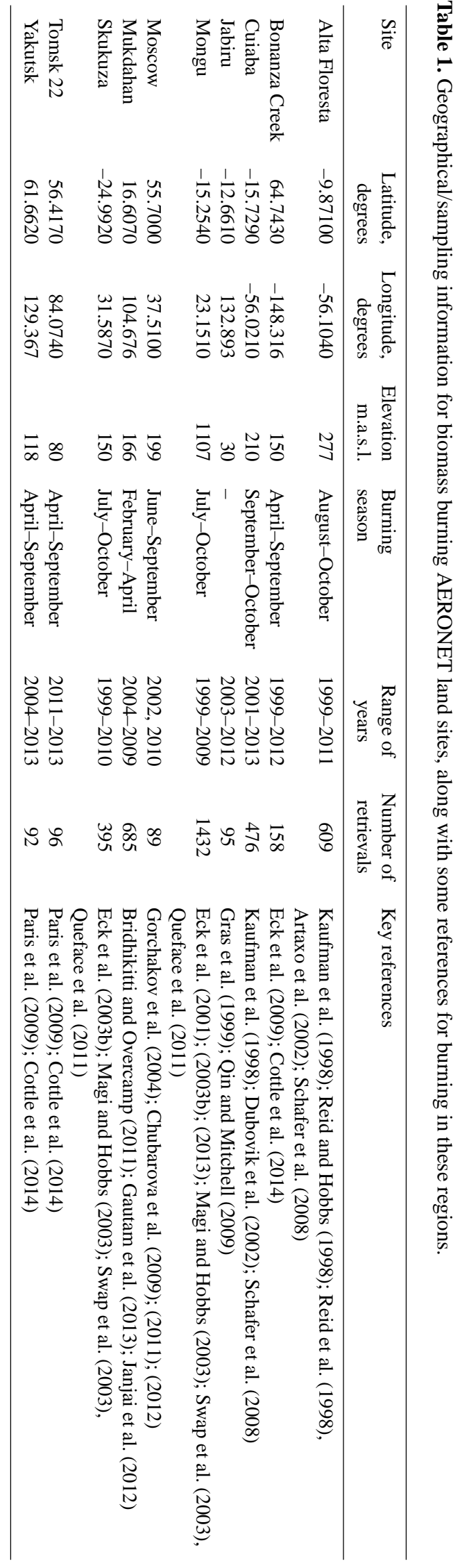

microphysical model based on column-average aerosol properties, when applied to real satellite data, could potentially be misleading or inaccurate (Kim et al., 2009). A similar rationale applies to sites in the Indo-Gangetic Plain and Himalayas (e.g. Pokhara, Nepal), as springtime biomass burning overlaps with transported dust, and some sites additionally have a significant urban component to the aerosol (Gautam et al., 2011). No sites located in the "Maritime Continent" are used in the near-source category in this study (although Singapore is used later to provide case studies). This is due to the lack of sites with a large data volume at present (although some sites have been set up in recent years which may alleviate this data gap, e.g. Salinas et al., 2013), due in part to frequent cloudiness limiting observability (Reid et al., 2013), and concerns about potential for residual cirrus cloud contamination in data from this region (Chew et al., 2011; Huang et al., 2011).

\subsection{Data filtering}

At each site, in order to remove likely nonsmoke cases from the data (as burning is seasonal and aerosol of other types may be transported periodically to sites), two sets of filters are applied. Firstly, it is required that $\tau_{440} \geq 0.4$ and $\alpha \geq 1.4$, to ensure reliability of retrieved refractive index/SSA and remove potential cases dominated by other aerosol types such as mineral dust (which has smaller $\alpha$, e.g. Eck et al., 1999) or mixed conditions. An exception are the boreal sites (Bonanza Creek in Alaska, USA, and Moscow, Tomsk 22, and Yakutsk in Russia), which can sample peat burning, whose large fine-mode particles (particularly in high-AOD conditions) can lead to $\alpha$ in the range 1-1.4 even without significant contributions from coarse-mode aerosols (e.g. Eck et al., 2003a, 2009); thus, $\alpha \geq 1$ is used for these sites. Resulting median values of $\alpha$ are approximately 1.5-1.9, dependent on site. Secondly, data are restricted to the main burning season for those sites where this is well-defined (see Table 1); some sites, such as Mongu (Zambia), exhibit fairly constant burning throughout a period of several months, while others, such as Bonanza Creek, have a comparatively low baseline AOD punctuated by episodes of burning (which tend to occur in local summer months in dry years). As biomass burning is the dominant reason for high-AOD conditions at all these sites, the main effect of these filters is to remove some outlying results.

Due to suspected instrument calibration problems which may lead to retrieval biases, certain years were excluded from the analysis: 2008 from CUIABA-MIRANDA (Mato Grosso, Brazil; hereafter Cuiaba); 2002 and 2004 from Jabiru (Australia); and 2005 and 2006 from Yakutsk (Russia). For Moscow State University (MSU) in western Russia (hereafter Moscow for brevity), only data from 2002 and 2010 were considered, to minimise the potential for urbandominated aerosol cases, as these 2 years had extensive summertime burning (Chubarova et al., 2011). 
(a) Americas (1243)

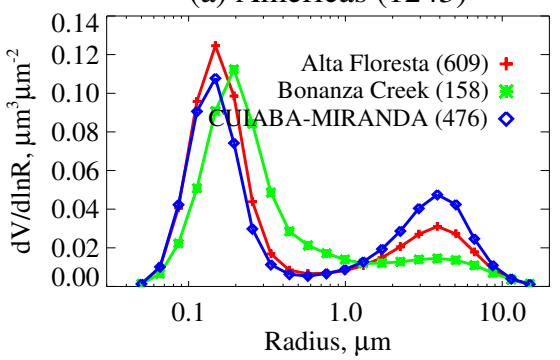

(c) Asia (962)

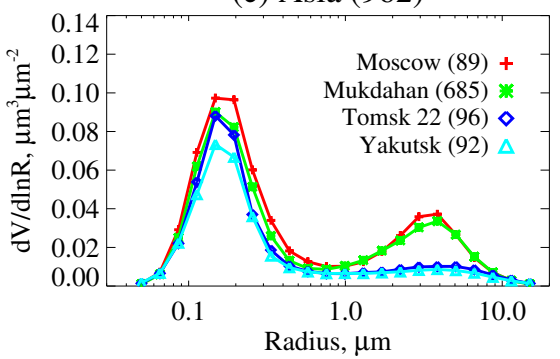

(b) Africa (1827)

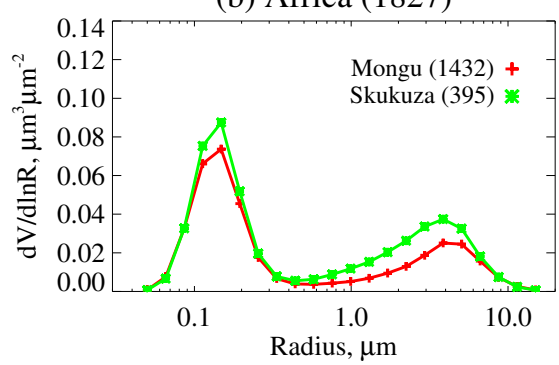

(d) Oceania (95)

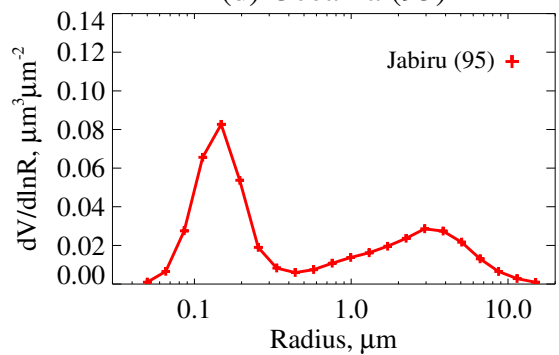

Figure 2. Median retrieved size distributions from biomass burning cases for near-source AERONET sites considered (Fig. 1, Table 1). Figures in parentheses indicate the number of retrievals for each site/geographical region.

The restriction to $\tau_{440} \geq 0.4$ (corresponding, for typical $\alpha \sim 1.5-1.9$, to $\tau_{550} \geq 0.26-0.29$ ) introduces a sampling bias in that it favours cases of more intense smoke, which may conceivably exhibit different microphysical/optical properties from less intense smoke. However, repetition of the analysis with a lower AOD threshold $\left(\tau_{440} \geq 0.2\right)$ gave very similar results in terms of size distribution; additionally, applications such as satellite AOD retrieval or radiative effect/forcing calculations become less dependent on SSA as AOD decreases. Thus, this sampling bias is not thought to affect the conclusions or presented aerosol models significantly for these applications.

\subsection{Overall and comparative microphysical/optical properties}

\subsubsection{Overview of summary figures and tables}

The median retrieved volume size distributions corresponding to these biomass burning cases at each site are shown in Fig. 2. These reveal the presence of a strong fine mode with peak radius in the range $0.13-0.2 \mu \mathrm{m}$, and a secondary coarse mode with peak radius in the range $3-5 \mu \mathrm{m}$. Both modes appear approximately lognormal, although the coarse mode has a slight low-radius skew; the minimum in the overall aerosol volume size distribution is most commonly from $0.5-0.9 \mu \mathrm{m}$. The median fine-mode relative contributions to total aerosol volume and AOD at $550 \mathrm{~nm}$ range between sites from 56 to $83 \%$ and 86-98\%, respectively; on an individual-retrieval basis, the higher values tend to be found for cases of higher AOD.
The AOD dependence of aerosol size distribution parameters has previously been noted for a wide variety of aerosol types (e.g. Dubovik et al., 2002). Therefore, these data were also examined for any such tendencies. An example of this process is shown in Fig. 3 for fine-mode radius and spread $\left(r_{\mathrm{v}, f}, \sigma_{\mathrm{f}}\right)$ at Alta Floresta (Mato Grosso, Brazil). To mitigate the effect of outliers, size distribution parameters more than two standard deviations away from the median at a given site were discarded for this portion of the analysis, and then a linear least-squares fit of parameter against fine-mode AOD was performed. The exclusion removed typically $\sim 5 \%$ of data, and did not lead to a significant difference in regression statistics, at most sites. Resulting linear regression relationships are shown in Table 2 for $\tau_{\mathrm{f}, 550}$ (and Table 3 for $\tau_{\mathrm{f}, 440}$, for reference). At some sites, AOD-dependent changes in $r_{\mathrm{v}, f}$ or $\sigma_{\mathrm{f}}$ were observed to level off for the highest-AOD cases; as a result, a second logarithmic fit of these parameters of the form $\mathrm{y}=a+b \log (c \mathrm{x})$ was also performed. These fits are also listed in Tables 2 and 3 where they appear to provide a better model (in terms of correlation coefficient and inspection of the tendencies in the data) than a simple linear fit, and are omitted otherwise, for clarity of use and to avoid overfitting of the data. These logarithmic relationships are used throughout where provided, linear otherwise, although the differences are in most cases small. At the majority of these sites the scatter about these relationships was similar to AERONET retrieval uncertainty (Sect. 2.2), suggesting one underlying dominant regime. Note that the weak positive relationship between $\tau_{\lambda}$ and $\sigma_{\mathrm{f}}$ found at some sites was not reported by the previous (version 1 , smaller data volume) 
(a) Alta Floresta, fine radius

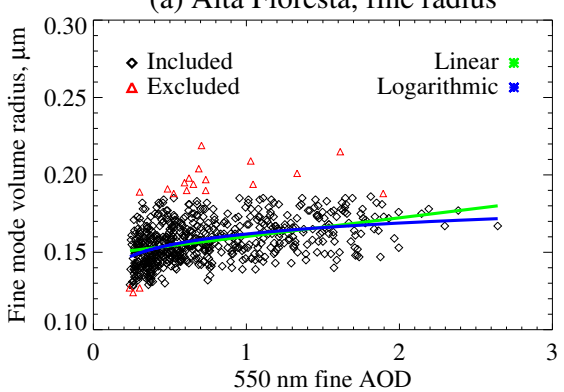

(b) Alta Floresta, fine spread

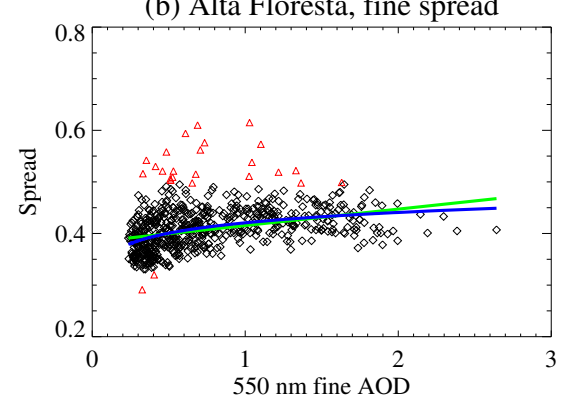

Figure 3. Example of linear and logarithmic fitting procedures used to arrive at relationships between AOD and fine-mode microphysical model parameters, for Alta Floresta. Black diamonds indicate points used in the fits (green and blue lines for linear and logarithmic fits, respectively), while excluded outliers are shown with red triangles. Panel (a) shows fine-mode volume radius $\left(r_{\mathrm{v}, f}\right)$, and (b) the fine-mode $\operatorname{spread}\left(\sigma_{\mathrm{f}}\right)$.

Table 2. Size distribution parameters and parametrisations for biomass burning aerosols from the climatological AERONET smoke sites (relative to fine/coarse AOD at $550 \mathrm{~nm}$ ). Note that the fine-mode volume relationship is calculated for $\tau_{\mathrm{f}, 550}=0.5$ as in Fig. 4 and so will vary for different AOD. $R$ indicates Pearson's linear correlation coefficient.

\begin{tabular}{|c|c|c|c|c|c|c|c|}
\hline Site & $\underset{\tau_{\mathrm{f}, 550}}{\text { Maximum }}$ & $\begin{array}{c}C_{\mathrm{v}, f} \\
\mu \mathrm{m}^{3} \mu \mathrm{m}^{-2}\end{array}$ & $\begin{array}{c}r_{\mathrm{v}, f} \\
\mu \mathrm{m}\end{array}$ & $\sigma_{f}$ & $\begin{array}{l}C_{\mathrm{v}, c} \\
\mu \mathrm{m}^{3} \mu \mathrm{m}^{-2}\end{array}$ & $\begin{array}{r}r_{\mathrm{V}, c} \\
\mu \mathrm{m}\end{array}$ & $\sigma_{\mathrm{c}}$ \\
\hline Alta Floresta & 2.64 & $0.185 \tau_{\mathrm{f}, 550}$ & $\begin{array}{l}0.148+0.012 \tau_{\mathrm{f}, 550}, R=0.43 \\
0.176+0.010 \log \left(0.24 \tau_{\mathrm{f}, 550}\right), R=0.45\end{array}$ & $\begin{array}{l}0.384+0.032 \tau_{\mathrm{f}, 550}, R=0.41 \\
0.396+0.029 \log \left(2.3 \tau_{\mathrm{f}, 550}\right), R=0.47\end{array}$ & $1.52 \tau_{\mathrm{c}, 550}$ & 3.20 & 0.65 \\
\hline Bonanza Creek & 2.79 & $0.141 \tau_{\mathrm{f}, 550}$ & $\begin{array}{l}0.192+0.018 \tau_{\mathrm{f}, 550}, R=0.43 \\
0.233+0.020 \log \left(0.37 \tau_{\mathrm{f}, 550}\right), R=0.50\end{array}$ & $\begin{array}{l}0.514+0.018 \tau_{\mathrm{f}, 550}, R=0.22 \\
0.486+0.024 \log \left(7.9 \tau_{\mathrm{f}, 550}\right), R=0.29\end{array}$ & $1.47 \tau_{\mathrm{c}, 550}$ & 3.20 & 0.69 \\
\hline Cuiaba & 2.43 & $0.190 \tau_{\mathrm{f}, 550}$ & $\begin{array}{l}0.135+0.024 \tau_{\mathrm{f}, 550}, R=0.62 \\
0.155+0.016 \log \left(1.4 \tau_{\mathrm{f}, 550}\right), R=0.63\end{array}$ & $\begin{array}{l}0.365+0.045 \tau_{\mathrm{f}, 550}, R=0.50 \\
0.354+0.035 \log \left(5.8 \tau_{\mathrm{f}, 550}\right), R=0.55\end{array}$ & $1.59 \tau_{\mathrm{c}, 550}$ & 3.27 & 0.63 \\
\hline Jabiru & 0.671 & $0.208 \tau_{\mathrm{f}, 550}$ & $\begin{array}{l}0.142+0.016 \tau_{\mathrm{f}, 550}, R=0.12 \\
0.146+0.0073 \log \left(3.4 \tau_{\mathrm{f}, 550}\right), R=0.15\end{array}$ & $0.357+0.058 \tau_{\mathrm{f}, 550}, R=0.20$ & $1.09 \tau_{\mathrm{c}, 550}$ & 2.55 & 0.73 \\
\hline Mongu & 1.58 & $0.168 \tau_{\mathrm{f}, 550}$ & $\begin{array}{l}0.133+0.025 \tau_{\mathrm{f}, 550}, R=0.47 \\
0.161+0.013 \log \left(0.63 \tau_{\mathrm{f}, 550}\right), R=0.49\end{array}$ & $\begin{array}{l}0.370+0.046 \tau_{\mathrm{f}, 550}, R=0.29 \\
0.469+0.023 \log \left(0.074 \tau_{\mathrm{f}, 550}\right), R=0.29\end{array}$ & $1.57 \tau_{\mathrm{c}, 550}$ & 3.34 & 0.67 \\
\hline Moscow & 2.05 & $0.165 \tau_{\mathrm{f}, 550}$ & $0.168+0.028 \tau_{\mathrm{f}, 550}, R=0.69$ & $0.495+0.014 \tau_{\mathrm{f}, 550}, R=0.13$ & $1.56 \tau_{\mathrm{c}, 550}$ & 3.14 & 0.59 \\
\hline Mukdahan & 1.63 & $0.178 \tau_{\mathrm{f}, 550}$ & $\begin{array}{l}0.157+0.037 \tau_{\mathrm{f}, 550}, R=0.45 \\
0.185+0.022 \log \left(1.4 \tau_{\mathrm{f}, 550}\right), R=0.45\end{array}$ & $\begin{array}{l}0.429+0.054 \tau_{\mathrm{f}, 550}, R=0.32 \\
0.577+0.034 \log \left(0.060 \tau_{\mathrm{f}, 550}\right), R=0.34\end{array}$ & $1.41 \tau_{\mathrm{c}, 550}$ & 2.95 & 0.63 \\
\hline Skukuza & 1.07 & $0.202 \tau_{\mathrm{f}, 550}$ & $\begin{array}{l}0.138+0.017 \tau_{\mathrm{f}, 550}, R=0.24 \\
0.167+0.0086 \log \left(0.21 \tau_{\mathrm{f}, 550}\right), R=0.27\end{array}$ & $0.356+0.037 \tau_{\mathrm{f}, 550}, R=0.21$ & $1.27 \tau_{\mathrm{c}, 550}$ & 2.81 & 0.69 \\
\hline Tomsk 22 & 2.08 & $0.167 \tau_{\mathrm{f}, 550}$ & $\begin{array}{l}0.165+0.026 \tau_{\mathrm{f}, 550}, R=0.49 \\
0.202+0.021 \log \left(0.68 \tau_{\mathrm{f}, 550}\right), R=0.54\end{array}$ & $0.481+0.012 \tau_{\mathrm{f}, 550}, R=0.075$ & $1.49 \tau_{\mathrm{c}, 550}$ & 3.29 & 0.70 \\
\hline Yakutsk & 2.98 & $0.169 \tau_{\mathrm{f}, 550}$ & $0.164+0.015 \tau_{\mathrm{f}, 550}, R=0.29$ & $\begin{array}{l}0.465+0.039 \tau_{\mathrm{f}, 550}, R=0.29 \\
0.692+0.051 \log \left(0.036 \tau_{\mathrm{f}, 550}\right), R=0.45\end{array}$ & $1.49 \tau_{\mathrm{c}, 550}$ & 3.36 & 0.73 \\
\hline
\end{tabular}

analysis of Dubovik et al. (2002), and SSA $/ g$ and their spectral dependences are also different in some cases.

The regression fits were performed against fine-mode AOD as this is likely a more reasonable metric of the contribution of biomass burning to the total aerosol burden than the total AOD. This is consistent with the primary emissions from biomass burning being small aerosol particles and aerosol precursor gases. For all sites the coarse-mode AOD was typically $\sim 0.01-0.04$ and roughly independent of the total AOD. Hence, similar results are obtained if total AOD is used instead. For a similar reason (low coarse-mode AOD and noisier size distribution parameters), no regression was performed for coarse-mode size distribution parameters as a function of coarse AOD; instead, median values of $r_{\mathrm{v}, c}$ and $\sigma_{\mathrm{c}}$ are given in Tables 2 and 3 .
The aerosol refractive index was also found to be largely independent of AOD, columnar water vapour $(w v)$, and coarse-mode spherical fraction (which could indicate the presence of mineral dust and/or cirrus cloud contamination), although real and imaginary components were often correlated positively with each other (which is likely attributable to the composition of the burning fuel at each individual event). For this reason, site-median refractive indices are used in the analysis. These, as well as $\alpha, \alpha_{\mathrm{abs}}$, SSA, and $g$ calculated using the relationships in Table 2 for the case of $\tau_{\mathrm{f}, 550}=0.5$ and $\tau_{\mathrm{c}, 550}=0.03$ at each site, are given in Table 4. Although the AOD dependence of model parameters means that SSA will itself be a factor of fine-mode AOD, the AOD dependence of SSA is small according to these relationships (generally becoming less absorbing by $\sim 0.01$ as fine-mode AOD increases from 0.2 to 2). Both $\alpha$ and $g$ vary 
Table 3. As Table 2, except expressed in terms of AOD at $440 \mathrm{~nm}$.

\begin{tabular}{|c|c|c|c|c|c|c|c|}
\hline Site & $\underset{\tau_{\mathrm{f}, 440}}{\operatorname{Maximum}}$ & $\begin{array}{c}C_{\mathrm{v}, f} \\
\mu \mathrm{m}^{3} \mu \mathrm{m}^{-2}\end{array}$ & $\begin{array}{c}r_{\mathrm{v}, f} \\
\mu \mathrm{m}\end{array}$ & $\sigma_{f}$ & $\begin{array}{l}C_{\mathrm{v}, c} \\
\mu \mathrm{m}^{3} \mu \mathrm{m}^{-2}\end{array}$ & $\begin{array}{r}r_{\mathrm{v}, c} \\
\mu \mathrm{m}\end{array}$ & $\sigma_{\mathrm{c}}$ \\
\hline Alta Floresta & 3.78 & $0.125 \tau_{\mathrm{f}, 440}$ & $\begin{array}{l}0.148+0.0080 \tau_{\mathrm{f}, 440}, R=0.40 \\
0.151+0.0099 \log \left(2.0 \tau_{\mathrm{f}, 440}\right), R=0.42\end{array}$ & $\begin{array}{l}0.383+0.022 \tau_{\mathrm{f}, 440}, R=0.40 \\
0.426+0.029 \log \left(0.56 \tau_{\mathrm{f}, 440}\right), R=0.45\end{array}$ & $1.55 \tau_{\mathrm{c}, 440}$ & 3.20 & 0.65 \\
\hline Bonanza Creek & 3.69 & $0.108 \tau_{\mathrm{f}, 440}$ & $\begin{array}{l}0.193+0.012 \tau_{\mathrm{f}, 440}, R=0.39 \\
0.246+0.019 \log \left(0.13 \tau_{\mathrm{f}, 40}\right), R=0.44\end{array}$ & $\begin{array}{l}0.513+0.015 \tau_{\mathrm{f}, 440}, R=0.23 \\
0.588+0.026 \log \left(0.10 \tau_{\mathrm{f}, 440}\right), R=0.30\end{array}$ & $1.50 \tau_{\mathrm{c}, 440}$ & 3.20 & 0.69 \\
\hline Cuiaba & 3.28 & $0.129 \tau_{\mathrm{f}, 440}$ & $\begin{array}{l}0.135+0.017 \tau_{\mathrm{f}, 440}, R=0.60 \\
0.177+0.016 \log \left(0.24 \tau_{\mathrm{f}, 440}\right), R=0.61\end{array}$ & $\begin{array}{l}0.364+0.032 \tau_{\mathrm{f}, 440}, R=0.49 \\
0.446+0.035 \log \left(0.29 \tau_{\mathrm{f}, 440}\right), R=0.54\end{array}$ & $1.62 \tau_{\mathrm{c}, 440}$ & 3.27 & 0.63 \\
\hline Jabiru & 1.11 & $0.141 \tau_{\mathrm{f}, 440}$ & $\begin{array}{l}0.147+-0.00017 \tau_{\mathrm{f}, 440}, R=-0.0019 \\
0.155+0.0025 \log \left(0.099 \tau_{\mathrm{f}, 440}\right), R=0.050\end{array}$ & $0.356+0.041 \tau_{\mathrm{f}, 440}, R=0.21$ & $1.12 \tau_{\mathrm{c}, 440}$ & 2.55 & 0.73 \\
\hline Mongu & 2.29 & $0.114 \tau_{\mathrm{f}, 440}$ & $\begin{array}{l}0.133+0.016 \tau_{\mathrm{f}, 440}, R=0.43 \\
0.175+0.012 \log \left(0.12 \tau_{\mathrm{f}, 440}\right), R=0.44\end{array}$ & $\begin{array}{l}0.369+0.031 \tau_{\mathrm{f}, 440}, R=0.28 \\
0.400+0.023 \log \left(1.0 \tau_{\mathrm{f}, 440}\right), R=0.27\end{array}$ & $1.60 \tau_{\mathrm{c}, 440}$ & 3.34 & 0.67 \\
\hline Moscow & 2.67 & $0.120 \tau_{\mathrm{f}, 440}$ & $0.167+0.021 \tau_{\mathrm{f}, 440}, R=0.66$ & $0.496+0.0093 \tau_{\mathrm{f}, 440}, R=0.11$ & $1.58 \tau_{\mathrm{c}, 440}$ & 3.14 & 0.59 \\
\hline Mukdahan & 2.11 & $0.128 \tau_{\mathrm{f}, 440}$ & $\begin{array}{l}0.158+0.024 \tau_{\mathrm{f}, 440}, R=0.40 \\
0.168+0.020 \log \left(2.2 \tau_{\mathrm{f}, 440}\right), R=0.39\end{array}$ & $\begin{array}{l}0.430+0.037 \tau_{\mathrm{f}, 440}, R=0.29 \\
0.476+0.032 \log \left(0.79 \tau_{\mathrm{f}, 440}\right), R=0.31\end{array}$ & $1.43 \tau_{\mathrm{c}, 440}$ & 2.95 & 0.63 \\
\hline Skukuza & 1.57 & $0.135 \tau_{\mathrm{f}, 440}$ & $\begin{array}{l}0.139+0.0093 \tau_{\mathrm{f}, 440}, R=0.19 \\
0.143+0.0066 \log \left(2.2 \tau_{\mathrm{f}, 440}\right), R=0.20\end{array}$ & $0.359+0.021 \tau_{\mathrm{f}, 440}, R=0.17$ & $1.30 \tau_{\mathrm{c}, 440}$ & 2.81 & 0.69 \\
\hline Tomsk 22 & 2.79 & $0.123 \tau_{\mathrm{f}, 440}$ & $\begin{array}{l}0.166+0.018 \tau_{\mathrm{f}, 440}, R=0.44 \\
0.249+0.020 \log \left(0.044 \tau_{\mathrm{f}, 440}\right), R=0.49\end{array}$ & $0.483+0.0066 \tau_{\mathrm{f}, 440}, R=0.052$ & $1.52 \tau_{\mathrm{c}, 440}$ & 3.29 & 0.70 \\
\hline Yakutsk & 3.89 & $0.119 \tau_{\mathrm{f}, 440}$ & $0.165+0.0090 \tau_{\mathrm{f}, 440}, R=0.24$ & $\begin{array}{l}0.461+0.032 \tau_{\mathrm{f}, 440}, R=0.31 \\
0.551+0.053 \log \left(0.42 \tau_{\mathrm{f}, 440}\right), R=0.45\end{array}$ & $1.52 \tau_{\mathrm{c}, 440}$ & 3.36 & 0.73 \\
\hline
\end{tabular}

Table 4. Spectral dependence of extinction, refractive index, SSA, and $g$ for biomass burning aerosols from the 10 AERONET sites. Note that $\alpha, \alpha_{\mathrm{abs}}$, SSA, and $g$ are calculated for $\tau_{\mathrm{f}, 550}=0.5$ and $\tau_{\mathrm{c}, 550}=0.03$ as in Fig. 4 and will vary for different AOD.

\begin{tabular}{|c|c|c|c|c|c|c|c|c|c|c|c|c|c|c|}
\hline \multirow[t]{2}{*}{ Site } & \multirow[t]{2}{*}{$\alpha$} & \multirow[t]{2}{*}{$\alpha_{\mathrm{abs}}$} & \multicolumn{4}{|c|}{ Refractive index ( $\mathrm{n}-\mathrm{ik}$ ), wavelengths in $\mathrm{nm}$} & \multicolumn{4}{|c|}{ SSA, wavelengths in nm } & \multicolumn{4}{|c|}{$g$, wavelengths in $\mathrm{nm}$} \\
\hline & & & 440 & 675 & 870 & 1020 & 440 & 675 & 870 & 1020 & 440 & 675 & 870 & 1020 \\
\hline Alta Floresta & 1.95 & 1.78 & $1.46-0.011 \mathrm{i}$ & $1.48-0.0094 \mathrm{i}$ & $1.48-0.0086 \mathrm{i}$ & $1.47-0.0083 \mathrm{i}$ & 0.92 & 0.92 & 0.92 & 0.91 & 0.68 & 0.63 & 0.57 & 0.50 \\
\hline Bonanza Creek & 1.42 & 2.20 & $1.52-0.0072 \mathrm{i}$ & $1.53-0.0047 \mathrm{i}$ & $1.53-0.0040 \mathrm{i}$ & $1.52-0.0038 \mathrm{i}$ & 0.95 & 0.96 & 0.97 & 0.97 & 0.69 & 0.66 & 0.63 & 0.59 \\
\hline Cuiaba & 1.91 & 1.68 & $1.46-0.016 \mathrm{i}$ & $1.48-0.014 \mathrm{i}$ & $1.49-0.013 \mathrm{i}$ & $1.49-0.012 \mathrm{i}$ & 0.89 & 0.89 & 0.89 & 0.88 & 0.68 & 0.62 & 0.56 & 0.49 \\
\hline Jabiru & 1.88 & 1.62 & $1.43-0.018 \mathrm{i}$ & $1.45-0.016 \mathrm{i}$ & $1.47-0.014 \mathrm{i}$ & $1.46-0.014 \mathrm{i}$ & 0.88 & 0.88 & 0.87 & 0.86 & 0.69 & 0.62 & 0.56 & 0.48 \\
\hline Mongu & 1.89 & 1.43 & $1.50-0.024 \mathrm{i}$ & $1.51-0.024 \mathrm{i}$ & $1.52-0.022 \mathrm{i}$ & $1.52-0.021 \mathrm{i}$ & 0.87 & 0.86 & 0.84 & 0.82 & 0.67 & 0.61 & 0.55 & 0.48 \\
\hline Moscow & 1.62 & 1.92 & $1.47-0.0073 \mathrm{i}$ & $1.48-0.0056 \mathrm{i}$ & $1.49-0.0050 \mathrm{i}$ & $1.48-0.0045 \mathrm{i}$ & 0.95 & 0.95 & 0.96 & 0.96 & 0.70 & 0.67 & 0.63 & 0.58 \\
\hline Mukdahan & 1.66 & 1.43 & $1.44-0.014 \mathrm{i}$ & $1.46-0.014 \mathrm{i}$ & $1.46-0.013 \mathrm{i}$ & $1.46-0.013 \mathrm{i}$ & 0.91 & 0.90 & 0.90 & 0.89 & 0.71 & 0.67 & 0.62 & 0.56 \\
\hline Skukuza & 1.97 & 1.66 & $1.45-0.016 \mathrm{i}$ & $1.47-0.014 \mathrm{i}$ & $1.47-0.012 \mathrm{i}$ & $1.47-0.012 \mathrm{i}$ & 0.90 & 0.89 & 0.89 & 0.87 & 0.68 & 0.62 & 0.55 & 0.47 \\
\hline Tomsk 22 & 1.54 & 1.95 & $1.46-0.0083 \mathrm{i}$ & $1.48-0.0061 \mathrm{i}$ & $1.50-0.0054 \mathrm{i}$ & $1.50-0.0051 \mathrm{i}$ & 0.94 & 0.95 & 0.95 & 0.96 & 0.70 & 0.66 & 0.62 & 0.57 \\
\hline Yakutsk & 1.74 & 1.99 & $1.48-0.0062 \mathrm{i}$ & $1.48-0.0047 \mathrm{i}$ & $1.48-0.0042 \mathrm{i}$ & $1.47-0.0042 \mathrm{i}$ & 0.95 & 0.96 & 0.96 & 0.96 & 0.69 & 0.65 & 0.61 & 0.56 \\
\hline
\end{tabular}

more strongly depending on the relative optical balance of the fine and coarse modes, and these are provided as representative typical values. However if the $\tau_{\mathrm{f}, 550}$ simulated is doubled from 0.5 to 1 while $\tau_{\mathrm{c}, 550}$ remains $0.03, \alpha$ and $\alpha_{\mathrm{abs}}$ change by 0.05 or less and $g$ by 0.02 or less. Note that $\alpha_{\text {abs }}$ for these sites is generally more positive by $0.2-0.5$ than calculations performed by Russell et al. (2010) using the AERONET version 1 smoke models from Dubovik et al. (2002); however, the differences between sites remain similar. Computations over other wavelength ranges (omitted for brevity) are also in the range of values for smoke aerosols determined in other studies (Kirchstetter et al., 2004; Bergstrom et al., 2007).

The relationships between all these properties and $w v$ were also explored, but in most cases omitted for brevity due to a lack of observed covariability. This is consistent with the idea that biomass burning aerosols show weaker hygroscopicity than other fine-dominated aerosols (e.g. Reid et al., 2005a; McMeeking et al., 2012), and that ageing processes may have occurred rapidly and prior to the aerosols reaching the AERONET site. This could also be linked to the small gradient of the observed $\tau_{\mathrm{f}, 550}-r_{\mathrm{v}, f}$ relationships at these sites, which are up to about an order of magnitude weaker than observed for more hygroscopic urban/industrial aerosol particles (e.g. Dubovik et al., 2002). Reid et al. (2005a) did note that some measurements of biomass burning aerosols in scattered regions showed larger hygroscopic growth factors than expected, due to various factors, not all of which were well-understood. Additionally, as the AERONET aerosol and water vapour data represent column-averaged quantities they do not provide information about the extent of vertical overlap between aerosol and moisture (or the history of a given column of air mass). Changes due to moisture uptake may also be masked amongst the variability of aerosol properties from other sources. One corollary of this is that, when using these parameters as optical models for radiative transfer calculations, it may not be necessary to account for hygroscopic growth of these particles for some burning types. 
To facilitate a comparison between the different sites, Fig. 4 compares calculated size distributions and optical properties for the aforementioned case of $\tau_{\mathrm{f}, 550}=0.5$ and $\tau_{\mathrm{c}, 550}=0.03$. Also shown are properties for the "finedominated" aerosol model used in the Sea-viewing Wide Field-of-view Sensor (SeaWiFS) Ocean Aerosol Retrieval (SOAR; Sayer et al., 2012a) algorithm, which is similar $\left(r_{\text {eff,f }}\right.$ within $0.03 \mu \mathrm{m}$, SSA lower by $\sim 0.02-0.03$ ) to models used in the operational over-ocean Moderate Resolution Imaging Spectroradiometer (MODIS; Remer et al., 2009) algorithm, and within the range of aerosol components included in the Multiangle Imaging Spectroradiometer (MISR; Kahn et al., 2010) algorithm.

The bimodal lognormal model employed here is an approximation of the AERONET (22-bin) inversion, which is itself an approximation of the true aerosol size distribution. As a result the distributions in Fig. 4 show subtle differences from the median AERONET distributions in Fig. 2; specifically, the coarse modes in the AERONET data at some sites are broader and more skewed. Despite this, for the reference $\tau_{\mathrm{f}, 550}=0.5$ and $\tau_{\mathrm{c}, 550}=0.03$ the bimodal approximation reproduces spectral SSA and $g$ within 0.01 . Spectral biases in AOD (illustrated later in Sect. 3.5) are also small. This confirms the basic validity of the bimodal lognormal approach for calculating the column-average optical properties of these aerosols.

\subsubsection{Discussion of aerosol properties}

Although all optically dominated by their fine modes, the 10 sites span a range of size distributions and optical properties. Bonanza Creek, Tomsk 22, and Yakutsk, boreal forest burning sites with contributions from peat fires (likely mostly dominated by smouldering combustion), show the weakest absorption with roughly spectrally neutral SSA $\left(\omega_{0} \sim 0.95\right)$ and highest $\alpha_{\mathrm{abs}} \sim 2$, and are among the sites with a larger volume radius and broader distribution. Linear relationships between aerosol properties and AOD or water vapour at this site show strong scatter but, if plotted together as a function of day of year (Fig. 5), some seasonal tendencies become visible. Both $r_{\mathrm{v}, f}$ and $\sigma_{\mathrm{f}}$ tend to be larger for higher $\tau_{\mathrm{f}, 550}$, which tends to be found later in the summer; this is likely due to soil drying through the season, increasing flammability of both peat and large woody fuels (Turquety et al., 2007). There is a suggestion of a bowl-shaped profile of $r_{\mathrm{v}, f}$, with the lowest values from May to July and higher values earlier and later in the season. Columnar water vapour begins to increase around the start of June, and falls off during September. At Tomsk there is a moderate correlation between $r_{\mathrm{v}, f}$ and $w v(R=0.53)$, although this appears to be driven by three outlying points with low radius and water vapour; without these points, the correlation drops to 0.33. Correlations with $w v$ at the other sites, and with $\sigma_{\mathrm{f}}$, are weaker. At small sample sizes, correlation coefficients can be somewhat unstable (e.g. Schonbrödt and Perugini, 2013), and so should not be overinterpreted. The SSA of the smoke is generally higher from mid-May onwards. It is possible that these seasonal changes reflect changes in moisture and/or vegetation phenology, resulting in a change of the nature of burning (flaming/smouldering combustion), and/or varying combinations of smoke from different sources present in the same atmospheric column (Eck et al., 2009; Warneke et al., 2009), including potentially the transport across the whole Northern Hemisphere (Damoah et al., 2004); increased scatter is expected in parametrisations for these three sites as a result.

Aerosol properties retrieved at Moscow are similar to the above sites. Biomass burning at Moscow during the period considered (summers of 2002 and 2010) was influenced more strongly by peat burning than the other boreal sites, although forest burning contributed in some cases (Gorchakov et al., 2004; Chubarova et al., 2011); $90 \%$ of the inversions obtained at Moscow were from intense (predominantly peat) burning during summer 2002. A complication for Moscow is that it is a large city and thus there will be an additional contribution from local aerosol sources, which may also lead to scatter in the parametrisations. However, Ulyumdzhieva et al. (2005) reported, based on measurements early summer 2002 prior to the fires, a typical $\tau_{500}$ around $0.15-0.2$, with little variability. Examination of (unfiltered) AERONET direct-sun data for June-September yields a median $\tau_{500}=$ 0.18 , consistent with this. The inversions selected in this study have the medians $\tau_{500}=0.86$ and $\tau_{440}=1.02$, suggesting that the smoke has a larger optical effect on the total column than the background urban aerosol (although, again, the local contribution cannot be discounted entirely). Chubarova et al. (2012) also noted that the typical $675 \mathrm{~nm}$ SSA at Moscow outside of burning cases was markedly lower $(\sim 0.88)$ than during the fire periods $(\sim 0.96)$. This is consistent with the inversions used in the present analysis being smoke-dominated. The nearby site of Zvenigorod ( $40 \mathrm{~km}$ from Moscow) may be less prone to urban influence, although it provides data only since 2006 , thus missing the 2002 fires.

In contrast, Cuiaba, Skukuza (South Africa), and Jabiru (grass, crop, and shrublands) are very similar to each other, with narrower lower-radius distributions, and are more strongly absorbing $\left(\omega_{0} \sim 0.88-0.9\right.$ in the visible, and $\sim 0.85$ in the near-infrared). Note that Cuiaba can also sample forest burning from the north, while Skukuza includes a sulfate contribution from industrial sources (Piketh et al., 1999). Mukdahan has a similar SSA to these sites, although with a size distribution and asymmetry parameter closer to Yakutsk/Tomsk 22. For this set of sites, relationships between aerosol properties and water vapour were not evident; except at Mukdahan, where a weak increase $(\sim 0.03)$ in SSA from February to April was mirrored by an increase in $w v$ during these inversions from $\sim 2.5$ to $4 \mathrm{~cm}$. However correlations between $w v$ and $r_{\mathrm{v}, f}$ or $\sigma_{\mathrm{f}}$ were negligible $(0.12$ and 0.11 , respectively). As a result it is suggested this is likely linked to transport of air masses including pollutants from 
(a) Reference size distributions

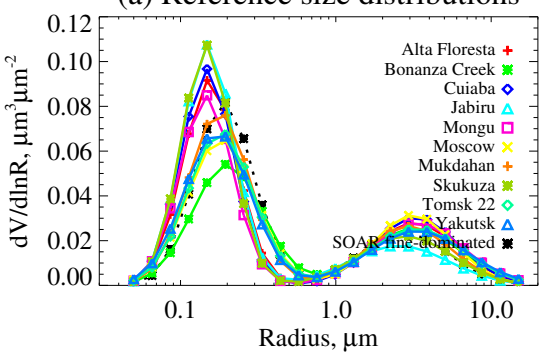

(c) Single scatter albedo

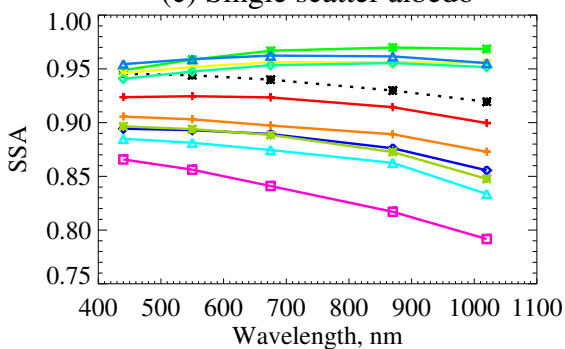

(b) Extinction relative to $550 \mathrm{~nm}$

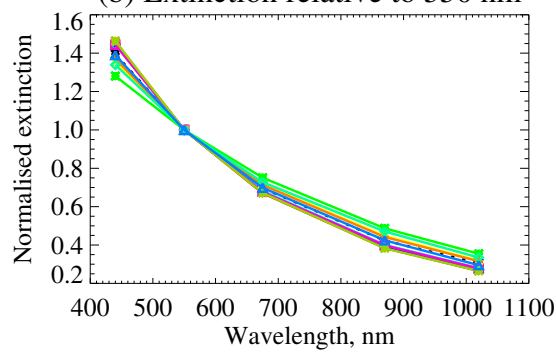

(d) Asymmetry parameter

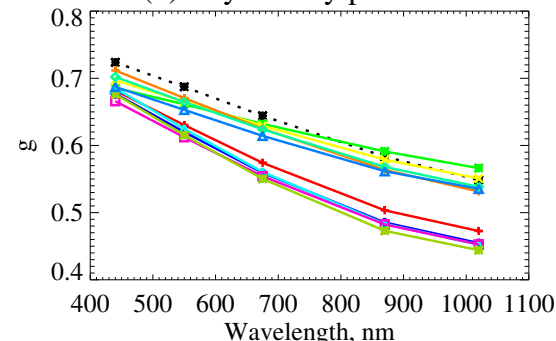

Figure 4. Properties of smoke aerosols for near-source sites, for a reference fine-mode AOD of 0.5 and coarse-mode AOD of 0.03 at $550 \mathrm{~nm}$. Also shown is the "fine-dominated" model of Sayer et al. (2012a) used in the SOAR data set. Panels show (a) size distributions, and the spectral (b) extinction, (c) single scatter albedo, and (d) asymmetry parameter.

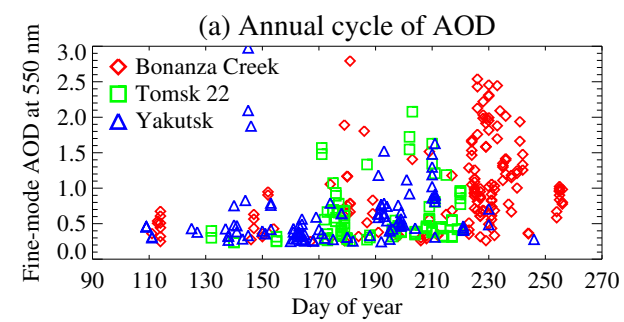

(c) Annual cycle of fine mode volume radius

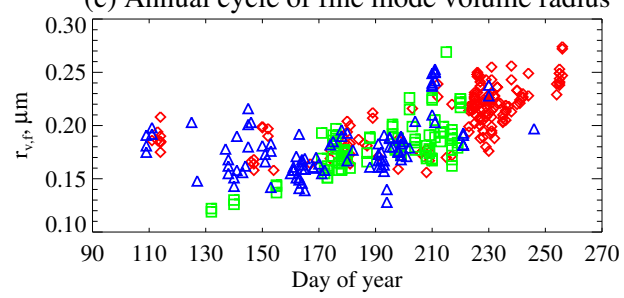

(e) Annual cycle of SSA at $440 \mathrm{~nm}$

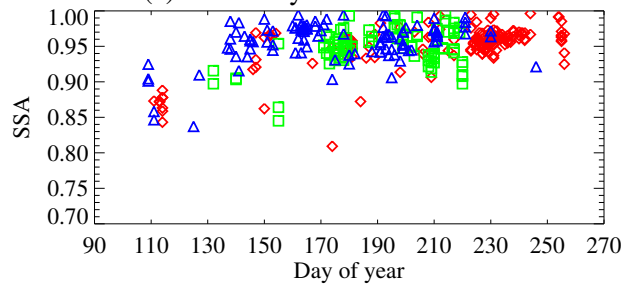

(b) Annual cycle of water vapour

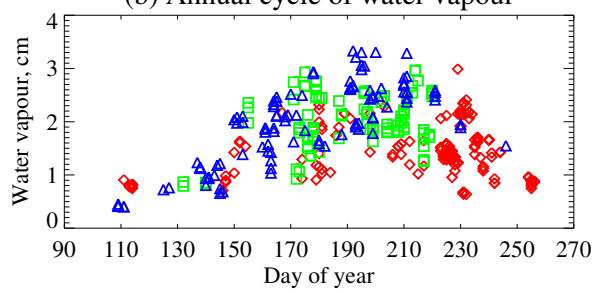

(d) Annual cycle of fine mode spread

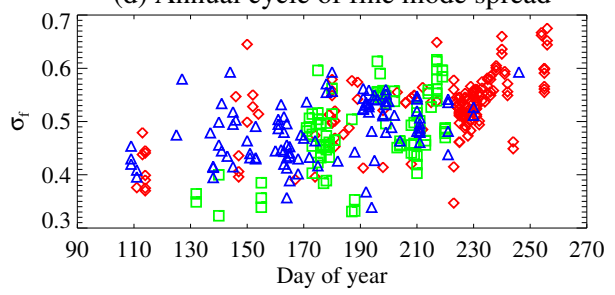

(f) Annual cycle of SSA at $1020 \mathrm{~nm}$

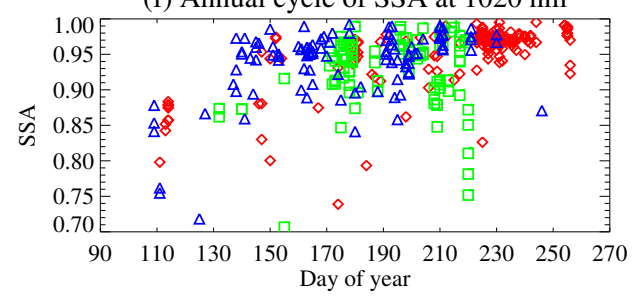

Figure 5. Annual cycle of AERONET-retrieved aerosol properties and water vapour at Bonanza Creek, Tomsk 22, and Yakutsk. Panels show (a) $\tau_{\mathrm{f}, 550}$, (b) $w v,(\mathbf{c}, \mathbf{d})$ fine-mode size, and $(\mathbf{e}, \mathbf{f})$ aerosol SSA.

China/India, and an increase of forest burning relative to agricultural burning during this period, rather than hygroscopic growth of aerosols from a single air mass type.
Alta Floresta samples tropical forest burning from the nearby area and properties are intermediate between these two groups (typical SSA 0.9-0.92). Relationships between 
aerosol fine-mode size/spread and water vapour (not shown) were found to be weak. The SSA at Cuiaba was found to be $\sim 0.05$ higher in October than August, while at the same time the monthly median $w v$ increased from $\sim 2$ to $4 \mathrm{~cm}$; a similar change in $w v$ at Alta Floresta through this period was not associated with any SSA change at this site. This is consistent with the change in SSA at Cuiaba being driven by an increase in air masses containing transported smoke from forested regions through the season. However, these sites both show positive correlations between $r_{\mathrm{v}, f}$ and $w v(R=0.44$ and 0.51$)$, which could indicate hygroscopic growth; these correlations, while significant, are weaker than those between AOD and $r_{\mathrm{v}, f}$ (Table 2). Schafer et al. (2008) noted almost no dependence of AERONET aerosol properties on water vapour in Amazonia, except for the very highest AOD cases $\left(\tau_{550}>1.5\right)$, so this is not entirely consistent. Additionally, correlations between $w v$ and $\sigma_{\mathrm{f}}$ are small ( $R=0.07$ and 0.14 ), while those between AOD and $\sigma_{\mathrm{f}}$ are much stronger $(0.41$ and 0.50$)$. It is also worth noting that the area around the Alta Floresta site has become less forested due to agricultural conversion since the site was originally set up; analysis of the time series of retrieved aerosol properties at this site (not shown) reveals some interannual variability but no apparent trends or secular changes.

Aerosols at Mongu and Skukuza have similar size and distribution properties, although the former is significantly more absorbing (SSA lower by about 0.05), likely due in part to the contribution from nonabsorbing sulfates to the aerosol at Skukuza (Piketh et al., 1999); i.e. the aerosol columns here are less "pure" smoke than elsewhere. Eck et al. (2013) found an increase in SSA of about 0.1 through the burning season at Mongu (as well as inferred elsewhere in the region), which is attributed to a likely decrease of black carbon content from July to November due to sampling fires of different fuel types. The bulk of the inversions at Mongu in this study are from August and September, and so the results are most representative of midseason smoke (although if required for a given application, the temporal dependence of the refractive index discussed in Eck et al., 2013 could be implemented). This temporal variability was also seen to be manifested as temporal variability in bias of satellite-retrieved AOD. At both of these sites, $w v$ was low (typically $\sim 1-2 \mathrm{~cm}$ ) and showed no links with aerosol properties.

The asymmetry parameter $(g)$ is $0.66-0.71$ at $440 \mathrm{~nm}$ for all models/regions (Fig. 4, Table 4), but diverges to the range $0.45-0.59$ at $1020 \mathrm{~nm}$ (due to the differences in fine/coarse AOD partition at longer wavelengths, and fine-mode aerosol size), again, roughly along the lines of the groupings mentioned previously. Similar values and spectral dependence for fine-dominated aerosols were found in previous analyses (e.g. Dubovik et al., 2002), while $g$ for dust aerosols tends to show less spectral variability. In terms of spectral dependence of AOD, most models give about $140 \%$ AOD at $440 \mathrm{~nm}$ relative to $550 \mathrm{~nm}$, and $30 \%$ at $1020 \mathrm{~nm}$ relative to $550 \mathrm{~nm}$, yielding values of $\alpha$ across the midvisible in the range from 1.42 (Bonanza Creek) to 1.97 (Skukuza), with a multi-site mean of 1.76. Note that although this linear $\alpha$ formulation is useful, it is only an approximation and caution should be taken when either using $\alpha$ to extrapolate AOD, or when comparing $\alpha$ determined across different wavelength ranges (e.g. Eck et al., 1999).

Examining the regression relationships in more detail, the fine-mode volume median radius for a moderate $\tau_{\mathrm{f}, 550} \sim 0.3$ is typically $\sim 0.14-0.15 \mu \mathrm{m}$ for the aforementioned grass/shrubland sites and larger $(0.15-0.2 \mu \mathrm{m})$ for the wood-/peat-burning-dominant sites. The gradient of the $\tau_{\mathrm{f}, 550}-r_{\mathrm{v}, f}$ relationship ranges from 0.012 to 0.040 (and changes of similar magnitude for the logarithmic relationships). Low to moderate correlations for these relationships (0.12 at Jabiru to 0.69 at Moscow) reflect both the low range of AOD spanned at some sites, possible contributions from other aerosol sources, and the fact that the scatter around these relationships (of order 0.01-0.02) has a similar size to the estimated uncertainty on AERONET retrievals of $r_{\mathrm{v}, f}$ (mentioned previously). Similarly, gradients and correlations with $\tau_{\mathrm{f}, 440}$ instead of $\tau_{\mathrm{f}, 550}$ are slightly lower as the same data and scatter are essentially being stretched across the AOD axis. Positive correlations between $\tau_{\mathrm{f}, 550}$ and $\sigma_{\mathrm{f}}$ are also observed, although they are weak, likely for the same reasons of large scatter and limited dynamic range. All the above relationships are statistically significant at the $90 \%$ level, except for $\tau_{\mathrm{f}}$ vs. $\sigma_{\mathrm{f}}$ at Jabiru (although, again, many relationships are numerically small). It is important to note that, although these relationships have been derived in a climatological sense, the scatter about them comprises a significant fraction of the observed variability, due to both retrieval noise and sources of true natural variability.

\subsection{Inter- and intrasite variability}

Given the facts that the regression relationships exhibit scatter (Table 4, Fig. 3), and properties appear similar for some sites (Fig. 4), it is natural to examine to what extent these climatological relationships for each site are able to represent the variability at each site and, additionally, whether the relationships developed for one site are able to reproduce aerosol optical properties at other sites. For this assessment, the outlier inversions (removed when developing the regression relationships, as discussed in Sect. 3.3.1) are left in. Each site's parametrisations (Table 4 ) were used with the observed $\tau_{\mathrm{f}, 550}$ and $\tau_{\mathrm{c}, 550}$ to predict the AERONET-retrieved spectral AOD, SSA, and $g$ at each of the eight sites (i.e. applying parametrisations developed for a site to itself, and to each other site in turn). A representivity/distinguishability score was then defined as an analogue of the $\chi^{2}$ statistic,

$$
\chi^{2}=\frac{1}{12} \sum_{i=1}^{3} \sum_{\lambda=1}^{4} \Delta\left(\left|\frac{q_{\bmod (i, \lambda)}-q_{\mathrm{ret}(i, \lambda)}}{\delta_{\operatorname{ret}(i, \lambda)}}\right|^{2}\right),
$$

where $q$ represents the three key optical properties $\left(\tau, \omega_{0}, g\right)$ at each of the four wavelengths $\lambda(440,675,870,1020 \mathrm{~nm})$, 
AOD (e.g. Jethva and Torres, 2011), and is strongly dependent on composition, with black carbon having a roughly spectrally neutral refractive index but absorption of organic carbon increasing at shorter visible and UV wavelengths (Bond, 2001; Kirchstetter et al., 2004, Andreae and Gelencsér, 2006; Lewis et al., 2008). As such the spectral dependence of UV AOD and absorption, as in the visible, may show strong variations dependent on combustion phase and fuel type (e.g. Sun et al., 2007; Lewis et al., 2008).

Although not used in the AERONET inversion algorithm, direct-sun AOD at 340 and $380 \mathrm{~nm}$ are available for a large fraction of the inversions used to generate the optical models. Thus, an empirical approach can be taken to suggest representative refractive indices to allow these models to be extended into the UV, by attempting to match the spectral dependence of AOD predicted by the model with that from the inversions. Unfortunately, only two sites have data at wavelengths longer than $1020 \mathrm{~nm}$, and only for a limited portion of the records, so this approach cannot be applied to these data to also check the validity of extension of the models into the swIR.

This analysis was performed as follows. First, the inversions used to create the aerosol models at each site were subsampled to consider only those where $\tau_{340}$ and $\tau_{380}$ were also available. The median AOD observed for these inversions (from 340 to $1020 \mathrm{~nm}$ ) was taken as a measure of typical spectral dependence. The median $\tau_{\mathrm{f}, 550}$ and $\tau_{\mathrm{c}, 550}$ were used to compute spectral AOD from the optical models, using the relationships from Table 2. Refractive indices used to compute $\tau_{340}$ and $\tau_{380}$ were taken from three methods: use of $440 \mathrm{~nm}$ values directly, linear extrapolation using the values from $440 \mathrm{~nm}$ and $675 \mathrm{~nm}$, and quadratic extrapolation using the four AERONET retrieval wavelengths. The resulting refractive indices/SSA at UV wavelengths are shown in Table 5.

The error in AOD spectral dependence (i.e. difference between modelled spectral dependence and direct-sun spectral dependence) is shown for each UV method (and for the optical model itself for the non-UV wavelengths) in Fig. 7. Figure 8 presents the same data, except expressed as percentage bias. The model bias is almost always within the uncertainty (taken as the larger of the standard error on the median AOD, or the AERONET direct-sun uncertainty, for each wavelength).

Use of $440 \mathrm{~nm}$ refractive indices for the UV spectral region tends to lead to an overestimate of $\tau_{340}$ and $\tau_{380}$. This assumption might be expected to be more reasonable in those cases where the absorption is dominated by black carbon, i.e. no spectral dependence of refractive index. The linear and quadratic extrapolation methods tend to result in a smaller real part and larger imaginary part of the refractive index; this leads to a lower calculated AOD (absorption AOD increases but scattering AOD decreases more strongly). Thus, these might be expected to be more reasonable in cases where the organic carbon contribution to absorption is more dom- inant. It is visible in Fig. 7 that there are differences in the error introduced by these assumptions from site to site, and in some cases also between the two UV wavelengths. However, in most cases, the average spectral behaviour at each UV wavelength can be reproduced with small bias by at least one of the methods for all sites. The differences between the three approximations are often too small to permit the meaningful attribution of compositional differences, particularly as sampling plays a role in the differences too, and so these results should be interpreted rather to guide suitable refractive index choices for UV applications. The exceptions are Moscow and, to an extent, Bonanza Creek, Tomsk 22, and Yakutsk; as discussed previously, greater scatter and model uncertainty is expected at these sites due to the greater potential for smoke from different source types (peat vs. forests) and of different ages (Damoah et al., 2004; Turquety et al., 2007; Eck et al., 2009; Warneke et al., 2009), limiting the fidelity of the model. The spectral slope of AOD at UV wavelengths is more sensitive to the size of fine-mode particles than the fine/coarse AOD split (Eck et al., 1999; Reid et al., 1999), and thus large variability in fine-mode particle size at these sites may in part be responsible. Additionally, the urban contribution at Moscow may have a comparatively large influence at these wavelengths at this site. Note, however, that the larger absolute biases at $340 \mathrm{~nm}$ at these sites represent relative biases approaching 5\% (10\% for Moscow) because of the rapid increase in AOD with decreasing wavelength (Fig. 8). Empirically altering $440 \mathrm{~nm}$ real/imaginary refractive indices by reasonable magnitudes (e.g. within 0.02 for the real part, or $30 \%$ for the imaginary part) can decrease these AOD biases by 0.01 , but this is not sufficient to bring them in line with median AERONET direct-sun values, and larger adjustments result in other quantities (e.g. SSA) becoming less reasonable.

In contrast, the larger relative biases in Fig. 8 tend to be found at the longer wavelengths. However, these biases are likely to be less significant in practical terms for applications of these smoke models, because the absolute AOD is lower at longer wavelengths.

The spectral biases arise in part due to the fact that the (true unknown) aerosol size distribution is being approximated by AERONET's 22-bin inversion, which are then being further approximated in this study by bimodal lognormal models. Although Sect. 3.4 illustrates that this works well for the 440-1020 nm spectral range, errors are expected to be amplified when the model is extrapolated outside of this range (e.g. to UV wavelengths) because scattering and absorption strength are strongly size-dependent. It is therefore not surprising that the larger errors are observed for the sites with broader fine-mode distributions at which there may be some ambiguity as to fine/coarse aerosol separation points.

Sayer et al. (2012b) found that spectral AOD was reproduced with smaller errors for cases of unpolluted maritime aerosols by performing bimodal lognormal fits to AERONET-retrieved size distributions than by using 
(a) Alta Floresta
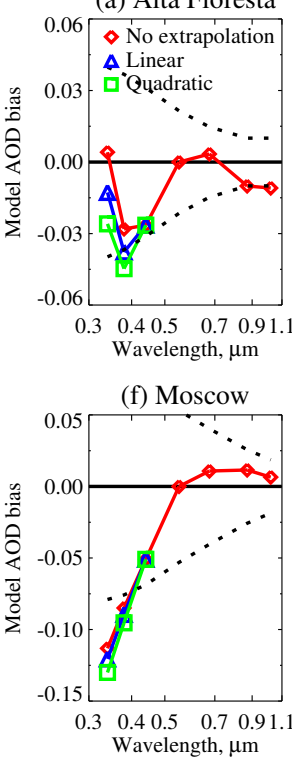

(b) Bonanza Creek
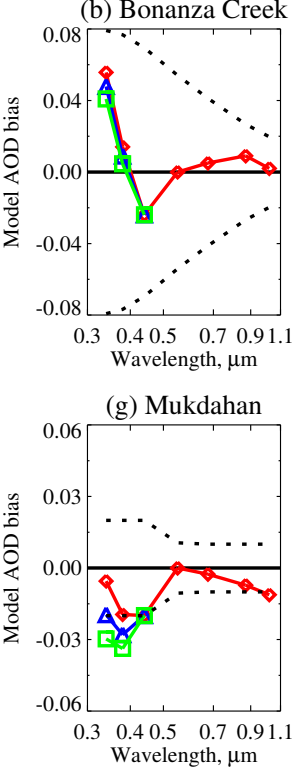

(c) Cuiaba

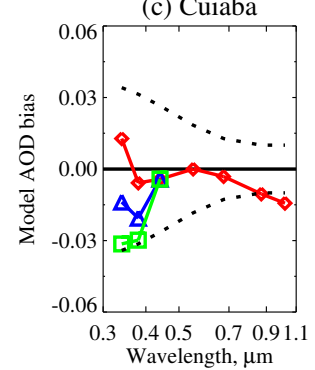

(h) Skukuza

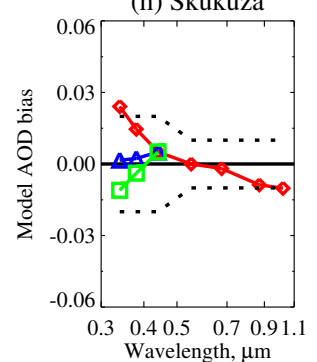

(d) Jabiru

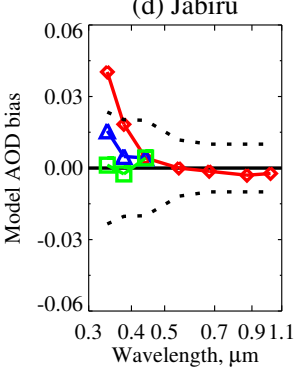

(i) Tomsk 22

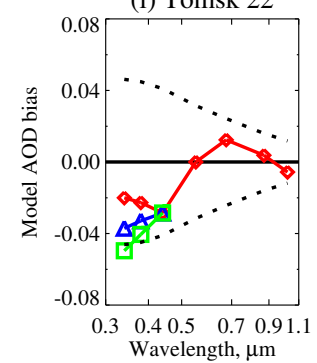

(e) Mongu
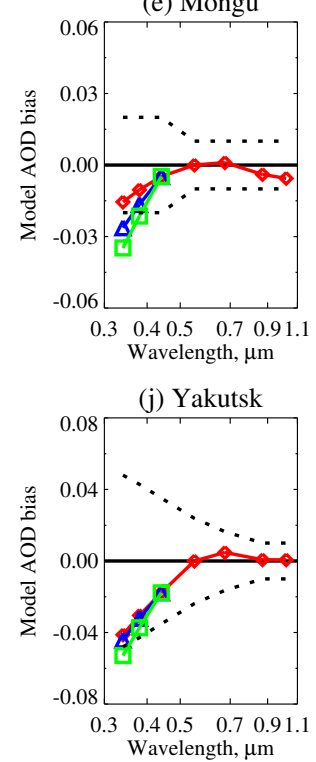

Figure 7. Difference between model-predicted spectral AOD and median AERONET-observed values for the optical models at each site, and various ways of extrapolating refractive index to UV wavelengths: red diamonds indicate use of $440 \mathrm{~nm}$ refractive indices directly; blue triangles linear extrapolation from $440 / 675 \mathrm{~nm}$; and green squares quadratic extrapolation of vis/nIR refractive indices. Resulting refractive indices/SSA are shown in Table 5. The solid black line indicates zero difference, and dashed black lines the greater of the standard error on the median AERONET AOD, or the AERONET direct-sun AOD uncertainty (i.e. \pm 0.02 up to $440 \mathrm{~nm}, \pm 0.01$ at longer wavelengths).
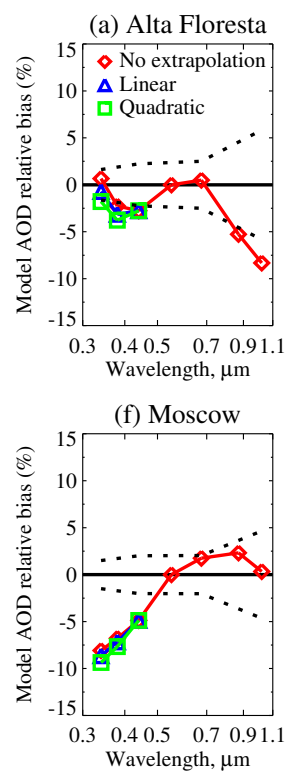

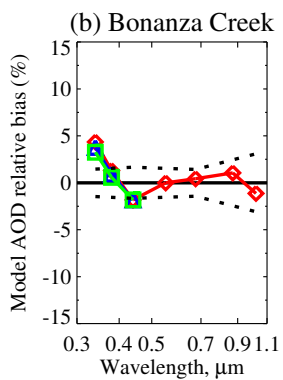

(g) Mukdahan

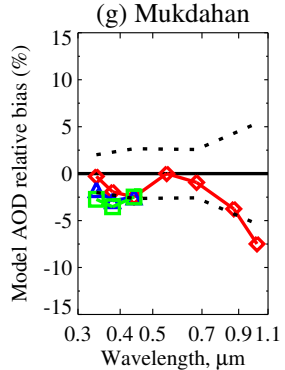

(c) Cuiaba

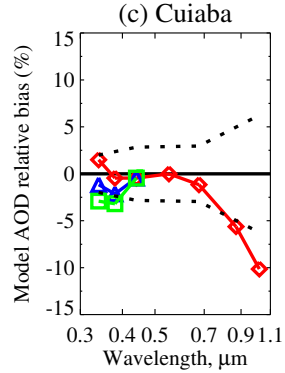

(h) Skukuza

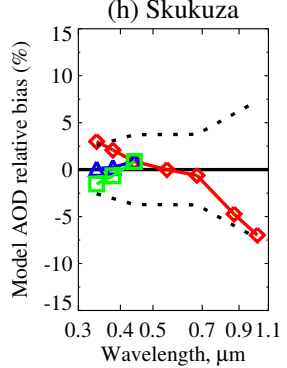

(d) Jabiru

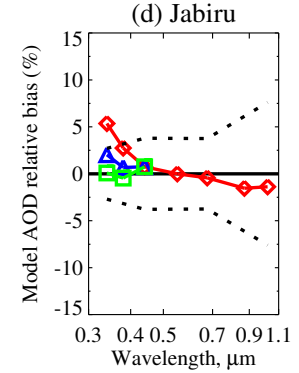

(i) Tomsk 22

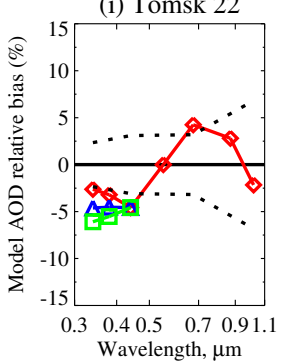

(e) Mongu

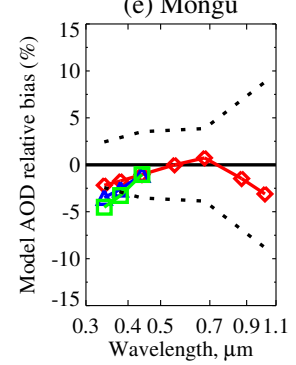

(j) Yakutsk

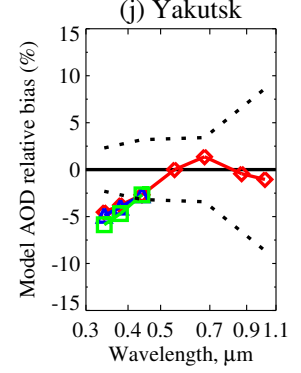

Figure 8. As Fig. 7, expressed in terms of relative (\%) bias instead of AOD bias.

retrieved $r_{\mathrm{v}, f}$ and $\sigma_{\mathrm{f}}$ directly. Taking that approach with these smoke data (omitted for brevity) was not helpful: the resulting $r_{\mathrm{v}, f}$ and $\sigma_{\mathrm{f}}$ both tended to decrease, with the resulting smaller particle size leading to increased AOD at UV wavelengths and decreased AOD at longer wavelengths, accentuating the spectral biases and causing a high bias in $\alpha$. Thus it appears that in these cases using the AERONET-retrieved size distribution parameters directly is the better approach. Satellite-based AOD retrievals for current sensors typically assume combinations of lognormal aerosol models; it may be the case that decreasing errors in spectral AOD below the $5-10 \%$ biases obtained here with the bimodal lognormal approach will require more complicated approaches to parametrise aerosol size distribution shapes. 


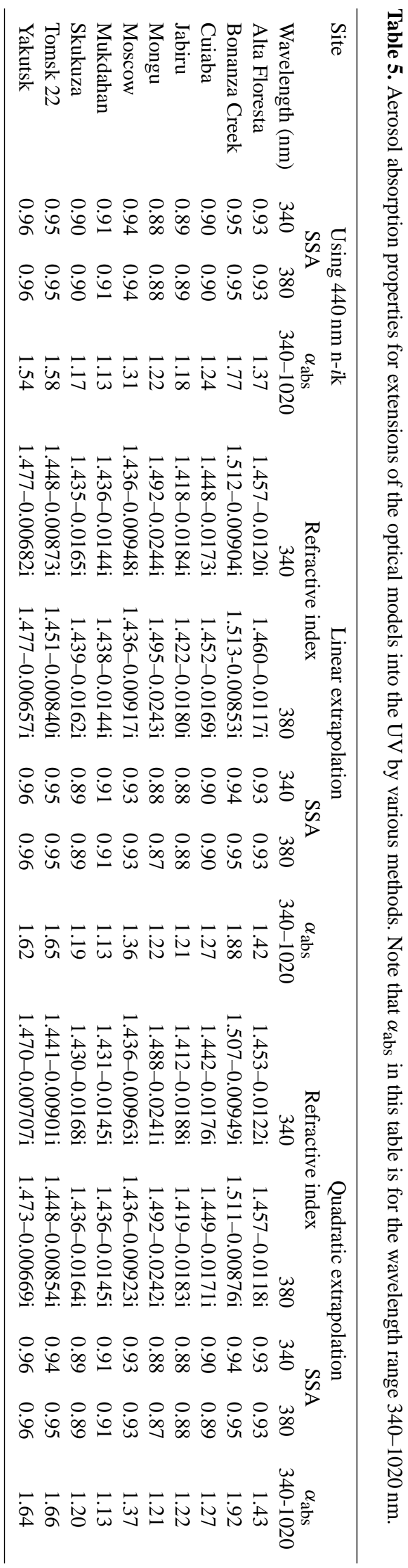

Table 5 also provides $\alpha_{\text {abs }}$ calculated over the wavelength range $340-1020 \mathrm{~nm}$. The variability resulting from different UV refractive index assumptions is of the order $0.01-0.2$, dependent on site. The difference between sites is larger than this: $\alpha_{\text {abs }}$ for Bonanza Creek, Tomsk 22, and Yakutsk (but not Moscow), likely dominated by smouldering combustion, is larger than for the other sites by typically $\sim 0.4$. These values are similar to those determined by other techniques over similar wavelength ranges (data analysed and collated by Kirchstetter et al., 2004), i.e. generally $\sim 1-2$, with lower values associated with increased soot, and higher with increased organic carbon, although there is some sensitivity to the precise wavelength interval used in such calculations.

\subsection{Lidar ratios}

Conversion of profiles of lidar backscatter to molecular, aerosol, or cloud extinction require knowledge of the extinction-to-backscatter ratio $S_{\lambda}$, also often called "lidar ratio", defined as

$S_{\lambda}=\frac{\int_{0}^{\pi} P_{\lambda}(\theta) d \theta}{P_{\lambda}(\pi) \omega_{0 \lambda}}$,

where $P_{\lambda}$ is the scattering phase function. Some lidar systems are able to retrieve the lidar ratio (e.g. Burton et al., 2012; Povey et al., 2014) while others, such as the spaceborne Cloud-Aerosol Lidar with Orthogonal Polarisation (CALIOP), make use of prescribed lidar ratios dependent on particle type (Omar et al., 2009). Calculated lidar ratios for common lidar wavelengths $(355,532$, and $1064 \mathrm{~nm})$ for each site are presented in Table 6 , as a function of $\tau_{\mathrm{f}, 550}$ and for the reference case $\tau_{\mathrm{f}, 550}=0.5$. These use the size distribution parameters from Table 2; refractive indices at $1064 \mathrm{~nm}$ use $1020 \mathrm{~nm}$ values, $532 \mathrm{~nm}$ use the average of 440 and $675 \mathrm{~nm}$ values, and $355 \mathrm{~nm}$ use either $440 \mathrm{~nm}$ values (Alta Floresta, Cuiaba, Mongu, Moscow, Mukdahan, Tomsk 22, Yakutsk), linear extrapolation (Skukuza), or quadratic extrapolation (Bonanza Creek, Jabiru), based on the discussion in Sect. 3.5. Note that the $355 \mathrm{~nm}$ data should be treated with more caution as this represents a more significant extrapolation than the other wavelengths.

The AOD dependence of size distribution parameters leads to a near-linear (calculated over the range $0.2 \leq \tau_{\mathrm{f}, 550} \leq 2$ ) variation of $S_{\lambda}$ with $\tau_{\mathrm{f}, 550}$ of around $5 \%$ at $355 \mathrm{~nm}, 10 \%$ at $532 \mathrm{~nm}$, and $20 \%$ at $1064 \mathrm{~nm}\left(R^{2}>0.9\right.$ for those cases with appreciable AOD dependence). The relative uncertainty in the calculated lidar ratio as a result of uncertainties in the AERONET inversion is approximately $8-15 \%$ (dependent on site and wavelength). The AOD dependence and spectral dependence are fairly robust to these uncertainties. The coarse-mode contribution was neglected for this calculation as the fine mode is optically dominant, and it is likely that in an aerosol column containing fine smoke aerosols and coarse 
Table 6. Fine-mode lidar ratios $S_{\lambda}$ for the optical models developed for each AERONET site. Data in parentheses are for $\tau_{\mathrm{f}, 550}=0.5$.

\begin{tabular}{lccc}
\hline Site & $S_{355}$ & $S_{532}$ & $S_{1064}$ \\
\hline Alta Floresta & $86.6-3.50 \tau_{\mathrm{f}, 550}(84.9)$ & $69.1+2.63 \tau_{\mathrm{f}, 550}(70.4)$ & $23.3+4.57 \tau_{\mathrm{f}, 550}(25.6)$ \\
Bonanza Creek & $52.5-5.90 \tau_{\mathrm{f}, 550}(49.6)$ & $59.3-4.65 \tau_{\mathrm{f}, 550}(57.0)$ & $37.2+4.91 \tau_{\mathrm{f}, 550}(39.7)$ \\
Cuiaba & $96.0-2.51 \tau_{\mathrm{f}, 550}(94.8)$ & $67.3+7.09 \tau_{\mathrm{f}, 550}(70.9)$ & $21.8+6.43 \tau_{\mathrm{f}, 550}(25.0)$ \\
Jabiru & $110-1.07 \tau_{\mathrm{f}, 550}(109)$ & $73.8+2.39 \tau_{\mathrm{f}, 550}(75.0)$ & $23.5+4.98 \tau_{\mathrm{f}, 550}(26.0)$ \\
Mongu & $100-3.33 \tau_{\mathrm{f}, 550}(98.6)$ & $72.0+6.86 \tau_{\mathrm{f}, 550}(75.4)$ & $24.8+4.89 \tau_{\mathrm{f}, 550}(27.3)$ \\
Moscow & $66.8-5.86 \tau_{\mathrm{f}, 550}(63.9)$ & $66.6-0.573 \tau_{\mathrm{f}, 550}(66.3)$ & $32.9+6.92 \tau_{\mathrm{f}, 550}(36.3)$ \\
Mukdahan & $93.6-3.56 \tau_{\mathrm{f}, 550}(91.8)$ & $77.5+3.83 \tau_{\mathrm{f}, 550}(79.4)$ & $30.6+8.65 \tau_{\mathrm{f}, 550}(35.0)$ \\
Skukuza & $101-0.857 \tau_{\mathrm{f}, 550}(100)$ & $69.6+3.88 \tau_{\mathrm{f}, 550}(71.6)$ & $22.2+4.06 \tau_{\mathrm{f}, 550}(24.3)$ \\
Tomsk 22 & $73.8-4.32 \tau_{\mathrm{f}, 550}(71.7)$ & $67.3+1.24 \tau_{\mathrm{f}, 550}(67.9)$ & $31.6+6.25 \tau_{\mathrm{f}, 550}(34.7)$ \\
Yakutsk & $66.6-6.04 \tau_{\mathrm{f}, 550}(63.6)$ & $66.6-2.90 \tau_{\mathrm{f}, 550}(65.1)$ & $29.9+5.80 \tau_{\mathrm{f}, 550}(32.8)$ \\
\hline
\end{tabular}

aerosols the two may (to an extent) be found in separate vertical layers. Calculation of the coarse-mode lidar ratio is also more error-prone because for these AERONET inversions the coarse-mode contribution to the size distribution is small, and the retrieved refractive indices are likewise heavily weighted toward the fine mode. However, calculated coarsemode lidar ratios were found to be of similar magnitude to those for the fine mode on average, and thus this is not expected to have a large numerical effect.

The sites fall, again, into two groups: boreal sites (Bonanza Creek, Moscow, Tomsk, and Yakutsk) with $S_{532}$ around 5570 and smaller spectral dependence, and the other six sites, with $S_{532}$ around 70-80 and larger spectral dependence. CALIOP processing assumes $S_{532}=70$ and $S_{1064}-40$ with a target uncertainty of up to $30 \%$, and therefore seem sensible global average values; although, note that this was also based on version 1 AERONET data (Omar et al., 2005), so these values are not independent of this work. Other researchers have estimated lidar ratios for smoke by independent methods. Müller et al. (2007) summarise the results of a decade of Raman lidar observations, from which smoke in Canada and Siberia was found to have on average $S_{355}=46 \pm 14$ and $S_{532}=53 \pm 11$; Murayama et al. (2004) reported $S_{355} \sim 40$ and $S_{532} \sim 60$ for Siberian smoke transported to Japan, both in agreement with the results for Bonanza Creek, Tomsk 22, and Yakutsk here. Smoke from China or Russia transported to Korea was also found to be within this range by Noh et al. (2008) $\left(S_{355}=46 \pm 7, S_{532}=65 \pm 8\right)$. Sugimoto et al. (2010) found $S_{532} \sim 50-75$ for Mongolian smoke observed at two sites in Japan; $S_{1064}$ was inferred as $\sim 50-60$, which is larger than this study, although Sugimoto et al. (2010) noted limited sensitivity of their $1064 \mathrm{~nm}$ data. Müller et al. (2007) also reported $S_{532}=65 \pm 16$ for air masses in northern India thought to be influenced by wood burning. Similar ranges have been found for Amazonian smoke $\left(S_{532}=50-80\right.$; Baars et al., 2012). Burton et al. (2012) classified airborne measurements by prevailing aerosol type, and found the average $S_{532}=30$ 50 for fresh smoke and $S_{532}=60-80$ for aged smoke. Ansmann et al. (2001) observed $S_{532} \sim 80$ for small, absorbing particles at Portugal (not explicitly linked to smoke). The li- dar ratios at $355 \mathrm{~nm}$ of smoke from fires of different types in Ukraine and Russia were found by Amiridis et al. (2009) to range widely (averages for individual episodes from 39 to 94), with larger $S_{355}$ associated with aged air masses, and an anticorrelation between $S_{355}$ and $\alpha$. Similar $S_{355}=69 \pm 17$, and dependence on $\alpha$, were found for fires transported to Greece by Giannakaki et al. (2010). These are intermediate between the typical values of $S_{355}$ found for the two groupings in Table 2; however Tesche et al. (2011) reported higher values of $S_{355}=87 \pm 17$ for dust-free smoke transported to Cape Verde, which are more similar to Table 2. Tesche et al. (2011) also found $S_{532}=79 \pm 17$, slightly higher but in the range of $S_{532}=60 \pm 6$ found by Voss et al. (2001) for smoke transported to the equatorial Atlantic. Thus, the spectral $S_{\lambda}$ in Table 6 appear supported by previous investigations.

\section{Isolated cases of smoke at coastal/island sites}

\subsection{Identification of cases}

As well as the sites used to develop optical models in Sect. 3, cases of smoke have been observed in smaller numbers at a wide range of coastal or island AERONET sites. Figure 9 shows smoke from several wildfires in California (USA), which are not uncommon in the Northern Hemisphere's summer and autumn, blown over the Pacific Ocean. Although fires in this area often occur on an annual basis, these sites are discussed in this section as there are insufficient cases passing over the AERONET sites to create a meaningful climatology of properties.

Figure 10 shows an example of more long-range transport, namely Amazonian smoke transported south through South America, eventually passing over the AERONET site in Buenos Aires (Argentina) and out over the southern Atlantic Ocean. This pathway is confirmed by the Hybrid Single Particle Lagrangian Integrated Trajectory (HYSPLIT; Draxler and Hess, 1998) model back-trajectory, for air arriving over Buenos Aires at $\sim 2 \mathrm{~km}$ altitude (HYPSPLIT estimates of the altitude of this air mass near the source were $3-4.5 \mathrm{~km}$ ). 
Table 7. Geographical/sampling information for smoke cases at AERONET coastal/island sites.

\begin{tabular}{|c|c|c|c|c|c|}
\hline Site & $\begin{array}{r}\text { Latitude, } \\
\text { degrees }\end{array}$ & $\begin{array}{r}\text { Longitude, } \\
\text { degrees }\end{array}$ & $\begin{array}{l}\text { Elevation, } \\
\text { m a.s.l. }\end{array}$ & $\begin{array}{l}\text { Number of } \\
\text { retrievals }\end{array}$ & Dates (YYYYMMDD) \\
\hline Ascension Island & -7.97600 & -14.4150 & 30 & 19 & $\begin{array}{l}20030902-06,20080904,20080906-07 \\
20080919,20080925,20080928\end{array}$ \\
\hline Bach Long Vy & 20.1330 & 107.733 & 5 & 10 & $\begin{array}{l}20100506,20100509,20110209,20110224, \\
20110314,20110418,20110421,20110423\end{array}$ \\
\hline Barrow & 71.3120 & -156.665 & 0 & 5 & 20040703,20100612 \\
\hline CEILAP Buenos Aires & -34.5670 & -58.5000 & 10 & 28 & $\begin{array}{l}\text { 20010803, 20010921-22, 20040813-15, } \\
20040827,20040904,20060722,20060824, \\
20060910,20060922,20100821-22,20110903\end{array}$ \\
\hline COVE & 36.9000 & -75.7100 & 37 & 12 & $20020706-09$ \\
\hline Darwin & -12.4240 & 130.892 & 29 & 20 & $\begin{array}{l}\text { 20071013, 20071016, 20071018-19, } \\
20091011-12,20091104\end{array}$ \\
\hline Hornsund & 77.0010 & 15.5600 & 10 & 6 & $20060502-03$ \\
\hline Inhaca & -26.0410 & 32.9050 & 73 & 33 & $\begin{array}{l}20000823,20000831,20000902-03, \\
20000905-06,20000910,20000914, \\
20001004-05,20001007,20001009-10, \\
20010820-21,20010823,20010829, \\
20010908,20010910-11,20010916\end{array}$ \\
\hline La Jolla & 32.8700 & -117.250 & 115 & 7 & $20031028,20070804,20071024-25$ \\
\hline Monterey & 36.5930 & -121.855 & 50 & 4 & $20080627,20080710,20080712$ \\
\hline Noto & 37.3340 & 137.137 & 200 & 5 & 20030606, 20080422, \\
\hline San Nicolas & 33.2570 & -119.487 & 133 & 2 & 20031027 \\
\hline Saturn Island & 48.7830 & -123.133 & 200 & 22 & $\begin{array}{l}\text { 20080630, 20080701-02, 20100802, } \\
\text { 20100804, 20100806, 20100816-17 }\end{array}$ \\
\hline Sevastopol & 44.6160 & 33.5170 & 80 & 28 & $\begin{array}{l}\text { 20070809-10, 20070901-03, 20080801, } \\
20100815-18\end{array}$ \\
\hline Singapore & 1.29800 & 103.780 & 30 & 10 & 20090806-07, 20110905-06, 20120924 \\
\hline Trinidad Head & 41.0540 & -124.151 & 105 & 13 & $20060925-26,20080709$ \\
\hline UCSB & 34.4150 & -119.845 & 33 & 19 & $\begin{array}{l}\text { 20031025-27, 20070817-18, 20071022-23, } \\
20071025-26\end{array}$ \\
\hline
\end{tabular}

Aerosol properties at the sites in this figure are shown in more detail in Fig. 11: $\tau_{440}$ at Buenos Aires is low for most of the period, while at the other sites it is larger, approaching 4 at Alta Floresta, and more variable (Alta Floresta and Cuiaba lack observations prior to 18 August). High $\tau_{440}$ and $\alpha$ at these sites is consistent with biomass burning; the finemode effective radius and SSA at Alta Floresta and Ji Paraná (Rondônia, Brazil) track each other reasonably closely, while the smoke at Cuiaba is slightly smaller and more absorbing. During 21-23 August, the plume travelled from the northern region to Buenos Aires (Fig. 10), and the SSA matches that at Alta Floresta/Ji Paraná $(\sim 0.9$ at $440 \mathrm{~nm})$, from where the plume is observed to travel. The absence of SSA retrievals outside this period at Buenos Aires is due to the low AOD. Note that the more-absorbing Cuiaba site lies outside of the main path of this plume. The fine-mode effective radius at Buenos Aires is slightly larger during this period than before or after, and also larger than the near-source sites, which may be coincidental or may result from mixing with another air mass during transport. Following this event, AOD at Buenos Aires returns to typical low levels. Towards the end of the month satellite images (not shown) reveal that smoke from the forested region is blown over Cuiaba; the SSA and finemode radius at Cuiaba increase to more closely match Alta Floresta/Ji Paraná.

Unfortunately, the number of cases where a smoke plume is observed at an AERONET site near its source and is conveniently transported past other sites over the course of days, thus providing the ability to track the evolution of the plume with AERONET, is limited. Thus the comparison herein is more of a categorical nature: comparing how the body of case studies at island/coastal sites compares with the climatology and variability of the sites in Sect. 3. The main focus is to examine whether the optical properties for these cases fall within the same range as at the climatological sites, to determine whether they are suitable to represent these isolated smoke cases in radiative transfer calculations, rather than to make statements about the origin or chemical composition of individual case studies, or persistent transport pathways.

Table 7 presents the list of AERONET inversions corresponding to smoke identified at coastal/island sites (Fig. 1) used in this study. These data were individually identified 


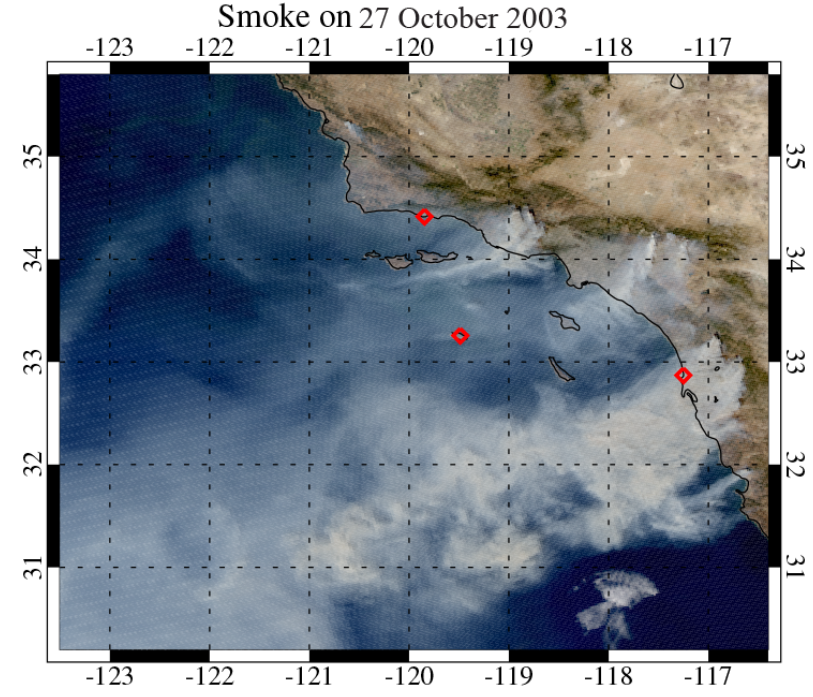

Figure 9. True-colour image from MODIS aboard the Aqua satellite showing smoke (grey-brown hues) blowing from fires in California (USA) over the Pacific Ocean on 27 October 2003. Red diamonds show, from north to south, the locations of the UCSB $\left(34.4^{\circ} \mathrm{N}\right.$, $\left.119.8^{\circ} \mathrm{W}\right)$, San Nicolas $\left(33.3^{\circ} \mathrm{N}, 119.5^{\circ} \mathrm{W}\right)$, and La Jolla $\left(32.9^{\circ} \mathrm{N}\right.$, $\left.117.3^{\circ} \mathrm{W}\right)$ AERONET sites.

as likely having a significant contribution from smoke using the same techniques used to make the judgement in Figs. 9 and 10, i.e. by examination of MODIS true-colour images and HYSPLIT back-trajectories, news/government agency reports, and guided by previous studies (Queface et al., 2003; O'Neill et al., 2005; Eck et al., 2009; Qin and Mitchell, 2009; Witte et al., 2011; Chubarova et al., 2012; Castro Videla et al., 2013). More recently, AERONET now provides a data synergy tool to facilitate this type of multi-data-set analysis, found at http://aeronet.gsfc.nasa.gov/cgi-bin/bamgomas_interactive.

\subsection{Discussion}

Derived aerosol optical properties for the near-source sites are shown in Fig. 12, split by geographic region, alongside the cases of smoke at coastal/island sites originating in similar regions. Figure 13 shows the median SSA and its spectral dependence in map form to provide a visual representation of the spatial variability in biomass burning aerosol absorption. Some geographical clustering is evident, along with the tendency for biomass burning aerosols with lower SSA to also show an increased spectral dependence of absorption (lower SSA at longer wavelengths).

The main point of this analysis is to illustrate the overlap between the climatological site and island/coastal site smoke aerosol optical properties, rather than to tie each individual case down to a specific burning type. For example, smoke cases at Buenos Aires lie in between those at Alta Floresta (more forest-influenced) and Cuiaba (more grass-

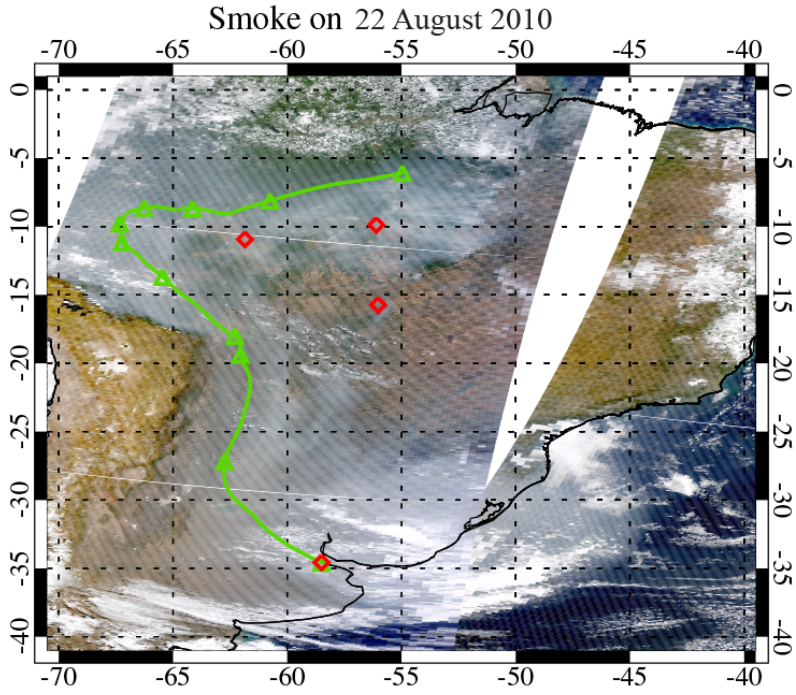

Figure 10. True-colour image from MODIS aboard the Terra satellite showing smoke (grey-brown hues) spreading across South America and into the southern Atlantic Ocean on 22 August 2010. Image acquired from two consecutive Terra orbits. Red diamonds show, from North to South, the locations of the Alta Floresta $\left(9.87^{\circ} \mathrm{S}, 56.1^{\circ} \mathrm{W}\right)$, Ji-Paraná $\mathrm{SE}\left(10.9^{\circ} \mathrm{S}, 61.9^{\circ} \mathrm{W}\right)$, CUIABA-MIRANDA $\left(15.7^{\circ} \mathrm{S}, 56.1^{\circ} \mathrm{W}\right)$, and CEILAP-Buenos Aires $\left(34.6^{\circ} \mathrm{S}, 58.5^{\circ} \mathrm{W}\right)$ AERONET sites. The green line shows the HYSPLIT 10-day back-trajectory for the air mass ending at $2 \mathrm{~km}$ above Buenos Aires at 00:00 UTC on 23 August 2010; triangles indicate the position at 00:00 UTC each day.

/shrubland-influenced), reflecting the range of potential pathways of smoke transport across the South American continent. Smoke at Noto (Japan) was traced back to boreal forest burning in Siberia, which is also observed at Tomsk 22 and Yakutsk, and shares similar optical properties with those sites. Some geographic regions sample smoke with a variety of optical properties (e.g. California), while others do not (e.g. similar properties at Darwin and Jabiru, both in northern Australia). In some cases smoke from unrelated sources in different geographical regions can exhibit similar optical properties to each other, even though the underlying burning type and chemical composition can differ. The intent is not to suggest a necessary commonality of underlying chemical composition, size, and shape, but rather a similarity in the apparent optical properties which are of most relevance for satellite AOD retrieval applications. Some additional variability is observed, attributable to factors such as additional ageing of the aerosol particles and/or combination with aerosol particles from different air masses. For example, burning at Barrow (Alaska, USA) is likely aged smoke from boreal fires. The SSA is similar to that at Alta Floresta (tropical forest/grassland burning) but $g$ is 0.05-0.1 higher at Barrow. Conversely, $g$ at Barrow is similar to the boreal burning site Bonanza Creek, but SSA is $\sim 0.05$ lower at Barrow. Optical properties at Barrow are, however, similar 
(a) AOD at $440 \mathrm{~nm}$

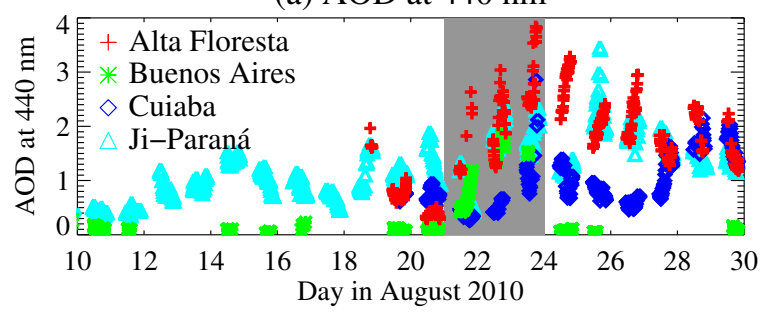

(b) $\alpha$

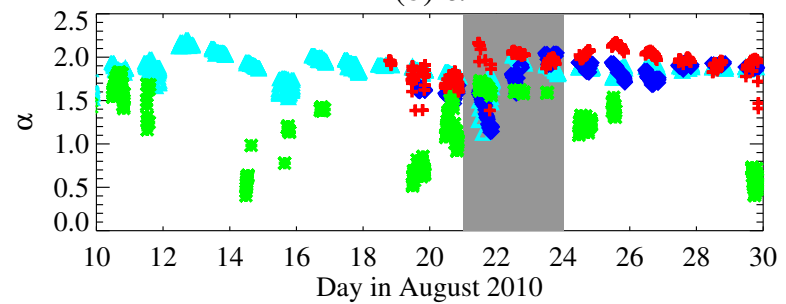

(c) Fine mode effective radius

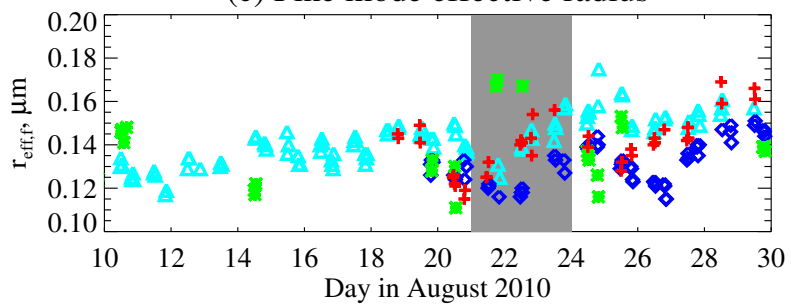

(d) SSA at $440 \mathrm{~nm}$

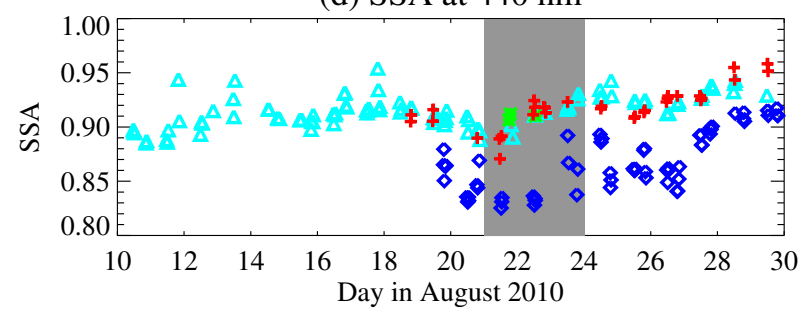

Figure 11. Time series of aerosol properties at AERONET sites shown in Fig. 10 for 10-29 August 2010. Panels show (a) $\tau_{440}$, (b) $\alpha$ (both from the direct-sun AERONET observations), (c) $r_{\text {eff,f }}$, and (d) SSA at $440 \mathrm{~nm}$ (both from the AERONET inversion data set). The shaded grey area indicates 21-23 August, when the smoke plume was observed at Buenos Aires.

to those at Mukdahan, although burning at Mukdahan is from a completely different ecosystem (and different chemical origin and composition).

Many of the island/coastal sites are in or near urban areas, and so even for these smoke cases there is likely a contribution from local urban aerosol sources which is not present to the same extent for the "climatological" sites. Examples include Bach Long Vy in the gulf of Tonkin (off the coast of Vietnam), COVE (off the coast of Virginia, USA), Sevastopol (Ukraine), and Singapore. The fact that the optical properties for these cases still generally fall within the range observed at these climatological sites reflects in part that the optical properties for urban- and smoke-dominated aerosol periods can be similar, i.e. fine-mode optically dominated with variable absorption strength, as determined by sun photometry (e.g. Eck et al., 1999; Dubovik et al., 2002; Salinas et al., 2009; Bovchaliuk et al., 2013) or other techniques (e.g. He et al., 2009; Gyawali et al., 2012; McMeeking et al., 2012). On the one hand this means that optical models based on smoke may also be appropriate optical proxies for mixed smoke/urban or urban aerosols in some cases (although again commonality of optical properties should not be taken to imply commonality of microphysical properties or origin). On the other hand, similarity between optical properties for different aerosol origins highlights again that the limited information content of many satellite instruments will be insufficient to discriminate between different smoke or smoke and urban aerosol mixtures. AERONET and other optical data have been used to find optical properties which can discriminate between different fine-mode-dominated aerosol "types" (Russell et al., 2010; Giles et al., 2012), although there is sometimes overlap in these classifications, and many of these quantities are typically not accessible from satellite observations with fidelity. Inversions at COVE were for a case of smoke from Canadian boreal forest fires in July 2002 (O'Neill et al., 2005), and most optical properties fall within the central $68 \%$ of data at the North American boreal burning site Bonanza Creek (as well as Tomsk 22 and Yakutsk, which sample primarily Siberian burning). However, a smaller $\sigma_{\mathrm{f}}$ for some of these inversions leads to a higher $\tau_{440} / \tau_{550}$ ratio (by $\sim 0.2$ ) and increased spectral dependence of fine-mode $g$. The background AOD before this episode at this site was fairly low ( $\tau_{550} \sim 0.1-0.15$ ), but increased to $0.25-1.4$ during the smoky period, indicating the smoke was optically dominant over the background.

In south-eastern Asia, both Bach Long Vy and Singapore differ more strongly from Mukdahan. Urban aerosols tend to exhibit greater AOD dependence of microphysical/optical properties than smoke, due in part to their tendency for higher hygroscopicity (e.g. Hess et al., 1998; Dubovik et al., 2002; Reid et al., 2005a), and so the background local urban contribution may have been relatively higher at these sites, contributing to the large variability at Bach Long Vy. However differences in the type of burning are likely also responsible. For example, optical properties for inversions at Singapore are similar to the climatology for Moscow; as well as potential urban influence, this may reflect that smoke at Singapore is often a combination of peat and forest burning from Indonesia, e.g. Langmann and Heil (2004), similar to Moscow. Note that Sevastopol is also a close match to optical properties at Moscow; some of the Sevastopol cases corresponded to transported smoke from burning in August 2010 near Moscow.

Aerosol optical properties for the five island/coastal sites with smoke cases in California show some diversity. Smoke from wildfires in California can, on a case-by-case basis, be influenced by varying combinations of forests and chaparral 

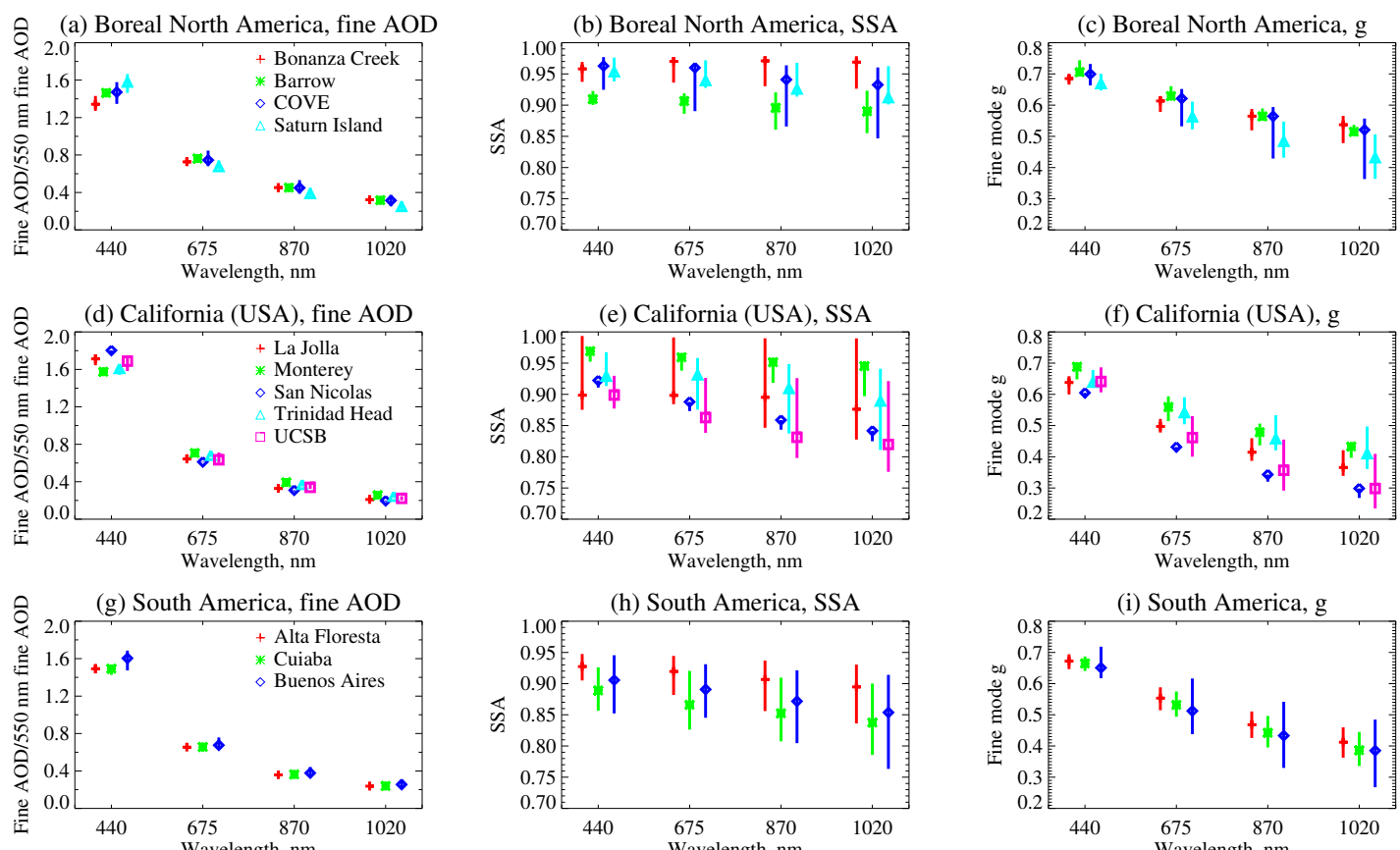

(h) South America, SSA

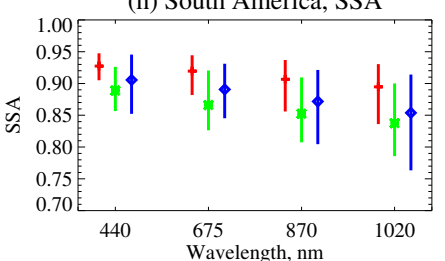

(i) South America, g

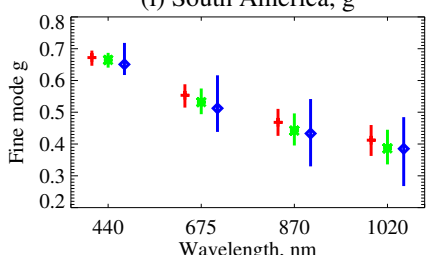

(k) Boreal Europe/Asia, SSA
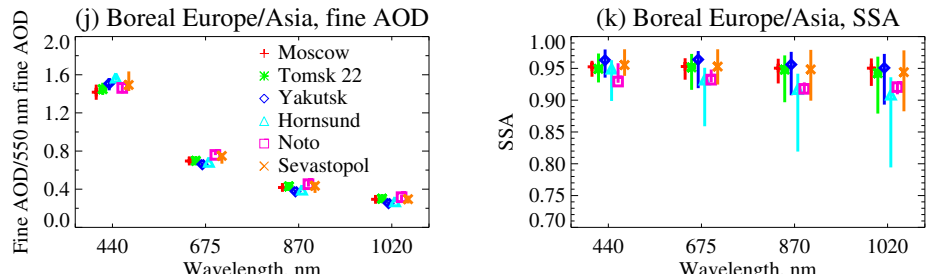

(1) Boreal Europe/Asia, g

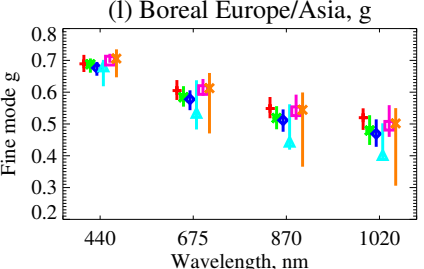

(n) South-east Asia, SSA
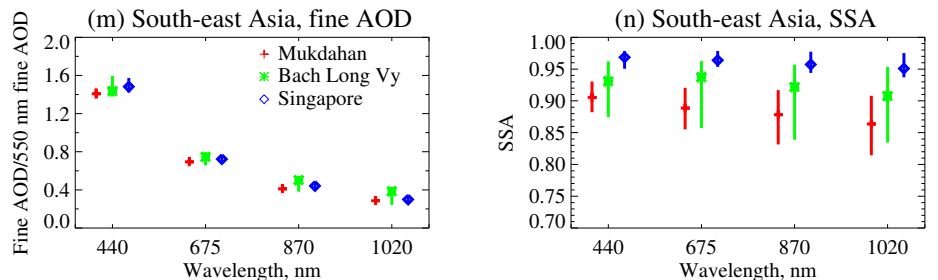

(o) South-east Asia, g
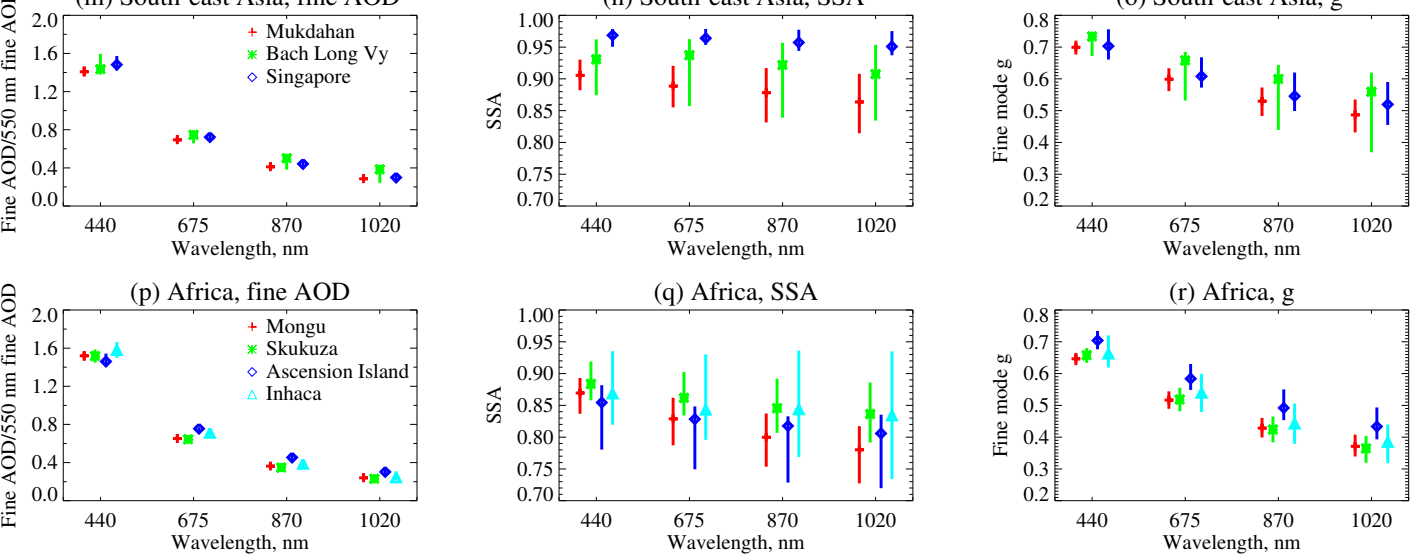

(q) Africa, SSA

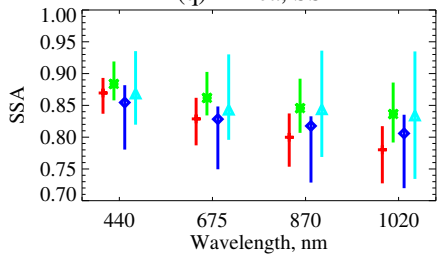

(r) Africa, g
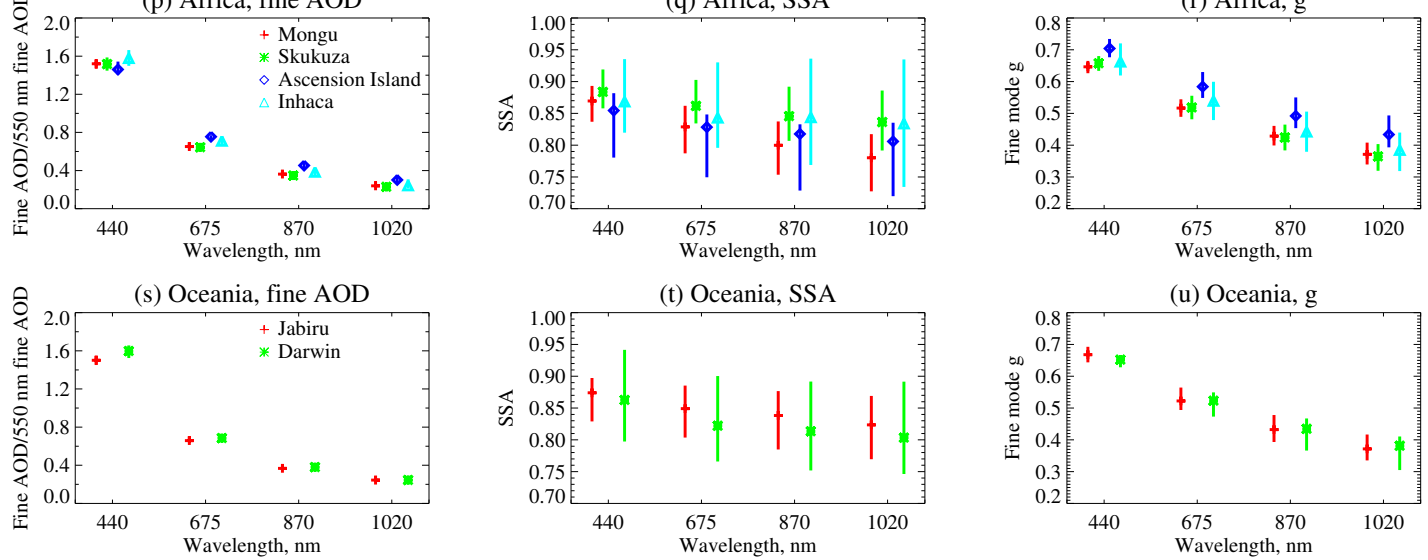

Figure 12. Optical properties of smoke-dominated aerosol from near-source sites, and coastal/island smoke cases, grouped by geographic region. From left to right, columns show the spectral dependence of fine-mode AOD (relative to fine-mode AOD at 550 nm), SSA, and fine-mode asymmetry parameter. Symbols indicate the median value for each site; lines show the central $68 \%$ of retrieved values at the site for the 10 near-source sites, and the range of values for the coastal/island smoke case sites. 
shrublands. Optical properties for cases of smoke transported to La Jolla (aside from one very weakly absorbing case), San Nicolas, and UCSB (University of California, Santa Barbara) tend to be similar to Cuiaba, which is often influenced by grassland/shrubland burning. However, a slightly smaller particle size at these sites leads to a slightly higher $\tau_{440} / \tau_{550}$ ratio (by about $15 \%$ ), and lower fine-mode $g$ (particularly at longer wavelengths), and as such use of an optical model based on Cuiaba data to represent these fires will lead to an underestimate of AOD at short visible wavelengths. In fact, $\tau_{440} / \tau_{550}$ for these sites is higher $(\sim 1.5-1.8)$ than observed for typical conditions at any of the climatological sites ( 1.3-1.5). The cases of smoke observed at Monterey have a higher SSA to these sites, perhaps suggesting more smouldering combustion; SSA is more similar to that from boreal burning at, for example, Bonanza Creek, although $g$ at Monterey is more similar to that at Cuiaba. Smoke properties at Trinidad Head in northern California tend to be more similar to smoke from Alta Floresta (perhaps reflecting a dominance of wood-burning fires).

African burning sites show the strongest absorption; a "river of smoke" is often responsible for transporting smokeladen air masses from burning near Skukuza out to the southeast (Swap et al., 2003), and thus the aerosols observed at Skukuza and Inhaca have similar optical properties. Ascension Island samples air masses including mixed Saharan/Sahelian dust and smoke aerosols from November to February, and central African smoke from June to November (Ben-Ami et al., 2009; Adams et al., 2012); only this second period contributed to the cases shown here. At this site, $\sigma_{\mathrm{f}}$ and SSA are a very close match to data from Mongu, while coarse-mode properties (not shown) are similar to the pure maritime case (Sayer et al., 2012b). However, $r_{\mathrm{v}, f}$ is about $0.02 \mu \mathrm{m}$ larger at Ascension Island than Mongu, which leads to a slightly weaker spectral dependence of AOD, and fine-mode $g$ larger by typically $0.05-0.1$. Ascension Island is fairly remote and in a harsh environment (exposed to salt from breaking waves, which may deposit on the instrument), which can lead to instrument problems more frequently than at some other AERONET sites. The most common symptom of these problems is an anomalously low SSA (typically up to 0.1 lower than expected), while retrieved size distribution parameters and direct-sun spectral AOD are less strongly affected. However, the AERONET inversions and source sky radiance data from Ascension Island were examined and no evidence of calibration/contamination problems was found for the data used here.

Therefore it is likely that the higher $r_{\mathrm{v}, f}$ at Ascension Island than Mongu is a real characteristic of the aerosol transported to this area, rather than an artefact. The most likely reasons include additional ageing (examination of HYSPLIT back-trajectories for these cases suggests the air masses left the African continent $\sim 5$ days before arriving at Ascension Island) and the possibility that properties of the freshly emitted aerosol are different from those near Mongu. Some air

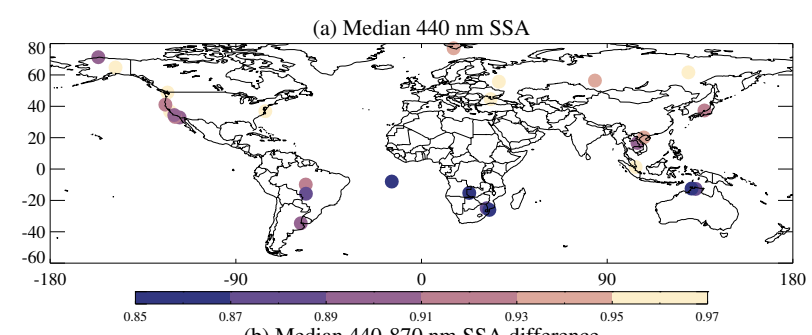

(b) Median 440-870 nm SSA difference

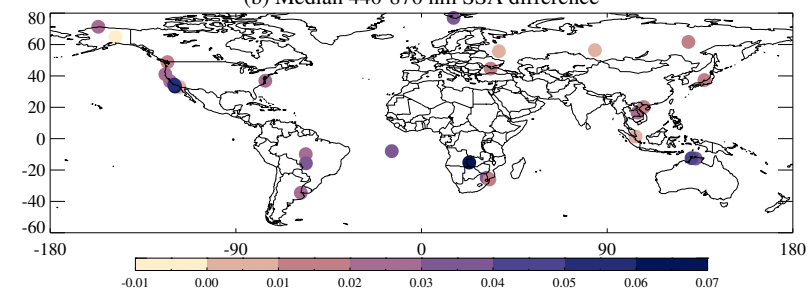

Figure 13. Maps of median (a) SSA at $440 \mathrm{~nm}$, and (b) SSA change from 440 to $870 \mathrm{~nm}$ (positive values indicate higher absorption at $870 \mathrm{~nm}$ ) at the sites used in this study.

masses reaching Ascension Island pass over parts of Africa north of Mongu, which are more heavily forested (Roberts et al., 2009; Adams et al., 2012), and could lead to different typical optical properties compared to savannah burning (Ward et al., 1996; Reid et al., 2005b). Unfortunately, there are no AERONET sites in this part of Africa.

Coarse-mode properties (not shown) show more diversity between sites, and also often differ from pure marine aerosol properties (Sayer et al., 2012b), although as the coarse-mode contribution to total AOD is minor this is not likely to be a significant source of error, particularly if the optical models are used to represent only the fine-mode aerosols.

Overall, these results imply that additional ageing or air mass mixing of these smoke-laden aerosol columns during transport changes their optical properties generally to a lesser extent than (i.e. within the range of) the variability of smoke from different source regions. The main conclusion from this is that the range of optical models based on fine-mode smoke aerosol inversions near source regions are also representative of the range of optical properties of smoke transported over the ocean, and therefore suitable for use in satellite AOD retrievals far from source regions (e.g. over ocean), although the optical properties for a given ecosystem type can in some cases differ.

\section{Implications for satellite AOD retrievals}

Figure 4 revealed that the "fine-dominated" aerosol microphysical model used in over-ocean SeaWiFS processing (Sayer et al., 2012a) is intermediate in strength of absorption between the more weakly absorbing boreal sites, and the more strongly absorbing tropical forest and grass/shrubland sites. Therefore, use of this model to retrieve AOD from satellite measurements in these latter cases is likely to result 
in an underestimate of AOD (or conversely overestimated AOD for cases of weakly absorbing smoke). The most absorbing fine-mode aerosol component in the widely used MODIS operational processing over ocean is slightly less absorbing than this SeaWiFS model (Remer et al., 2009). This suggests that the over-ocean AOD from some regional smoke aerosols in both of these data sets, which are large and seasonally repeating features in some parts of the world but have been validated only sparsely due to a lack of ground truth data in some regions, may be underestimated. In contrast, the MISR aerosol mixtures include aerosols with a midvisible SSA down to about 0.8 (Kahn et al., 2010), which covers a greater range of the observed variability in SSA. All algorithms also include effectively nonabsorbing aerosol models. In addition to reported biases over ocean (e.g. Zhang and Reid, 2006), it is worth mentioning that incorrect SSA also leads to biased AOD retrievals over land (see, e.g. Ichoku et al., 2003; Hyer et al., 2011; and Eck et al., 2013, for smoke examples).

Turning to observations, Fig. 14 compares midvisible AOD from these satellite products against AERONET directsun data at Ascension Island. This site is chosen as its location and atmospheric circulation permit filtering to include only cases of transported smoke, with reasonable confidence. The most recent versions of the satellite products are used: MODIS Collection 6 (Aqua data only; Terra data are not yet available), SeaWiFS version 4, and MISR version 22. Several filters are applied to the AERONET data. First, data from November to February are excluded to minimise the contribution from transported dust, which mostly happens in this season, while smoke transport is most frequent from June to November (Ben-Ami et al., 2009; Adams et al., 2012). Second, data with $\tau_{550}<0.1$ or $\alpha<0.8$ are excluded, as the former cases are likely dominated by maritime aerosols, and the latter likely have little contributions from fine-mode (smoke) aerosols. This removes $\sim 75 \%$ of the data but increases confidence of the influence of smoke aerosols (mixed with marine aerosols) in the remaining points. Other than these filters, the satellite-AERONET matchup protocol is as in Sayer et al. (2012a); namely, AERONET data are spectrally interpolated to $550 \mathrm{~nm}$ and averaged within $\pm 30 \mathrm{~min}$ of the satellite overpass, and satellite data are averaged within $\pm 25 \mathrm{~km}$ of the AERONET site and restricted to only those retrievals meeting the data set creators' recommended quality assurance flags.

The positive bias of MODIS and MISR data in low-AOD conditions (0-0.2), and smaller SeaWiFS bias in these conditions, has been noted in previous studies (Kahn et al., 2010; Shi et al., 2011; Sayer et al., 2012a, c). However, all data sets exhibit a low bias in AOD in conditions of elevated AOD. This is most notable in SeaWiFS, where a weakly absorbing $\left(\omega_{0} \sim 0.99\right)$ model is often chosen. Note that the linear fits are shown in Fig. 14 as a guideline only, as the regressions are subject to high uncertainty due to a fairly small data volume (especially for MISR) and the decreasing number

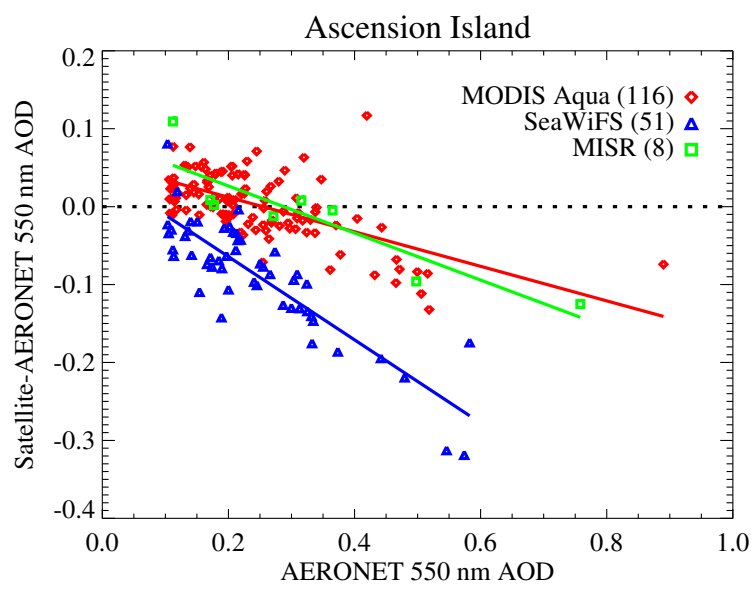

Figure 14. Error on retrieved $A O D$ at $550 \mathrm{~nm}$ as a function of AERONET AOD at $550 \mathrm{~nm}$, from MODIS, SeaWiFS, and MISR data products at Ascension Island, excluding likely maritime or dust-dominated cases. Coloured lines indicate the least-squares linear fit of bias vs. AOD for each data set. The number of matches for each sensor is shown in parentheses.

of matchups as AOD increases. Interestingly, although the current MISR algorithm includes strongly absorbing aerosol mixtures, the change of bias from low-AOD to high-AOD conditions is similar to that in MODIS data. This suggests that these mixtures may not always be chosen when needed (and the selection of an appropriate aerosol optical model to use in a system with a limited information content is a difficult problem in itself).

To test the effect of aerosol absorption on satellite measurements, the $6 \mathrm{~S}$ radiative transfer code (Vermote et al., 1997) was used to simulate TOA reflectance at wavelengths used for AOD retrieval by these sensors, for a variety of geometries, over an ocean surface with $6 \mathrm{~m} \mathrm{~s}^{-1}$ wind speed. Three aerosol types were considered: strongly absorbing aerosol using the model for Mongu (Table 2; $\omega_{0} \sim 0.85$ at $440 \mathrm{~nm}$ ), moderately absorbing aerosol using the finedominated model of Sayer et al. (2012a) $\left(\omega_{0} \sim 0.95\right.$ at $440 \mathrm{~nm}$ ), and the pure marine model of Sayer et al. (2012b) $\left(\omega_{0} \sim 0.99\right.$ at $\left.440 \mathrm{~nm}\right)$. Then, for each wavelength simulated, the two latter models were used to retrieve AOD (reported relative to $550 \mathrm{~nm}$ ) in each band, taking the Mongu case as "truth", and so calculate the AOD retrieval error. Although this does not mirror how the previously mentioned individual satellite algorithms function, which would be out of the scope of this study, it does provide a direct comparative baseline of the sensitivity of each wavelength to the assumed strength of aerosol absorption.

Figure 15 illustrates the results of this test for a solar zenith angle of $45^{\circ}$, viewing zenith angle of $10^{\circ}$, and relative azimuth angle of $135^{\circ}$. Similar patterns are observed at other common sun/sensor viewing geometries (not shown). This figure shows the increase of TOA reflectance with AOD, 

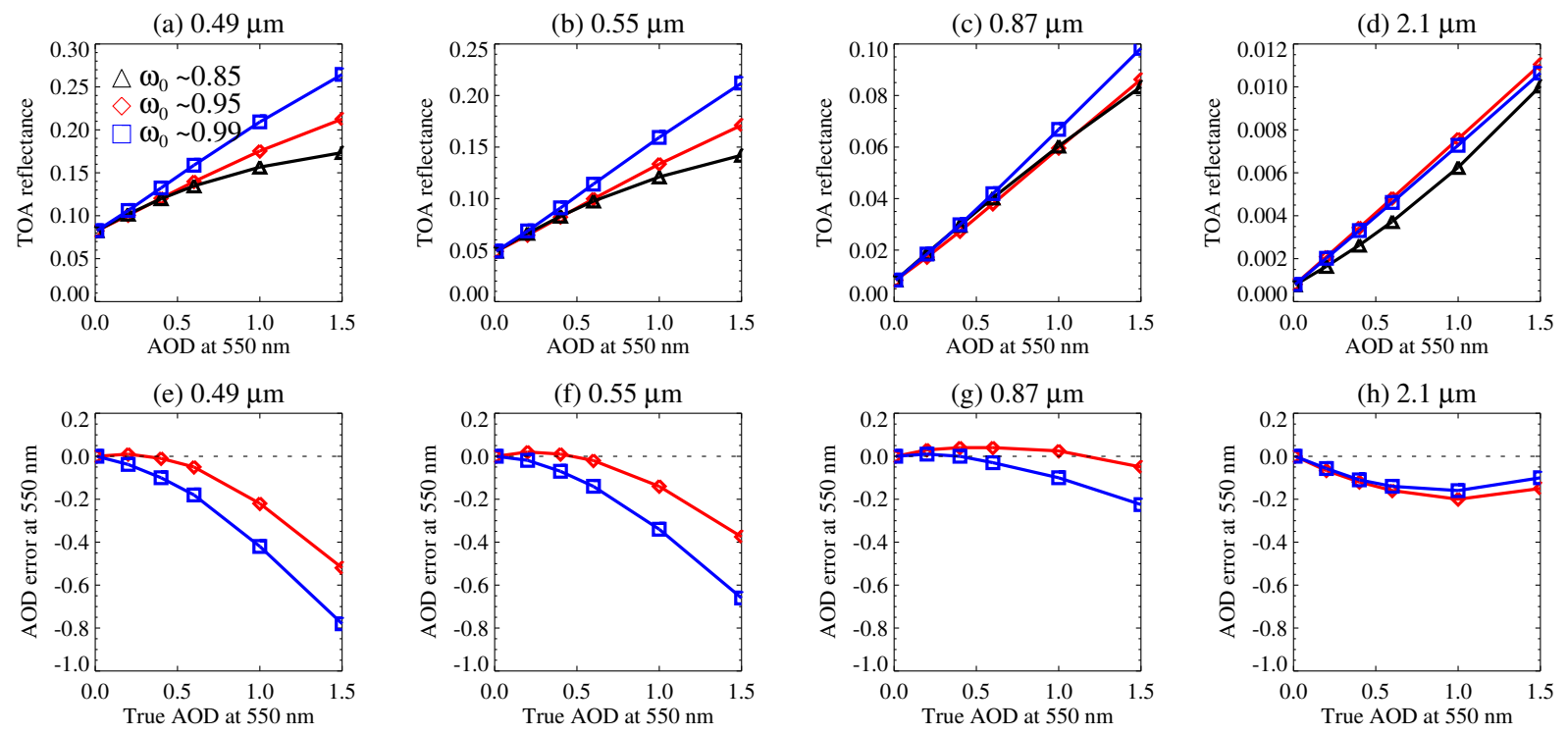

Figure 15. TOA reflectance and AOD retrieval errors for four wavelengths. Panels (a-d) show TOA reflectance as a function of $\tau_{550}$, for strongly (black), moderately (red), and weakly (blue) absorbing aerosol microphysical models over ocean. Panels (e-h) show the error in AOD which would be retrieved if measurements at that wavelength were used and a moderately or weakly absorbing aerosol assumed, if the true aerosol were instead strongly absorbing.

with the increase being less pronounced for more strongly absorbing aerosols, leading to a low bias in retrieved AOD if the real aerosol is less absorbing than assumed. The difference is larger for shorter wavelengths, linked to the larger aerosol signal and increased Rayleigh-aerosol interactions. This lends support to the interpretation of Fig. 14, although other factors (e.g. surface reflectance, calibration, pixel selection) may also contribute, and suggests that future versions of satellite AOD retrieval algorithms should include an analogue for these strongly absorbing aerosol particles.

\section{Conclusions}

Biomass burning is one of the major contributors to the global aerosol burden, with both natural and anthropogenic sources. The analysis of AERONET retrievals of size distribution and refractive index revealed considerable variety between microphysical and optical properties of biomass burning aerosols in different global source regions. In line with previous analyses, retrieved fine-mode radius tends to increase with AOD; increases in fine-mode width as a function of AOD were also observed, but had not been reported by previous studies for smoke aerosols (e.g. the early AERONET database used by Dubovik et al., 2002). The gradients of these relationships differ between the sites, although the site-to-site variability of size distribution parameters could be similar to that within a single site. A corollary of the AOD dependence is that techniques such as $k$-means clustering, which can be very sensitive to the clustering variables used and their dynamic range, may not be suitable for iden- tifying properties characteristic of different biomass burning types, because of the interrelationships of microphysi$\mathrm{cal} /$ optical properties with each other and with AOD. As a result, the analysis was performed on a site-by-site basis, rather than attempting a cluster analysis on the data set as a whole.

Of the 10 sites studied, the scatter of AERONETretrieved microphysical/optical parameters around the AODdependent regression relationships was generally within the AERONET uncertainty at six sites. This supports the use of these relationships as optical models to represent climatological aerosol properties representative of these biomass burning regions. Boreal sites (Bonanza Creek, Moscow, Tomsk 22, and Yakutsk) exhibited slightly increased scatter, attributed to potentially different optical properties from sampled burning of boreal forests and peat (and potentially an urban influence at Moscow), and may additionally sample smoke transported around the Northern Hemisphere, a process which can take several weeks (Damoah et al., 2004), during which additional ageing may occur. These boreal sites are characterised by comparatively large fine-mode particles and broader size distributions, with weaker and nearly spectrally neutral absorption (typical SSA of 0.95-0.97). At the other extreme are sites dominated by grass/shrub burning (smaller particles with narrower distributions and stronger absorption, SSA $\sim 0.88-0.9$, becoming more strongly absorbing as wavelength increases from 440 to $1020 \mathrm{~nm}$ ). Alta Floresta (primarily tropical forest burning, with contributions from grassland) is intermediate between these two groups, with similar size distribution properties to the grass/shrub sites (e.g. the comparatively nearby Cuiaba), but higher SSA 
due to the imaginary part of refractive index being approximately one-third lower than these other sites. Mongu in the southern African savannah exhibits strongest absorption, with an average SSA around 0.85 in the midvisible, although this varies through the burning season (Eck et al., 2013).

Derived aerosol properties were found to be within a similar range to those observed in other studies by a variety of techniques (e.g. reviews by Reid et al., 2005a, b); an advantage of AERONET is the long-term nature of observations at some sites, and consistency in observation, retrieval, and quality assurance procedures between sites, making it a useful tool for region-to-region comparisons of this type. The main advances over the previous AERONET-based analysis by Dubovik et al. (2002) are use of the updated AERONET version 2 inversion algorithm, longer time series, expanded range of biomass burning sites considered, and presentation of complete sets of microphysical/optical properties required for a range of radiative transfer calculations, including assessments of extension into the UV spectral range and the lidar ratio.

These results can serve as candidate sets of aerosol microphysical/optical properties for use in satellite AOD retrievals, which are reliant on assumptions about aerosol properties due to the limited information content available from existing passive spaceborne imaging radiometers. This does not, however, alleviate the difficulty of assuring that an appropriate microphysical model is used for any particular individual pixel-level satellite retrieval. Additionally, case studies of smoke retrievals at coastal/island AERONET sites were examined and also frequently fell within the range of variability for these near-source sites. The similarity between these two data sets implies that these models can be used for satellite AOD retrieval over ocean, as well as over land.

As these models represent the climatological properties of biomass burning at these sites, they cannot capture the full range of variability at a given site, but variability between sites tends to be larger than variability within individual sites. At a given site the models are generally able to reproduce the median spectral AOD to within $\sim 5 \%$, which would then represent a likely practical lower bound that such retrieval algorithms for satellite sensors could achieve on spectral AOD by using them (although there is some dependence on site and wavelength). Larger uncertainties tend to be found at UV wavelengths, and further improvement may require moving beyond the bimodal lognormal size distribution approximation.

Despite different underlying physical sources and chemical compositions, optical properties between some sites are similar to each other, and to typical optical properties for urban/industrial aerosol mixtures. This suggests both that a small set of optical properties may be useful for representing a range of smoke and mixed smoke and urban aerosols in radiative transfer calculations, but also that inferring aerosol composition or origin may often not be possible from some observable optical properties alone.
A low bias has been found previously in some satellite AOD data sets for cases of smoke aerosols (e.g. Zhang and Reid, 2006; Kahn et al., 2010; Hyer et al., 2011; Shi et al., 2011; Sayer et al., 2012a). The optical models used in these satellite algorithms often do not encompass the lower end of the SSA associated with AERONET inversions of biomass burning, and the magnitude of biases in satellite AOD are generally consistent with radiative transfer simulations investigating the effect of inappropriate SSA assumptions on satellite measurements. Thus, it is likely that these assumptions make a notable contribution to the total retrieval error. As these satellite data sets are increasingly used in climate applications, and as an evaluation tool for chemistry transport models, this is potentially a significant shortcoming. Rare cases of Sahelian smoke where the fine mode is opticallydominant suggest that even stronger absorption may be seen (Johnson et al., 2008; Eck et al., 2010), which would further exacerbate these biases (although in this particular situation the smoke is almost always mixed with more weakly absorbing dust). Until the launch of future satellite sensors with increased measurement capabilities, it is important that the continual evolution of algorithms using existing sensors includes the adoption of more realistic aerosol microphysical models as our knowledge of aerosol properties increases.

Acknowledgements. This work was supported by the NASA EOS program, managed by Hal Maring. The authors are grateful to the AERONET PIs and site managers (I. Abboud, R. Aguiar, P. Andryszczak, N. X. Anh, P. Arruda, P. Artaxo, E. Bernardino de Andrade, T. Bigala, J. de Brito Gomes, W. Brower, S. Campbell, P. Cesarano, N. Chubarova, G. Crooks, F. Denn, E. G. Dutton, R. D. Elia, B. Fabbri, R. Frouin, P. Glowacki, P. Greenwood, S. Halewood, N. M. Hoan, J. Hollingsworth, J. Ivanoff, M. Ives, D. Jatoba dos Santos, A. Jorge, D. M. Kabanov, G. Karasinski, K. L. Keong, M. E. Lee, S.-C. Liew, S. Meesiri, R. Mitchell, F. Morais, M. Mukulabai, N. Nelson, N. P. Ndhlovu, S. Nikolashkin, C. B. Ning, A. Niyompam, E. Ojeda de Almeida Filho, N. O'Neill, L. Otero, M. Panchenko, S. Piketh, E. Quel, E. Reid, J. S. Reid, A. Royer, S. Sakerin, S. V. Salinas Cortijo, I. Sano, P. Sobolewski, J. de Souza Nogueira, E. Stolyarova, G. A. Tolkachenko, G. Thomas, J. R. Vande Castle, R. Wagener, A. D. Webler, E. Wolfram, A. Yangthaisong, B. Zak) for the creation and stewardship of the ground-based data records used, and useful discussions about their sites. MODIS data were obtained from the Level 1 and Atmosphere Archive and Distribution System (LAADS). F. Patadia, J. Limbacher, R. A. Kahn, and K. J. Mueller are thanked for their assistance in interpreting the MISR aerosol product file format. The authors gratefully acknowledge the NOAA Air Resources Laboratory (ARL) for the provision of the HYSPLIT transport and dispersion model and/or READY website (http://www.ready.noaa.gov) used in this publication. R. Gautam is acknowledged for useful discussions about Asian aerosols. The authors are grateful to A. Bovchaliuk, J. S. Reid, and three anonymous reviewers for their extensive comments.

Edited by: J.-Y. C. Chiu 


\section{References}

Abel, S. J., Haywood, J. M., Highwood, E. J., Li, J., and Buseck, P. R.: Evolution of biomass burning aerosol properties from an agricultural fire in southern Africa, Geophys. Res. Lett., 30, doi:10.1029/2003GL017342, 2003.

Adams, A. A., Prospero, J. M., and Zhang, C.: CALIPSODerived Three-Dimensional Structure of Aerosol over the Atlantic Basin and Adjacent Continents, J. Climate, 25, 6862-6879, doi:10.1175/JCLI-D-11-00672.1, 2012.

Amiridis, V., Balis, D. S., Giannakaki, E., Stohl, A., Kazadzis, S., Koukouli, M. E., and Zanis, P.: Optical characteristics of biomass burning aerosols over Southeastern Europe determined from UVRaman lidar measurements, Atmos. Chem. Phys., 9, 2431-2440, doi:10.5194/acp-9-2431-2009, 2009.

Andreae, M. O. and Gelencsér, A.: Black carbon or brown carbon? The nature of light-absorbing carbonaceous aerosols, Atmos. Chem. Phys., 6, 3131-3148, doi:10.5194/acp-6-3131-2006, 2006.

Ansmann, A., Wagner, F., Althausen, D., Müller, D., Herber, A., and Wandinger, U.: European pollution outbreaks during ACE 2: Lofted aerosol plumes observed with Raman lidar at the Portuguese coast, J. Geophys. Res., 106, 20725-20733, doi:10.1029/2000JD000091, 2001.

Artaxo, P., Martins, J. V., Yamasoe, M. A., Procópio, A. S., Pauliquevis, T. M., Andreae, M. O., Guyon, P., Gatti, L. V., and Leal, A. M. C.: Physical and chemical properties of aerosols in the wet and dry seasons in Rondônia, Amazonia, J. Geophys. Res., 107, doi:10.1029/2001JD000666, 2002.

Baars, H., Ansmann, A., Althausen, D., Engelmann, R., Heese, B., Müller, D., Artaxo, P., Paixao, M., Pauliquvis, T., and Souza, R.: Aerosol profiling with lidar in the Amazon Basin during the wet and dry season, J. Geophys. Res., 117, doi:10.1029/2012JD018338, 2012.

Ben-Ami, Y., Koren, I., and Altaratz, O.: Patterns of North African dust transport over the Atlantic: winter vs. summer, based on CALIPSO first year data, Atmos. Chem. Phys., 9, 7867-7875, doi:10.5194/acp-9-7867-2009, 2009.

Bergstrom, R. W.: Extinction and absorption coefficients of the atmospheric aerosol as a function of particle size, Beitr. Phys. Ah., 46, 223-234, 1973.

Bergstrom, R. W., Pilewskie, P., Russell, P. B., Redemann, J., Bond, T. C., Quinn, P. K., and Sierau, B.: Spectral absorption properties of atmospheric aerosols, Atmos. Chem. Phys., 7, 5937-5943, doi:10.5194/acp-7-5937-2007, 2007.

Bond, T. C.: Spectral dependence of visible light absorption by carbonaceous particles emitted from coal combustion, Geophys. Res. Lett, 18, 4075-4078, doi:10.1029/2001GL01365, 2001.

Bovchaliuk, A., Milinevsky, G., Danylevsky, V., Goloub, P., Dubovik, O., Holdak, A., Ducos, F., and Sosonkin, M.: Variability of aerosol properties over Eastern Europe observed from ground and satellites in the period from 2003 to 2011, Atmos. Chem. Phys., 13, 6587-6602, doi:10.5194/acp-13-6587-2013, 2013.

Bridhikitti, A. and Overcamp, T. J.: Optical Characteristics of Southeast Asia's Regional Aerosols and Their Sources, J. Air Waste Management Assoc., 61, 747-754, doi:10.3155/10473289.61.7.747, 2011.

Burton, S. P., Ferrare, R. A., Hostetler, C. A., Hair, J. W., Rogers, R. R., Obland, M. D., Butler, C. F., Cook, A. L., Harper, D. B., and Froyd, K. D.: Aerosol classification using airborne High Spectral Resolution Lidar measurements-methodology and examples, Atmos. Meas. Tech., 5, 73-98, doi:10.5194/amt-5-732012, 2012.

Castro Videla, F., Barnaba, F., Angelini, F., Cremades, P., and Gobbi, G. P.: The relative role of Amazonian and nonAmazonian fires in building up the aerosol optical depth in South America: A five year study (2005-2009), Atmos. Res., 122, 298309, doi:10.1016/j.atmosres.2012.10.026, 2013.

Chew, B. N., Campbell, J. R., Reid, J. S., Giles, D. M., Welton, E. J., Salinas, S. V., and Liew, S. C.: Tropical cirrus cloud contamination in sun photometer data, Atmos. Environ, 45, 6724-6731, doi:10.1016/j.atmosenv.2011.08.017, 2011.

Chubarova, N., Prilepsky, N. G., Rublev, A. N., and Riebau, A. R.: A Mega-Fire Event in Central Russia: Fire Weather, Radiative, and Optical Properties of the Atmosphere, and Consequences for Subboreal Forest Plants, Elsevier, doi:10.1016/S14748177(08)00011-9, in: Developments in Environmental Science, Volume 8, A. Bytnerowicz, M. Arbaugh, A. Riebau and C. Andersen (eds.)., 2009.

Chubarova, N. E., Gorbarenko, E. V., Nezval', E. I., and Shilovtseva, O. A.: Aerosol and Radiation Characteristics of the Atmosphere during Forest and Peat Fires in 1972, 2002, and 2010 in the Region of Moscow, Izvestiya, Atmos. Ocean. Phys., 47, 729738, doi:10.1134/S0001433811060028, 2011.

Chubarova, N. E., Nezval', Y., Sviridenkov, I., Smirnov, A., and Slustker, I.: Smoke aerosol and its radiative effects during extreme fire event over Central Russia in summer 2010, Atmos. Meas. Tech., 5, 557-568, doi:10.5194/amt-5-557-2012, 2012.

Cottle, P., Strawbridge, K., and McKendry, I.: Long-range transport of Siberian wildfire smoke to British Columbia: Lidar observations and air quality impacts, Atmos. Environ, 90, 71-77, doi:10.1016/j.atmosenv.2014.03.005, 2014.

Damoah, R., Spichtinger, N., Forster, C., James, P., Mattis, I., Wandinger, U., Beirle, S., Wagner, T., and Stohl, A.: Around the world in 17 days-hemispheric-scale transport of forest fire smoke from Russia in May 2003, Atmos. Chem. Phys., 4, 1311-1321, doi:10.5194/acp-4-1311-2004, 2004.

Draxler, R. R. and Hess, G. D.: An overview of the HYSPLIT_4 modeling system of trajectories, dispersion, and deposition, Aust. Meteor. Mag., 47, 295-308, 1998.

Dubovik, O. and King, M. D.: A flexible inversion algorithm for retrieval of aerosol optical properties from Sun and sky radiance measurements, J. Geophys. Res., 105, 206730-20696, doi:10.1029/2000JD900282, 2000.

Dubovik, O., Smirnov, A., Holben, B. N., King, M. D., Kaufman, Y. J., Eck, T. F., and Slutsker, I.: Accuracy assessments of aerosol optical properties retrieved from Aerosol Robotic Network (AERONET) Sun and sky radiance measurements, J. Geophys. Res., 105, 9791-9806, 2000.

Dubovik, O., Holben, B., Eck, T. F., Smirnov, A., Kaufman, Y., King, M., Tanré, D., and Slutsker, I.: Variability and optical properties of key aerosol types observed in worldwide locations, J. Atmos. Sci., 59, 590-608, doi:10.1175/15200469(2002)059<0590:VOAAOP>2.0.CO;2, 2002.

Dubovik, O., Sinyuk, A., Lapyonok, T., Holben, B., Mischenko, M., Yang, P., Eck, T., Volten, H., Muñoz, O., Veihelmann, B., van der Zande, W. J., Leon, J.-F., Sorokin, M., and Slutsker, I.: The application of spheroid models to account for aerosol particle non- 
sphericity in remote sensing of desert dust, J. Geophys. Res., 111, doi:10.1029/2005JD006619, 2006.

Dubovik, O., Herman, M., Holdak, A., Lapyonok, T., Tanré, D., Deuzé, J. L., Ducos, F., Sinyuk, A., and Lopatin, A.: Stastically optimized inversion algorithm for enhanced retrieval of aerosol properties from spectral multi-angle polarimetric satellite observations, Atmos. Meas. Tech., 4, 975-1018, doi:10.5194/amt-4975-2011, 2011.

Eck, T. F., Holben, B. N., Reid, J. S., Dubovik, O., Smirnov, A., O'Neill, N. T., Slutsker, I., and Kinne, S.: Wavelength dependence of the optical depth of biomass burning, urban, and desert dust aerosols, J. Geophys. Res., 104, 31333-31349, 1999.

Eck, T. F., Holben, B. N., Ward, D. E., Dubovik, O., Reid, J. S., Smirnov, A., Mukelabai, M. M., Hsu, N. C., O'Neill, N. T., and Slutsker, I.: Characterization of the optical properties of biomass burning aerosols in Zambia during the 1997 ZIBBEE field campaign, J. Geophys. Res., 106, 3425-3448, doi:10.1029/2000JD900555, 2001.

Eck, T. F., Holben, B. N., Reid, J. S., O’Neill, N. T., Schafer, J. S., Dubovik, O., Smirnov, A., Yamasoe, M. A., and Artaxo, P.: High aerosol optical depth biomass burning events: A comparison of optical properties for different source regions, Geophys. Res. Lett., 30, doi:10.1029/2003GL017861, 2003 a.

Eck, T. F., Holben, B. N., Ward, D. E., Mukelabai, M. M., Dubovik, O., Smirnov, A., Schafer, J. S., Hsu, N. C., Piketh, S. J., Quedace, A., Le Roux, J., Swap, R. J., and Slutsker, I.: Variability of biomass burning aerosol optical characteristics in southern Africa during the SAFARI 2000 dry season campaign and a comparison of single scattering albedo estimates from radiometric measurements, J. Geophys. Res., 108, 8477, doi:10.1029/2002JD002321, 2003b.

Eck, T. F., Holben, B. N., Reid, J. S., Sinyuk, A. Dubovik, O., Smirnov, A., Giles, D. M., O’Neill, N. T., Tsay, S.-C., Ji, Q., Al Mandoos, A., Ramzan Khan, M., Reid, E. A., Schafer, J. S., Sorokin, M., Newcomb, W., and Slusker, I.: Spatial and temporal variability of column-integrated aerosol optical properties in the southern Arabian Gulf and United Arab Emirates in summer, J. Geophys. Res., 113, doi:10.1029/2007JD008944, 2008.

Eck, T. F., Holben, B. N., Reid, J. S., Sinyuk, A., Hyer, E. J., O'Neill, N. T., Shaw, G. E., Vande Castle, J. R., Chapin, F. S., Dubovik, O., Smirnov, A., Vermote, E., Schafer, J. S., Giles, D., Slutsker, I., Sorokine, M., and Newcomb, W. W.: Optical properties of boreal region biomass burning aerosols in central Alaska and seasonal variation of aerosol optical depth at an Arctic coastal site, J. Geophys. Res., 114, doi:10.1029/2008JD010870, 2009.

Eck, T. F., Holben, B. N., Sinyuk, A., Pinker, R. T., Goloub, P., Chen, H., Chatenet, B., Li, Z., Singh, R. P., Tripathi, S. N., Reid, J. S., Giles, D. M., Dubovik, O., O’Neill, N. T., Smirnov, A., Wang, P., and Xia, X.: Climatological aspects of the optical properties of fine/coarse mode aerosol mixtures, J. Geophys. Res., 115, doi:10.1029/2010JD014002, 2010.

Eck, T. F., Holben, B. N., Reid, J. S., Mukelabai, M. M., Piketh, S. J., Torres, O., Jethva, H. T., Hyer, E. J., Ward, D. E., Dubovik, O., Sinyuk, A., Schafer, J. S., Giles, D. M., Sorokin, M., Smirnov, A., and Slutsker, I.: A seasonal trend of single scattering albedo in southern African biomass-burning particles: Implications for satellite products and estimates of emissions for the world's largest biomass-burning source, J. Geophys. Res., 118, doi:10.1002/jgrd.50500, 2013.

Gautam, R., Hsu, N. C., Tsay, S.-C., Lau, W. K., Holben, B., Bell, S., Smirnov, A., Li, C., Hansell, R., Ji, Q., Payra, S., Aryal, D., Kayastha, R., and Kim, K. M.: Accumulation of aerosols over the Indo-Gangetic plains and southern slopes of the Himalayas: distribution, properties and radiative effects during the 2009 pre-monsoon season, Atmos. Chem. Phys., 11, 1284112 863, doi:10.5194/acp-11-12841-2011, 2011.

Gautam, R., Hsu, N. C., Eck, T. F., Holben, B. N., Janjai, S., Jantarach, T., Tsay, S.-C., and Lau, W. K.: Characterization of aerosols over the Indochina peninsula from satellite-surface observations during biomass burning pre-monsoon season, Atmos. Environ, 78, 51-59, doi:10.1016/j.atmosenv.2012.05.038, 2013.

Giannakaki, E., Balis, D. S., Amiridis, V., and Zerefos, C.: Optical properties of different aerosol types: seven years of combined Raman-elastic backscatter lidar measurements in Thessaloniki, Greece, Atmos. Meas. Tech., 3, 569-578, doi:10.5194/amt-3569-2010, 2010

Giles, D. M., Holben, B. N., Eck, T. F., Sinyuk, A., Smirnov, A., Slutsker, I., Dickerson, R. R., Thompson, A. M., and Schafer, J. S.: An analysis of AERONET aerosol absorption properties and classifications representative of aerosol source regions, J. Geophys. Res., 117, doi:10.1029/2012JD018127, 2012.

Gorchakov, G. I., Anikin, P. P., Volokh, A. A., Emilenko, A. S., Isakov, A. A., Kopeikin, V. M., Ponomareva, T. Y., Semutnikova, E. G., Sviridenkov, M. A., and Shukurov, K. A.: Studies of the smoky atmosphere composition over Moscow during peatbog fires in the summer-fall season of 2002, Izvestiya, Atmos. Ocean. Phys., 40, 366-380, 2004.

Gras, J. L., Jensen, J. B., Okada, K., Ikegami, M., Zaizen, Y., and Makino, Y.: Some optical properties of smoke aerosol in Indonesia and tropical Australia, Geophys. Res. Lett., 26, 1393-1396, doi:10.1029/1999GL900275, 1999.

Gyawali, M., Arnott, W. P., Zaveri, R. A., Song, C., Moosmüller, H., Liu, L., Mishchenko, M. I., Chen, L.-W. A., Green, M. C., Watson, J. G., and Chow, J. C.: Photoacoustic optical properties at UV, VIS, and near IR wavelengths for laboratory generated and winter time ambient urban aerosols, Atmos. Chem. Phys., 12, 2587-2601, doi:10.5194/acp-12-2587-2012, 2012.

Hasekamp, O., Litvinov, P., and Butz, A.: Aerosol properties over the ocean from PARASOL multi-angle photopolarimetric measurements, J. Geophys. Res., 116, doi:10.1029/2010JD015469, 2011.

Hasekamp, O. P. and Landgraf, J.: Retrieval of aerosol properties over the ocean from multispectral single-viewing-angle measurements of intensity and polarization: Retrieval approach, information content, and sensitivity study, J. Geophys. Res., 110, doi:10.1029/2005JD006212, 2005.

He, X., Li, C. C., Lau, A. K. H., Deng, Z. Z., Mao, J. T., Wang, M. H., and Liu, X. Y.: An intensive study of aerosol optical properties in Beijing urban area, Atmos. Chem. Phys., 9, 8903-8915, doi:10.5194/acp-9-8903-2009, 2009.

Hess, M., Koepke, P., and Schult, I.: Optical properties of aerosols and clouds: The software package OPAC, Bull. Am. Met. Soc., 79, 831-944, doi:10.1175/1520-0477(1998)079, 1998.

Hobbs, P. V., Reid, J. S., Herring, J. A., Nance, J. D., Weiss, R. E., Ross, J. L., Hegg, D. A., Ottmar, R. D., and Liousse, C. A.: Particle and trace-gas measurements in the smoke from prescribed 
bums of forest products in the Pacific Northwest, MIT Press, in: Global Biomass Burning and Global Change, J. S. Levine (ed.)., 1997.

Holben, B. N., Eck, T. F., Slutsker, I., Tanré, D., Buis, J. P., Setzer, A., Vermote, E., Reagan, J. A., Kaufman, Y. J., Nakajima, T., Lavenu, F., Jankowiak, I., and Smirnov, A.: AERONET: A federated instrument network and data archive for aerosol characterization, Remote Sens. Environ., 66, 1-16, doi:10.1016/S00344257(98)00031-5, 1998.

Holben, B. N., F., E. T., Slustker, I., Smirnov, A., Sinyuk, A., Shafer, J., Giles, D., and Dubovik, O.: AERONET's version 2.0 quality assurance criteria, in: Proceedings of SPIE, volume 6408, paper number 6408-27, 2006.

Huang, J., Hsu, N. C., Tsay, S.-C., Jeong, M.-J., Holben, B. N., Berkoff, T. A., and Welton, E. J.: Susceptibility of aerosol optical thickness retrievals to thin cirrus contamination during the BASE-ASIA campaign, J. Geophys. Res., 116, doi:10.1029/2010JD014910, 2011.

Hyer, E. H., Reid, J. S., and Zhang, J.: An over-land aerosol optical depth data set for data assimilation by filtering, correction, and aggregation of MODIS Collection 5 optical depth retrievals, Atmos. Meas. Tech., 4, 379-408, doi:10.5194/amt-4-379-2011, 2011.

Ichoku, C., Remer, L. A., Kaufman, Y. J., Levy, R., Chu, D. A., Tanré, D., and Holben, B. N.: MODIS observation of aerosols and estimation of aerosol radiative forcing over southern Africa during SAFARI 2000, J. Geophys. Res., 108, doi:10.1029/2002JD002366, 2003.

Janhäll, S., Andreae, M. O., and Pöschl, U.: Biomass burning aerosol emissions from vegetation fires: particle number and mass emission factors and size distributions, Atmos. Chem. Phys., 10, 1427-1439, doi:10.5194/acp-10-1427-2010, 2010.

Janjai, S., Nunuez, M., Masiri, I., Wattan, R., Buntoung, S., Jantarach, T., and Promsen, W.: Aerosol optical properties at Four Sites in Thailand, Atmos. Clim. Sci, 2, 441-453, doi:10.4236/acs.2012.24038, 2012.

Jethva, H. and Torres, O.: Satellite-based evidence of wavelengthdependent aerosol absorption in biomass burning smoke inferred from Ozone Monitoring Instrument, Atmos. Chem. Phys., 11, 10541-10551, doi:10.5194/acp-11-10541-2011, 2011.

Johnson, B. T., Osborne, S. R., Haywood, J. M., and Harrison, M. A. J.: Aircraft measurements of biomass burning aerosol over West Africa during DABEX, J. Geophys. Res., 113, doi:10.1029/2007JD009451, 2008.

Johnson, B. T., Christopher, S., Haywood, J. M., Osborne, S. R., McFarlane, S., Hsu, C., Salustro, C., and Kahn, R.: Measurements of aerosol properties from aircraft, satellite and groundbased remote sensing: a case-study from the Dust and Biomassburning Experiment (DABEX), Q. J. R. Meteorol. Soc., 135, 922-934, doi:10.1002/qj.420, 2009.

Kahn, R., West, R., McDonald, D., Rheingans, B., and Mischenko, M. I.: Sensitivity of multiangle remote sensing observations to aerosol sphericity, J. Geophys. Res., 102, 16861-16870, doi:10.1029/96JD01934, 1997.

Kahn, R., Garay, M. J., Nelson, D. L., Yau, K. K., Bull, M. A., Gaitley, B. J., Martonchik, J. V., and Levy, R.: Satellite-derived aerosol optical depth over dark water from MISR and MODIS: Comparisons with AERONET and implications for climatolog- ical studies, J. Geophys. Res., 112, doi:10.1029/2006JD008175, 2007.

Kahn, R. A., Gaitley, B. J., Garay, M. J., Diner, D. J., Eck, T. F., Smirnov, A., and Holben, B. N.: Multiangle Imaging SpectroRadiometer global aerosol product assessment by comparison with the Aerosol Robotic Network, J. Geophys. Res., 115, doi:10.1029/2010JD014601, 2010.

Kaufman, Y. J., Hobbs, P. V., Kirchoff, V. W. J. H., Artaxo, P., Remer, L. A., Holben, B. N., King, M. D., Ward, D. E., Prins, E. M., Longo, K. M., Mattos, L. F., Nobre, C. A., Spinhirne, J. D., HI, Q., Thompson, A. M., Gleason, J. F., Christopher, S. A., and Tsay, S.-C.: Smoke, Clouds, and Radiation-Brazil (SCAR-B) experiment, J. Geophys. Res., 103, 31783-31808, doi:10.1029/98JD02281, 1998.

Kaufman, Y. J., Remer, L. A., Tanré, D., Li, R.-R., Kleidman, R., Mattoo, S., Levy, R. C., Eck, T. F., Holben, B. N., Ichoku, C., Martins, J. V., and Koren, I.: A Critical Examination of the Residual Cloud Contamination and Diurnal Sampling Effects on MODIS Estimates of Aerosol Over Ocean, IEEE Trans. Geosci. Remote Sens., 43, 2886-2897, doi:10.1109/TGRS.2005.858430, 2005.

Kim, S.-W., Chazette, P., Dulac, F., Sanak, J., Johnson, B., and Yoon, S.-C.: Vertical structure of aerosols and water vapor over West Africa during the African monsoon dry season, Atmos. Chem. Phys., 9, 8017-8038, doi:10.5194/acp-9-8017-2009, 2009.

Kirchstetter, T. W., Novakov, T., and Hobbs, P. V.: Evidence that the spectral dependence of light absorption by aerosols is affected by organic carbon, J. Geophys. Res., 109, doi:10.1029/2004JD004999, 2004.

Kokhanovsky, A. A., Deuzé, J. L., Diner, D. J., Dubovik, O., Ducos, F., Emde, C., Garay, M. J., Grainger, R. G., Heckel, A., Herman, M., Katsev, I. L., Keller, J., Levy, R., North, P. R. J., Prikhach, A. S., Rozanov, V. V., Sayer, A. M., Ota, Y., Tanré, D., Thomas, G. E., and Zege, E. P.: The determination of spectral aerosol optical thickness from satellites: an inter-comparison of algorithms using synthetic backscattered solar light characteristics, Atmos. Meas. Tech., 3, 909-932, doi:10.5194/amt-3-909-2010, 2010.

Langmann, B. and Heil, A.: Release and dispersion of vegetation and peat fire emissions in the atmosphere over Indonesia 1997/1998, Atmos. Chem. Phys., 4, 2145-2160, doi:10.5194/acp-4-2145-2004, 2004.

Leahy, L. V., Anderson, T. L., Eck, T. F., and Bergstrom, R. W.: A synthesis of single scattering albedo of biomass burning aerosol over southern Africa during SAFARI 2000, Geophys. Res. Lett, doi:10.1029/2007GL029697, 2007.

Lee, J., Kim, J., Yang, P., and Hsu, N. C.: Improvement of aerosol optical depth retrieval from MODIS spectral reflectance over the global ocean using new aerosol models archived from AERONET inversion data and tri-axial ellipsoidal dust database, Atmos. Chem. Phys., 12, 7087-7102, doi:10.5194/acp-12-70872012, 2012.

Lee, K. H., Li, Z., Wong, M. s., Xin, J., Wang, Y., Hao, W.-M., and Zhao, F.: Aerosol single scattering albedo estimated across China from a combination of ground and satellite measurements, J. Geophys. Res., 112, doi:10.1029/2007JD009077, 2007.

Levy, R. C., Leptoukh, G. G., Kahn, R., Zubko, V., Gopalan, A., and Remer, L. A.: A Critical Look at Deriving Monthly Aerosol 
Optical Depth From Satellite Data, IEEE Trans. Geosci. Remote Sens., 47, 2942-2956, doi:10.1109/TGRS.2009.2013842, 2009.

Lewis, K., Arnott, W. P., Moosmüller, H., and Wol, C. E.: Strong spectral variation of biomass smoke light absorption and single scattering albedo observed with a novel dualwavelength photoacoustic instrument, J. Geophys. Res., 113, doi:10.1029/2007JD009699, 2008.

Magi, B. I. and Hobbs, P. V.: Effects of humidity on aerosols in southern Africa during the biomass burning season, J. Geophys. Res., 108, 8495, doi:10.1029/2002JD002144, 2003.

Martins, J. V., Artaxo, P., Hobbs, P. V., Liousse, C., Cachier, H., Kaufman, Y., and Plana-Fattoria, A.: Particle size distributions, elemental compositions, carbon measurements, and optical properties of smoke from biomass burning in the Pacific Northwest of the United States, MIT Press, in: Global Biomass Burning and Global Change, J. S. Levine (ed.)., 1997.

Martonchik, J. V., Diner, D. J., Kahn, R. A., Ackerman, T. P., Verstraete, M. M., Pinty, B., and Gordon, H. R.: Techniques for the retrieval of aerosol properties over land and ocean using multiangle imaging, IEEE Trans. Geosci. Remote Sens., 36, 4, doi:10.1109/36.701027, 1998.

McMeeking, G. R., Bart, M., Chazette, P., Haywood, J. M., Hopkins, J. R., McQuaid, J. B., Morgan, W. T., Raut, J.-C., Ryder, C. L., Savage, N., Turnbull, K., and Coe, H.: Airborne measurements of trace gases and aerosols over the London metropolitan region, Atmos. Chem. Phys., 12, 5163-5187, doi:10.5194/acp12-5163-2012, 2012.

Mishchenko, M. I., Travis, L. D., Kahn, R. A., and West, R. A.: Modeling phase functions for dustlike tropospheric aerosols using a shape mixture of randomly oriented polydisperse spheroids, J. Geophys. Res., 102, 16831-16847, doi:10.1029/96JD02110, 1997.

Mishchenko, M. I., Geogdzhayev, I. V., Cairns, B., Rossow, W. B., and Lacis, A. A.: Aerosol retrievals over the ocean by use of channels 1 and 2 AVHRR data: sensitivity analysis and preliminary results, Appl. Opt., 38, 7325-7341, doi:10.1364/AO.38.007325, 1999.

Müller, D., Ansmann, A., Mattis, I., Tesche, M., Wandinger, U., Althausen, D., and Pisani, G.: Aerosol-type-dependent lidar ratios observed with Raman lidar, J. Geophys. Res., 112, doi:10.1029/2006JD008292, 2007.

Murayama, T., Müller, D., Wada, K., Shimizu, A., Sekiguchi, M., and Tsukamoto, T.: Characterization of Asian dust and Siberian smoke with multi-wavelength Raman lidar over Tokyo, Japan in spring 2003, Geophys. Res. Lett., 31, doi:10.1029/2004GL021105, 2004.

Noh, Y. M., Müller, D., and Kim, Y. J.: Seasonal characteristics of lidar ratio measured with a Raman lidar at Gwangju, Korea in spring and autumn, Atmos. Environ, 42, 2208-2224, doi:10.1016/j.atmosenv.2007.11.045, 2008.

O'Dowd, C. D. and de Leeuw, G.: Marine aerosol production: a review of the current knowledge, Phil. Trans. R. Soc. A, 365, doi:10.1098/rsta.2007.2043, 2007.

Omar, A. H., Won, J.-G., Winker, D. M., Yoon, S.-C., Dubovik, O., and McCormick, M. P.: Development of global aerosol models using cluster analysis of Aerosol Robotic Network (AERONET) measurements, J. Geophys. Res., 110, doi:10.1029/2004JD004874, 2005.
Omar, A. H., Winker, D. M., Vaughan, M. A., Hu, Y., Trepte, C. A., Ferrare, R. A., Lee, K.-P., and Hostetler, C. A.: The CALIPSO Automated Aerosol Classification and Lidar Ratio Selection Algorithm, J. Atmos. Oceanic Technol., 26, 1994-2014, doi:10.1175/2009JTECHA1231.1, 2009.

O’Neill, N. T., Thulasiraman, S., Eck, T. F., and Reid, J. S.: Robust optical features of fine mode size distributions: Application to the Québec smoke event of 2002, J. Geophys. Res., 110, doi:10.1029/2004JD005157, 2005.

Pandithurai, G., Pinker, R. T., Dubovik, O., Holben, B. N., and Aro, T.: Remote sensing of aerosol optical characteristics in sub-Sahel, West Africa, J. Geophys. Res., 106, 28347-28356, doi:10.1029/2001JD900234, 2001.

Paris, J.-D., Stohl, A., Nédélec, P., Arshinov, M. Y., Panchenko, M. V., Shmargunov, V. P., Law, K. S., Belan, B. D., and Ciais, P.: Wildfire smoke in the Siberian Arctic in summer: source characterization and plume evolution from airborne measurements, Atmos. Chem. Phys., 9, 9315-9327, doi:10.5194/acp-9-9315-2009, 2009.

Piketh, S. J., Annegarn, H. J., and Tyson, P. D.: Lower tropospheric aerosol loadings over South Africa: The relative contribution of aeolian dust, industrial emissions, and biomass burning, J. Geophys. Res., 104, 1597-1607, doi:10.1029/1998JD100014, 1999.

Povey, A. C., Grainger, R. G., Peters, D. M., and Agnew, J. L.: Retrieval of aerosol backscatter, extinction, and lidar ratio from Raman lidar with optimal estimation, Atmos. Meas. Tech., 7, 757776, doi:10.5194/amt-7-757-2014, 2014.

Qin, Y. and Mitchell, R. M.: Characterisation of episodic aerosol types over the Australian continent, Atmos. Chem. Phys., 9, 1943-1956, doi:10.5194/acp-9-1943-2009, 2009.

Queface, A. J., Piketh, S. J., Annegarn, H. J., Holben, B. N., and Uthui, R. J.: Retrieval of aerosol optical thickness and size distribution from the CIMEL Sun photometer over Inhaca Island, Mozambique, J. Geophys. Res., 108, doi:10.1029/2002JD002374, 2003.

Queface, A. J., Piketh, S. J., Eck, T. F., Tsay, S.-C., and Mavume, A. F.: Climatology of aerosol optical properties in Southern Africa, Atmos. Environ, 45, 2910-2921, doi:10.1016/j.atmosenv.2011.01.056, 2011.

Radke, L. F., Hegg, D. A., Hobbs, P. V., Nance, J. D., Lyons, J. H., Laursen, K. K., Weiss, R. E., Riggan, P. J., and Ward, D. E.: Particulate and Trace Gas Emissions from Large Biomass Fires in North America, MIT Press, in: Global Biomass Burning: Atmospheric, Climatic, and Biopheric Implications, J. S. Levine (ed.)., 1991.

Reid, J. S. and Hobbs, P. V.: Physical and optical properties of young smoke from individual biomass fires in Brazil, J. Geophys. Res., 103, 32013-32030, doi:10.1029/98JD00159, 1998.

Reid, J. S., Hobbs, P. V., Ferek, R. J., Blakde, D. R., Martins, J. V., R., D. M., and Liousse, C.: Physical, chemical, and optical properties of regional hazes dominated by smoke in Brazil, J. Geophys. Res., 103, 32059-32080, doi:10.1029/98JD00458, 1998.

Reid, J. S., Eck, T. F., Christopher, S. A., and Hobbs, P. V. Holben, B.: Use of the Angström exponent to estimate the variability of optical and physical properties of aging smoke particles in Brazil, J. Geophys. Res., 104, 27473-27489, doi:10.1029/1999JD900833, 1999.

Reid, J. S., Eck, T. F., Christopher, S. A., Koppmann, R., Dubovik, O., Eleuterio, D. P., Holben, B. N., Reid, E. A., and Zhang, J.: 
A review of biomass burning emissions part III: intensive optical properties of biomass burning particles, Atmos. Chem. Phys., 5, 827-849, doi:10.5194/acp-5-827-2005, 2005a.

Reid, J. S., Koppmann, R., Eck, T. F., and Eleuterio, D. P.: A review of biomass burning emissions part II: intensive physical properties of biomass burning particles, Atmos. Chem. Phys., 5, 799825, doi:10.5194/acp-5-799-2005, 2005b.

Reid, J. S., Hyer, E. J., Johnson, R. S., Holben, B. N., Yokelson, R. J., Zhang, J., Campbell, J. R., Christopher, S. A., L., D. G., Giglio, L., Holz, R. E., Kearney, C., Miettinen, J., Reid, E. A., Turk, F. J., Wang, J., Xian, P., Zhao, G., Balasubramanian, R., Chew, B. N., Janjai, S., Lagrosas, N., Lestari, P., Lin, N. H., Mahmud, M., Nguyen, A., Norris, B., Oanh, N. T. K., Oo, M., Salinas, S. V., Welton, E. J., and Liew, S. C.: Observing and understanding the Southeast Asian aerosols system by remote sensing: an initial review and analysis for the Seven Southeast Asian Studies (7 SEAS) program, Atmos. Res., 122, 303-468, doi:10.1016/j.atmosres.2012.06.005, 2013.

Remer, L. A., Kleidman, R. G., Levy, R. C., Kaufman, Y. J., Tanré, D., Mattoo, S., Martins, J. V., Ichoku, C., Koren, I., Yu, H., and Holben, B. N.: Global aerosol climatology from the MODIS satellite sensors, J. Geophys. Res., 113, D14S07, doi:10.1029/2007JD009661, 2008.

Remer, L. A., Tanré, D., and Kaufman, Y. J.: Algorithm for remote sensing of tropospheric aerosol from MODIS: Collection 5, Tech. rep., NASA Goddard Space Flight Center, ATBD-MOD02, product ID MOD04/MYD04, available online from http: //modis.gsfc.nasa.gov/data/atbd/, last access: July 2013, 2009.

Roberts, G., Wooster, M. J., and Lagoudakis, E.: Annual and diurnal African biomass burning temporal dynamics, Biogeosciences, 6, 849-866, doi:10.5194/bg-6-849-2009, 2009.

Russell, P. B., Bergstrom, R. W., Shinozuka, Y., Clarke, A. D., DeCarlo, P. F., Jimenez, J. L., Livingston, J. M., Redemann, J., Dubovik, O., and Strawa, A.: Absorption Angstrom Exponent in AERONET and related data as an indicator of aerosol composition, Atmos. Chem. Phys., 10, 1155-1169, doi:10.5194/acp-101155-2010, 2010.

Salinas, S. V., Chew, B. N., and Liew, S. C.: Retrievals of aerosol optical depth and Ångström exponent from ground-based Sunphotometer data of Singapore, Appl. Opt., 48, 1473-1484, doi:10.1364/AO.48.001473, 2009.

Salinas, S. V., Chew, B. N., Mohamad, N., and Liew, S. C.: First measurements of aerosol optical depth and Angstrom exponent number from AERONET's Kuching site, Atmos. Environ, 78, doi:10.1016/j.atmosenv.2013.02.016, 2013.

Sayer, A. M., Thomas, G. E., and Grainger, R. G.: A sea surface reflectance model for (A)ATSR, and application to aerosol retrievals, Atmos. Meas. Tech., 3, 813-838, doi:10.5194/amt-3813-2010, 2010a.

Sayer, A. M., Thomas, G. E., Palmer, P. I., and Grainger, R. G.: Some implications of sampling choices on comparisons between satellite and model aerosol optical depth fields, Atmos. Chem. Phys., 10, 10705-10716, doi:10.5194/acp-10-107052010, 2010b.

Sayer, A. M., Hsu, N. C., Bettenhausen, C., Ahmad, Z., Holben, B. N., Smirnov, A., Thomas, G. E., and Zhang, J.: SeaWiFS Ocean Aerosol Retrieval (SOAR): Algorithm, validation, and comparison with other datasets, J. Geophys. Res, 117, doi:10.1029/2011JD016599, 2012a.
Sayer, A. M., Smirnov, A., Hsu, N. C., and Holben, B. N.: A pure marine aerosol model, for use in remote sensing applications, J. Geophys. Res, 117, doi:10.1029/2011JD016689, 2012b.

Sayer, A. M., Smirnov, A., Hsu, N. C., Munchak, L. A., and Holben, B. N.: Estimating marine aerosol particle volume and number from Maritime Aerosol Network data, Atmos. Chem. Phys., 12, 8889-8909, doi:10.5194/acp-12-8889-2012, 2012c.

Schafer, J. S., Eck, T. F., Holben, B. N., Artaxo, P., and Duarte, A. F.: Characterization of the optical properties of atmospheric aerosols in Amazônia from long-term AERONET monitoring (1993-1995 and 1999-2006), J. Geophys. Res., 113, doi:10.1029/2007JD009319, 2008.

Schafer, J. S., Eck, T. F., Holben, B. N., Thorngill, K. L., Anderson, B. E., Sinyuk, A., Giles, D. M., Winstead, E. L., Ziemba, L. D., Beyersdorf, A. J., Kenny, P. R., Smirnov, A., and Slutsker, I.: Intercomparison of aerosol single-scattering albedo derived from AERONET surface radiometers and LARGE in situ aircraft profiles during the 2011 DRAGON-MD and DISCOVER-AQ experiments, J. Geophys. Res., 119, doi:10.1002/2013JD021166, 2014.

Schonbrödt, F. D. and Perugini, M.: At what sample size do correlations stabilize?, J. Res. Person., 47, 609-612, doi:10.1016/j.jrp.2013.05.009, 2013.

Shettle, E. P. and Fenn, R. W.: Models for the aerosols of the lower atmosphere and the effects of humidity variations on their optical properties, Tech. rep., Air force geophysics laboratory, report number AFGL-TR-79-0214, environmental research paper 676., 1979.

Shi, Y., Zhang, J., Reid, J. S., Holben, B. N., Hyer, E. J., and Curtis, C.: An analysis of the collection 5 MODIS over-ocean aerosol optical depth product for its implication in aerosol assimilation, Atmos. Chem. Phys., 11, 557-565, doi:10.5194/acp11-557-2011, 2011.

Smirnov, A., Holben, B. N., Eck, T. F., Dubovik, O., and Slutsker, I.: Cloud-screening and quality control algorithms for the AERONET database, Remote Sens. Environ., 73, 337-349, 2000.

Streets, D. G., Yarber, K. F., Woo, J.-H., and Carmichael, G. R.: Biomass burning in Asia: Annual and seasonal estimates and atmospheric emissions, Global Biogeochem. Cycles, 17, 1099, doi:10.1029/2003GB002040, 2003.

Sugimoto, N., Tatarov, B., Shimizu, A., Matsui, I., and Nishizawa, T.: Optical Characteristics of Forest-Fire Smoke Observed with Two-Wavelength Mie-Scattering Lidars and a HighSpectral-Resolution Lidar over Japan, SOLA, 6, 93-96, doi:10.2151/sola.2010-024, 2010.

Sun, H., Biedermann, L., and Bond, T. C.: Color of brown carbon: A model for ultraviolet and visible light absorption by organic carbon aerosol, Geophys. Res. Lett., 34, doi:10.1029/2007GL029797, 2007.

Swap, R. J., Annegarn, H. J., Suttles, J. T., King, M. D., Platnick, S., Privette, J. L., and Scholes, R. J.: Africa burning: A thematic analysis of the Southern African Regional Science Initiative (SAFARI 2000), J. Geophys. Res., 108, 8465, doi:10.1029/2003JD003747, 2003.

Tesche, M., Müller, D., Gross, S., Ansmann, A., Althausen, D., Freudenthaler, V., Weinzierl, B., Veira, A., and Petzold, A.: Optical and microphysical properties of smoke over Cape Verde in- 
ferred from multiwavelength lidar measurements, Tellus B., 63, 677-694, doi:10.1111/j.1600-0889.2011.00549.x, 2011.

Thomas, G. E., Poulsen, C. A., Sayer, A. M., Marsh, S. H., Dean, S. M., Carboni, E., Siddans, R., Grainger, R. G., and Lawrence, B. N.: The GRAPE aerosol retrieval algorithm, Atmos. Meas. Tech., 2, 679-701, doi:doi:10.5194/amt-2-679-2009, 2009.

Turquety, S., Logan, J. A., Jacob, D. J., Hudman, R. C., Leung, F. Y., Heald, C. L., Yantosca, R. M., Wu, S., Emmons, L. K., Edwards, D. P., and Sachse, G. W.: Inventory of boreal fire emissions for North America in 2004: Importance of peat burning and pyroconvective injection, J. Geophys. Res., 112, doi:10.1029/2006JD007281, 2007.

Ulyumdzhieva, N. N., Chubarov, N. E., and Smirnov, A. V.: Aerosol characteristics of the atmosphere over Moscow from CIMEL sun photometer data, Russ. Met. Hydro., 1, 37-44, 2005.

Vakkari, V., Kerminen, V.-M., Beukes, J. P., Tiitta, P., van Zy, P. G., Josipovic, M., Venter, A. D., Jaatrs, K., Worsnop, D. R., Kulmala, M., and Laakso, L.: Rapid changes in biomass burning aerosols by atmospheric oxidation, Geophys. Res. Lett., 41, 2644-2651, doi:10.1002/2014GL059396, 2014.

van der Werf, G. R., Randerson, J. T., Giglio, L., Collatz, G. J., Mu, M., Kasibhatla, P. S., Morton, D. C., DeFries, R. S., Jin, Y., and van Leeuwen, T. T.: Global fire emissions and the contribution of deforestation, savanna, forest, agricultural, and peat fires (19972009), Atmos. Chem. Phys., 10, 11707-11735, doi:10.5194/acp10-11707-2010, 2010.
Vermote, E. F., Tanré, D., Deuzé, J. L., Herman, M., and Morcrette, J.-J.: Second Simulation of the Satellite Signal in the Solar Spectrum, 6S: An Overview, IEEE Trans. Geosci. Remote Sens., 35, 675-686, doi:10.1109/36.581987, 1997.

Voss, K. J., Welton, E. J., Quinn, P. K., Johnson, J., Thompson, A. M., and Gordon, H. R.: Lidar measurements during Aerosols99, J. Geophys. Res., 106, doi:10.1029/2001JD900217, 2001.

Ward, D. E., Hao, W. M., Susott, R. A., Babbitt, R. E., Shea, R. W., Kauffman, J. B., and Justice, C. O.: Effect of fuel composition on combustion efficiency and emission factors for African savanna ecosystems, J. Geophys. Res., 101, 2356923576, doi:10.1029/95JD02595, 1996.

Warneke, C., Bahreini, R., Brioude, J., Brock, C. A., de Gouw, J. A., Fahey, D. W., Froyd, K. D., Holloway, J. S., Middlebrook, A., Miller, L., Montzka, S., Murphy, D. M., Peischl, J., Ryerson, T. B., Schwarz, J. P., Spackman, J. R., and Veres, P.: Biomass burning in Siberia and Kazakhstan as an important source for haze over the Alaskan Arctic in April 2008, Geophys. Res. Lett., 37, doi:10.1029/2008GL036194, 2009.

Witte, J. C., Douglass, A. R., da Silva, A., Torres, O., Levy, R., and Duncan, B. N.: NASA A-Train and Terra observations of the 2010 Russian wildfires, Atmos. Chem. Phys., 11, 9287-9301, doi:10.5194/acp-11-9287-2011, 2011.

Zhang, J. and Reid, J. S.: MODIS Aerosol Product Analysis for Data Assimilation: Assessment of Over-Ocean level 2 Aerosol Optical Thickness Retrievals, J. Geophys. Res., 111, doi:10.1029/2005JD006898, 2006. 